\title{
Bone mass and fractures in patients at risk for secondary osteoporosis
}

Citation for published version (APA):

Heijckmann, A. C. (2007). Bone mass and fractures in patients at risk for secondary osteoporosis.

[Doctoral Thesis, Maastricht University]. Datawyse / Universitaire Pers Maastricht.

https://doi.org/10.26481/dis.20071219ah

Document status and date:

Published: 01/01/2007

DOI:

10.26481/dis.20071219ah

Document Version:

Publisher's PDF, also known as Version of record

\section{Please check the document version of this publication:}

- A submitted manuscript is the version of the article upon submission and before peer-review. There can be important differences between the submitted version and the official published version of record.

People interested in the research are advised to contact the author for the final version of the publication, or visit the DOI to the publisher's website.

- The final author version and the galley proof are versions of the publication after peer review.

- The final published version features the final layout of the paper including the volume, issue and page numbers.

Link to publication

\footnotetext{
General rights rights.

- You may freely distribute the URL identifying the publication in the public portal. please follow below link for the End User Agreement:

www.umlib.nl/taverne-license

Take down policy

If you believe that this document breaches copyright please contact us at:

repository@maastrichtuniversity.nl

providing details and we will investigate your claim.
}

Copyright and moral rights for the publications made accessible in the public portal are retained by the authors and/or other copyright owners and it is a condition of accessing publications that users recognise and abide by the legal requirements associated with these

- Users may download and print one copy of any publication from the public portal for the purpose of private study or research.

- You may not further distribute the material or use it for any profit-making activity or commercial gain

If the publication is distributed under the terms of Article $25 \mathrm{fa}$ of the Dutch Copyright Act, indicated by the "Taverne" license above, 
Bone mass and fractures in patients at risk for secondary osteoporosis 



\section{Bone mass and fractures in patients at risk for secondary osteoporosis}

\section{Proefschrift}

ter verkrijging van de graad van doctor

aan de Universiteit Maastricht,

op gezag van de Rector Magnificus, Prof. mr. G.P.M.F. Mols,

volgens het besluit van het College van Decanen,

in het openbaar te verdedigen

op woensdag 19 december 2007 om 14.00 uur

door

Anna Caroline Heijckmann

geboren te Eindhoven

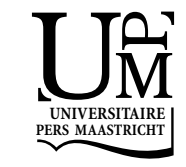




\section{Promotores:}

Prof. dr. A.C. Nieuwenhuijzen Kruseman

Prof. dr. P. Geusens, Universiteit van Hasselt

Prof. dr. B.H.R. Wolffenbuttel, UMC Groningen

Copromotor:

Dr. M.S.P. Huijberts

Beoordelingscommissie:

Prof. dr. G.J. Dinant, voorzitter

Prof. dr. J.M.A. van Engelshoven

Prof. dr. A.A.M. Masclee

Prof. dr. G.J.J. Teule

Prof. dr. E.F.M. Wouters 
Vandaag is de dag

morgen is het vandaag niet meer

Voor: Bart-Jeroen, Bram, Hannah, Thijs en Lotte 



\section{Contents}

Chapter $1 \quad$ Introduction and outline of this thesis 9

Chapter $2 \quad$ Osteoporosis and fracture risk: an overview 13

Chapter $3 \quad$ Hip bone mineral density, bone turnover and risk of 37 fracture in patients on long-term suppressive L-thyroxine therapy for differentiated thyroid carcinoma

Chapter $4 \quad$ High prevalence of morphometric vertebral deformities in patients with inflammatory bowel disease

Chapter $5 \quad$ Bone turnover and hip bone mineral density in patients with sarcoidosis

Chapter 6 Progressive vertebral deformities despite unchanged bone mineral density in patients with sarcoidosis:

a 4 year follow-up study

Chapter $7 \quad$ Quantitative ultrasound does not identify patients with an inflammatory disease at risk for vertebral deformities

Chapter 8 General discussion

Chapter $9 \quad$ Summary

Chapter $10 \quad$ Samenvatting

Dankwoord

Curriculum vitae 



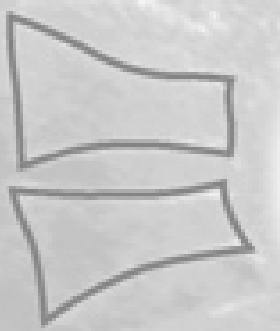

Chapter 1

Introduction and outline of this thesis 
10 Chapter 1 


\section{Introduction and outline of the thesis}

The studies described in this thesis focus on components of bone that contribute to its resistance to fracture, often referred to as bone quality, in patients who are considered at risk for secondary osteoporosis. The objectives of these studies were:

1. What is the fracture risk profile in patients at risk for secondary osteoporosis, based on clinical risk factors for fractures and parameters of bone's resistance to fracture, including bone mineral density (BMD), quantitative ultrasound (QUS), bone turnover markers and morphometry of the vertebrae

2. What is the relation between disease characteristics (including treatment) and these parameters of bone's resistance to fracture

3. What does follow-up add to the assessment of the fracture risk profile

To this end, studies were performed in patients treated with a suppressive dose of levothyroxin because of differentiated thyroid carcinoma, inflammatory bowel disease and sarcoidosis. In these patient groups BMD was measured with dual-energy X-ray absorptiometry (DXA) and QUS. In addition, the bone turnover parameters of resorption, serum carboxy-terminal cross-linked telopeptide of type I collagen (ICTP), and formation, serum procollagen type I amino-terminal propeptide (PINP), were determined. Clinical risk factors were evaluated following a standard questionnaire and disease activity parameters according to standard evaluation procedures for each disease. An assessment of the prevalence of non-clinical morphometric vertebral factures was done on the basis of semiquantitative morphometric analysis of DXA-images of the spine.

In chapter 2 general aspects of osteoporosis are summarized as far as relevant for the studies performed within the framework of this thesis. Chapter 3, 4 and 5 describe the observations done in cross sectional studies in patients with respectively thyroid carcinoma, inflammatory bowel disease and sarcoidosis. Chapter 6 concerns a follow-up study in patients with sarcoidosis to determine the effects on BMD and the incidence of morphometric vertebral deformities in the course of this condition. Chapter 7 comprises the observations made with QUS in patients with inflammatory bowel disease and sarcoidosis and discusses the value of this technique in the screening of patients with an increased risk for vertebral deformities. This thesis is concluded by a general discussion of the main findings of the studies performed and by recommendations for further investigations. 


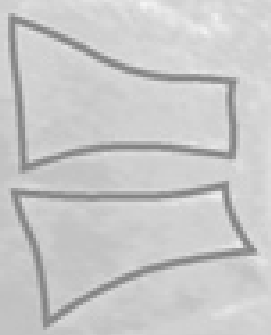

\section{Chapter 2}

Osteoporosis and fracture risk:

an overview 
14 Chapter 2 


\section{Definition}

Osteoporosis is a skeletal disease characterized by low bone mass and micro architectural deterioration resulting in increased bone fragility and hence susceptibility to fracture. ${ }^{1}$ It is a major health problem because of its consequent morbidity, mortality and health-care costs. In 1994, an expert panel convened by the World Health Organization (WHO) formulated an operational definition of the disease for postmenopausal women based on bone mineral density (BMD). ${ }^{2}$ BMD can be expressed as a T-score, the value used for diagnosis of osteoporosis, which is a score for the standard deviation (SD) above or below the mean value of peak bone mass in young adults. In addition, a Z-score is used to compare the patient's BMD to a population of peers (SD from the mean BMD of an age-, ethnicity-, and sex-matched reference population). In the WHO definition osteoporosis is defined as a T-score of $\leq-2.5$ and osteopenia as a T-score between -1 and -2.5 . (Table 2.1).

Table 2.1 Diagnostic criteria for osteoporosis

\begin{tabular}{ll}
\hline T-score value & Diagnosis \\
\hline Above -1.0 & Normal bone \\
Below -1.0 and above -2.5 & Osteopenia \\
Below -2.5 & Osteoporosis \\
Below -2.5 and at least one fragility fracture & Established osteoporosis \\
\hline
\end{tabular}

This definition of osteoporosis has several limitations. The fracture risk increases with decreasing BMD (gradient of risk) and these cut-offs are somewhat arbitrary. In addition, this definition was established for postmenopausal Caucasian women and may not be applicable to men or premenopausal women and people from other ethnic groups. Besides this, fractures occur in persons without osteoporosis implicating that bone density is not the only determinant of bone's resistance to fracture. It is nowadays well recognized that in particular in minimal trauma fractures bone fragility can be due to reduced bone mass as well as changes in the matrix composition and microarchitecture of bone. In support of this view, a recent consensus conference has defined osteoporosis as 'a skeletal disorder characterized by compromised bone strength leading to an increased risk of fracture'. ${ }^{4}$ The WHO is currently developing algorithms to refine prediction of 5- and 10-year fracture risk in the individual patient. These algorithms will be based not only on BMD but also on a set of clinical risk factors for fractures that are independent of BMD, underscoring the necessity to combine BMD-independent fracture assessment with BMD for such predictions. ${ }^{5}$ 


\section{The magnitude of the problem}

Based on the WHO definition, it has been estimated that $30 \%$ of postmenopausal Caucasian women in the USA have osteoporosis at the hip, lumbar spine or mid-radius, and a further $54 \%$ have osteopenia at these sites. ${ }^{6}$ Figure 2.1 shows the prevalence of osteoporosis and osteopenia amongst men and women in several age groups in the Rotterdam study, a large populationbased cohort study of men and women aged 55 years and over in the Netherlands. ${ }^{7}$

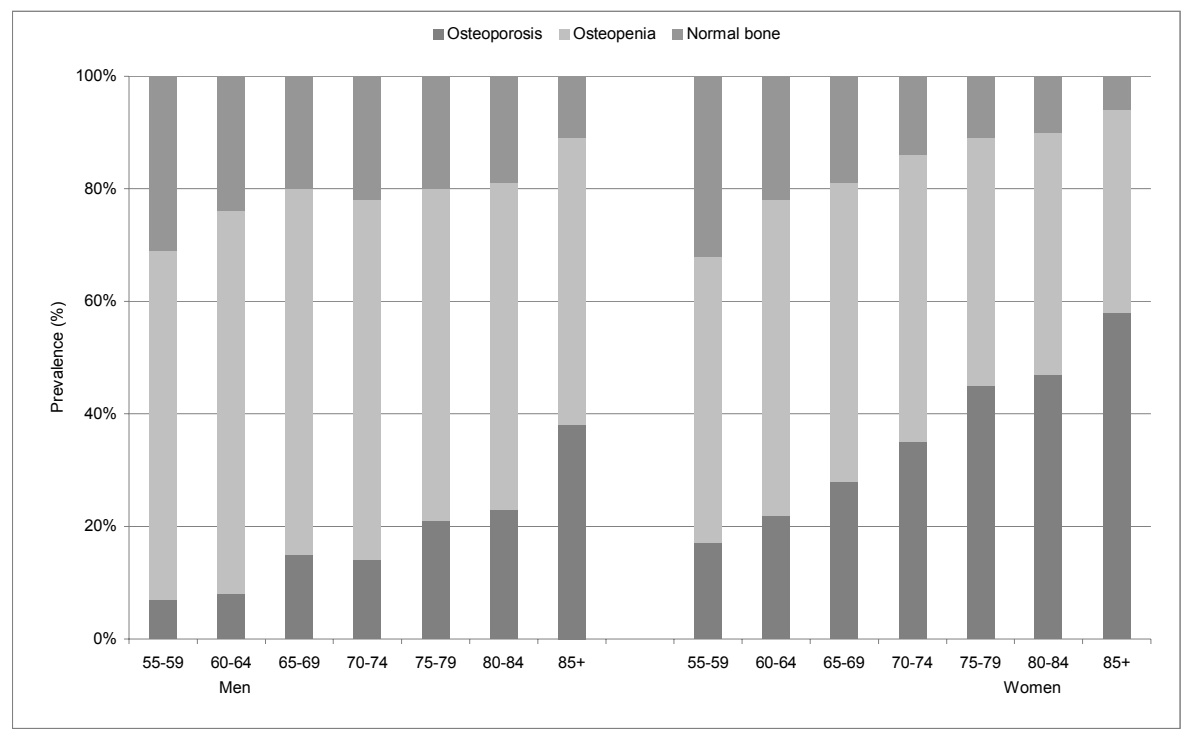

Figure 2.1 Prevalence of osteoporosis in men and women (the Rotterdam Study, 2004).

However, as mentioned before, low BMD alone is not the only determinant for an increased fracture risk. In the Rotterdam study the majority of fractures occurred in subjects who had a BMD T-score in the osteopenic range. ${ }^{7}$ In the Study of Osteoporotic Fractures (SOF-study), a multicenter, observational study of 10000 older women, $74 \%$ of women of 65 years and over with a fracture did not fulfil the criteria of osteoporosis. ${ }^{8}$ Eighty-two percent of women with a fracture of the distal forearm, hip or spine in the Nordic Research on Ageing (NORA) study also had no osteoporosis. ${ }^{9}$

Fragility fractures are an important public health issue because of the related morbidity and mortality. In white populations, about $50 \%$ of women and $20 \%$ of men older than 50 years will have a fragility fracture in their remaining lifetime. ${ }^{6,10}$ Of the postmenopausal women with recurrent fractures, one out of four with a vertebral fracture will have another fracture within one year. ${ }^{11}$ Women with a vertebral fracture have a fivefold risk for an other vertebral 
fracture and a twofold risk for a hip fracture. About $6 \%$ of women and $11 \%$ of men die during hospital admission because of a hip fracture. ${ }^{12}$

Worldwide, elderly people represent the fastest growing age-group, and the yearly number of fractures is therefore likely to rise substantially with continued ageing of the population. Thus even if age-adjusted incidence rates for hip fractures remain stable, the estimated number of hip fractures worldwide will rise from 1.7 million in 1990 to 6.3 million in $2050 .^{13}$

Fragility fractures also impose a major economic burden on health-care systems worldwide. The combined annual costs of all osteoporotic fractures have been estimated to be $\$ 20$ billion in the USA, about $\$ 30$ billion in the European Union ${ }^{1}$ and $€ 210$ million in the Netherlands. ${ }^{14}$

\section{Clinical fractures}

Most of the clinical fractures are due to a fall. As the risk to fall increases with ageing, this is another reason that the incidence of fractures increases with age. For vertebral fractures, however, falls play a less important role. The majority of vertebral fractures occur during routine daily activities such as lifting or changing position, though for many even no triggering activity or event can be identified. ${ }^{15}$ When these fractures come to clinical attention, back pain is the most frequent presenting symptom. These fractures may also present with a range of other symptoms, including height loss, sleep disturbance, anxiety, depression, loss of self esteem, fear of falling, poor appetite and reduced quality of life. ${ }^{16,17}$

\section{Morphometric vertebral fractures}

Comparison of the incidence of clinically ascertained fractures with the estimated incidence derived from a population survey in the community indicates that only about one third of women with a vertebral fracture come to clinical attention because of lack of typical signs and symptoms of an acute fracture ${ }^{15,18}$ Radiographic survey of the spine is therefore required to document its prevalence and incidence. But even then fractures may be missed, as qualitative assessment of fractures from plain radiographs is often overlooked ${ }^{19}$ and subject to observer disagreement. For this reason morphometric and semiquantitative visual techniques have been developed and are now widely used in clinical and epidemiological studies. ${ }^{20,21}$ Since there is as yet no consensus concerning the optimal criteria to determine whether or not a vertebral deformity is indeed a fracture, the prevalence and incidence of vertebral fractures is still ambiguous and heterogeneous between studies.

Data from the European Vertebral Osteoporosis Study (EVOS) indicate that $12 \%$ of men and women aged $50-80$ years have evidence of a radiographic vertebral fracture. ${ }^{22}$ Prevalence of these fractures increases with age in both 
men and women. At younger age more fractures can be found in men than in women, probably as a result of trauma sustained during previous occupational or recreational activity. ${ }^{23}$ The majority of morphometric vertebral fractures of the spine are found in the mid-thoracic area (T7-8) and the thoraco-lumbar junction (T12-L1). ${ }^{24}$

There are only a few population-based incidence data on vertebral fractures. Subjects in EVOS were followed prospectively and the incidence of a morphometrically defined vertebral fracture was $10.7 / 1000$ person years in women and 5.7/1000 person years in men. ${ }^{25} \mathrm{~A}$ similar incidence has been reported in the Rotterdam study. ${ }^{26}$

Recognition of all vertebral fractures is an important contributor to identifying patients at risk for further fractures, as the presence of both clinical and morphometric vertebral fractures are strong predictors of fracture risk, independent of BMD. ${ }^{27}$

\section{Pathophysiology of fractures}

From a mechanical perspective, fractures represent a structural failure of the bone, whereby the forces applied to the bone exceed its load-bearing capacity (Figure 2.1). ${ }^{28}$ The forces applied to the bone will depend on the specific activity, and will vary with the rate and direction of the applied loads. The load bearing capacity of a bone (also referred as 'whole bone strength') depends on the amount of bone (i.e. mass, size), the spatial distribution of the bone mass (i.e. shape and microarchitecture), and the intrinsic properties of the materials that comprise the bone. ${ }^{28}$ Thus, properties at the cellular, matrix, micro- and macroarchitectural levels may all impact the mechanical properties of bone. ${ }^{29}$

Bone must be stiff, able to resist deformation, so loading is possible. If bone is not sufficiently stiff - too flexible for the loads imposed on it - it will deform beyond its peak strain and crack. Bone must also be flexible, able to deform to allow energy absorption during impact loading. If bone is not sufficiently flexible - too brittle - the energy imposed on it will be released by cracking because it cannot deform 'enough' to absorb it when loaded. Bone must also be light to allow movement. ${ }^{30}$ These seemingly contradictory properties, stiffness yet flexibility, and lightness yet strength, are determined by bone's material composition and how this material is fashioned into a three dimensional structure. $^{3}$

A change in the material or structural components of bone, or the inability of bone modelling and remodelling to adapt these material and structural properties to the prevailing loads results in bone fragility (Figure 2.2). 


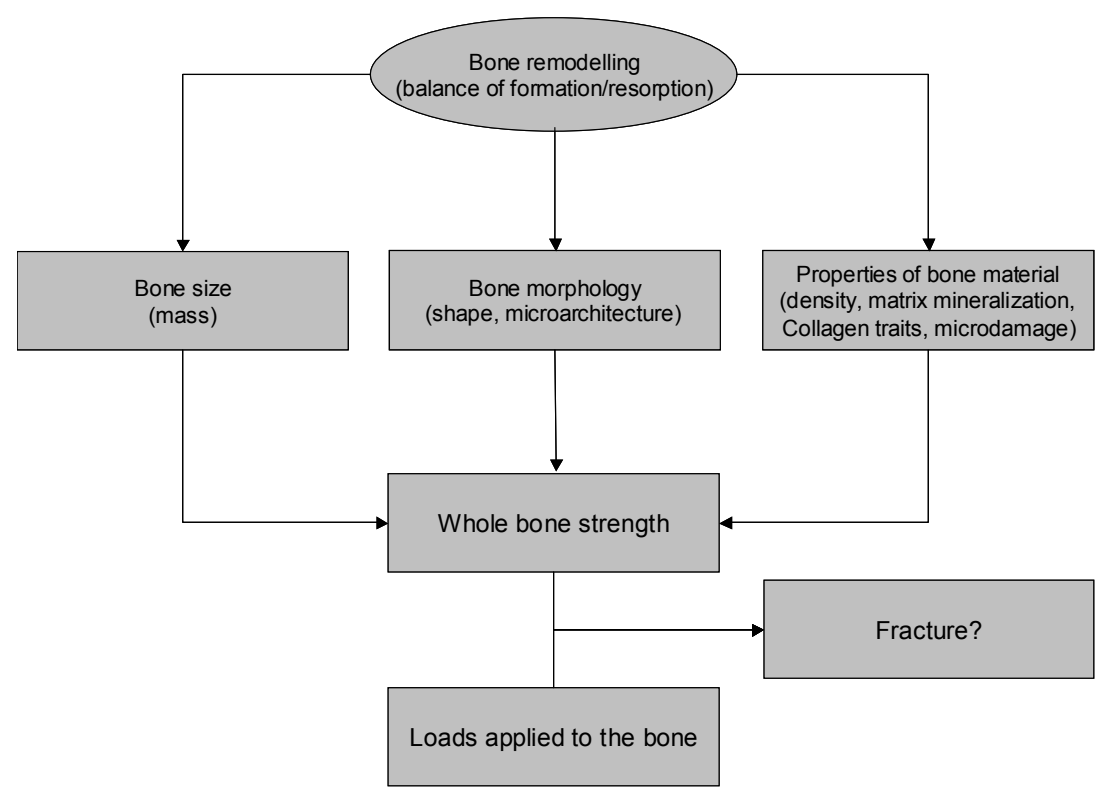

Figure 2.2 Etiology of age-related fractures and determinants of whole bone strength.

Although BMD remains currently the best available non-invasive assessment of bone mass in routine clinical practice, many other skeletal characteristics also contribute to bone strength. The recognition of these other determinants (often referred to as 'bone quality') is becoming more important, and their incorporation into algorithms of fracture detection remains the subject of continuing translational research. ${ }^{31}$

The bone mass of an individual in middle age is a result of the peak bone mass accrued during intrauterine life, childhood, and puberty, as well as the subsequent rate of bone loss. Bone loss takes place as a result of estrogen deficiency in postmenopausal women, as well as through estrogenindependent age-related mechanisms and is furthermore influenced by other factors, such as diseases and medications, and than referred to as secondary osteoporosis.

At the cellular level, bone loss occurs because of an imbalance between the activity of osteoclasts and osteoblasts. During life, the skeleton is continuously remodelled in an orderly sequence of bone resorption followed by bone formation - referred to as coupling. If the processes of resorption and formation are not matched, there is a remodelling imbalance. This imbalance can be magnified by a rise in the rate of initiation of new bone remodelling cycles (activation frequency). ${ }^{31}$ 


\section{Bone remodelling}

Understanding of the cellular basis of remodelling has advanced rapidly in recent years. The receptor activator of NFKB (RANK), its ligand (RANKL), and the decoy receptor Osteoprotegerin (OPG) are now known to be key regulators of osteoclastic bone resorption in vitro and in vivo. ${ }^{32}$ The bone remodelling is initiated on a bone surface usually covered by a very thin layer of unmineralized matrix and lining cells. These cells may respond to stimuli (local and systemic cytokines, hormones), which initiate the remodelling. The differentiation of osteoclasts is stimulated and they start to restore bone. The stimulation of osteoclast activity requires an interaction with the osteoblastic cells. RANK ligand (RANKL) is expressed and secreted by osteoblast precursor cells and binds RANK expressed by osteoclasts, thus promoting the differentiation and activity of the osteoclasts. Osteoblasts secrete OPG which binds to RANKL and inhibits the RANK-RANKL interaction and thus acts as a physiological regulator of bone turnover. ${ }^{3}$ (Figure 2.3)

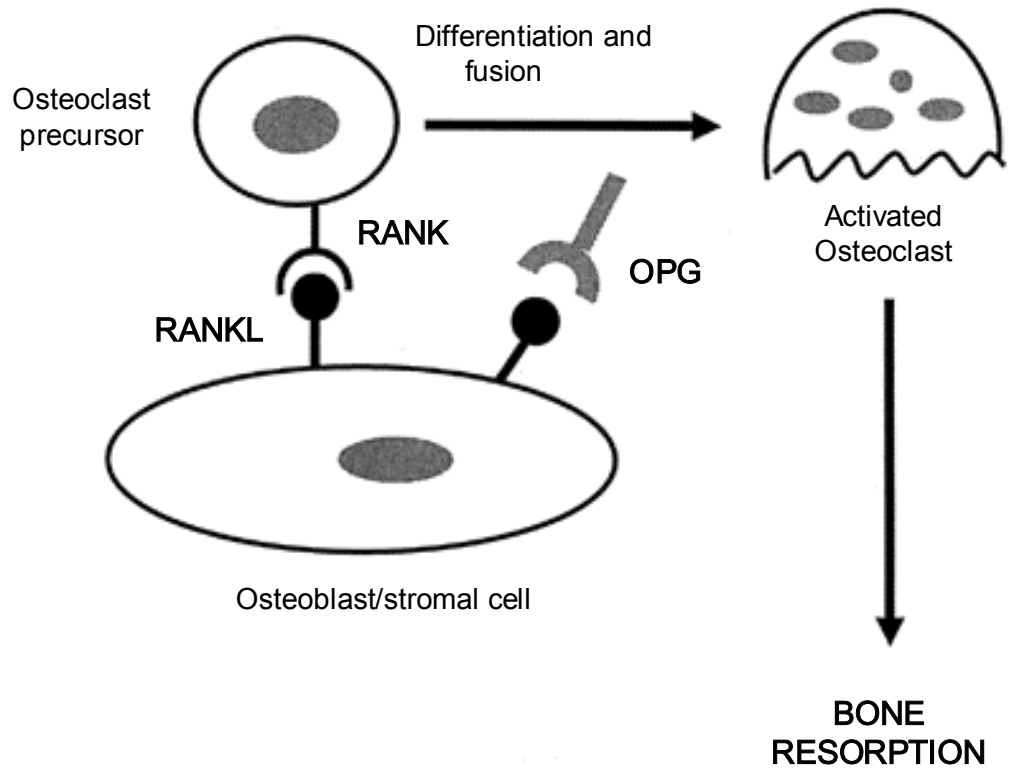

Figure 2.3 A schematic overview of the RANKL/RANK/OPG system. ${ }^{33}$

Osteoblasts and osteoclasts form the bone multicellular unit that reconstructs bone in distinct locations. Its purpose in adulthood is to maintain bone strength and to be available for adequate calcium homeostasis. In bone, damage due to fatigue develops during repeated loading, but only bone has the mechanism to 
detect the location and magnitude of the damage, remove it, replace it with new bone, and then reconstruct the material composition, microarchitecture, and macroarchitecture. ${ }^{30}$ The positive balance in the bone multicellular unit (net bone formation) during growth and the negative balance (net bone loss) during ageing are small. For these reasons, the rate of gain in bone during growth and loss during ageing is driven more by a high remodelling rate than by the magnitude of the positive or negative balance in the bone multicellular unit. Rapid remodelling is associated with an increased risk of fracture for several reasons. First, more densely mineralized bone is removed and replaced with younger, less densely mineralized bone, reducing material stiffness. ${ }^{34}$ As a result, bone may become too flexible, bend excessively, and crack under usual loading conditions. Second, excavated resorption sites remain temporarily unfilled, creating stress concentrators that predispose bone to microdamage. Third, increased remodelling impairs isomerization and maturation of collagen, which increases the fragility of bone, probably by altering the cross linking between adjacent collagen fibrils. ${ }^{35}$

Bone remodelling is also influenced in the context of the calcium homeostasis. Calcium and vitamin $\mathrm{D}$ deficiency result in secondary hyperparathyroidism that increases bone remodelling and in variable degrees of mineralization defects, that contribute to bone deformities and fractures, such as in rachitis and osteomalacia. $^{36}$

Recently, important novel genes and pathways for osteoblast differentiation and function have been discovered. In particular the identification of the role of the low-density lipoprotein receptor-related protein 5 (LRP5) gene in the regulation of bone mass is a landmark discovery. LRP5 is a modulator of osteoblast function and hence bone formation. It is a co-receptor for a series of osteoblast stimulating proteins operating through the Wnt signalling pathway. LRP5 is expressed on the osteoblast membrane between two other receptors, Frizzled and Kremen. Frizzled and LRP5 bind to Wnt, thereby activating bone formation. ${ }^{31}$

Last but not least, the central role of the osteocyte, the most frequent bone cell type, has been described in the context of signalling towards the osteoblast according to mechanical load on the skeleton, yet another pathway to influence bone remodelling. Recent discoveries have revealed the complex interaction between osteocytes with involvement of prostaglandins, sclerostin and Dickkopf. $^{31,37}$

\section{Assessment of fracture risk}

Since 1994, the benchmark for the diagnosis of osteoporosis is the assessment of BMD. However, as mentioned before, low BMD alone is not the only determinant of fracture risk. ${ }^{7}$ Although it is well established that the risk of 
future fracture rises with the decline of BMD, it is nowadays evident that assessment of fracture risk should encompass all aspects of risk and that intervention should not be guided exclusively by results of bone mineral density measurements. $^{38}$

\section{Clinical risk factors}

The WHO analyzed all international cohort studies in which information of clinical risk factors and bone mineral density are available and incident fractures have been ascertained. ${ }^{38}$ On the basis of this information, several risk factors independent of bone mineral density have been identified. These include history of fracture, glucocorticoid use, family history of fracture, cigarette smoking, excessive alcohol consumption, rheumatoid arthritis and low body weight.

For the Dutch Guidelines on Osteoporosis, a clinical fracture risk assessment score is developed using the most important risk factors (Relative Risk of at least two compared to the general population risk). ${ }^{12}$ Based on the risk score presented in Table 2.2, the individual absolute 10-year fracture risk can be calculated. When the risk score is 0 , the absolute fracture risk in that part of the general population is on average half of that in the total population. With one risk factor present, fracture risk is doubled etc.

Table 2.2 Selected risk factors with the estimated associated relative fracture risk (Dutch Guidelines on Osteoporosis, 2002).

\begin{tabular}{lcc}
\hline Risk factor & Fracture risk & Risk score points \\
\hline Fracture after age 50 years & X2 & 1 \\
Prevalent vertebral fracture & X & 2 \\
Low body weight $(<60 \mathrm{~kg})$ & $\mathrm{X} 2$ & 1 \\
Severe immobility & $\mathrm{X} 2$ & 1 \\
Corticosteroid use $(\geq 7.5 \mathrm{mg}$ prednisolone daily $)$ & $\mathrm{X} 2$ & 1 \\
\hline
\end{tabular}

\section{Age}

De Laet and co-workers clearly demonstrated that age and BMD are the two strongest independent risk factors for future fractures, both vertebral and nonvertebral and in both men and women. ${ }^{39}$ The incidence of hip fractures increases both with decreasing BMD and with increasing age, and these two factors add independently to fracture risk in men and women equally. In addition, age can be regarded as a surrogate marker for various other risk factors for fractures, such as changes in bone remodelling and bone quality, increased tendency of falling, deficient calcium homeostasis and concurrent polymorbidity. 


\section{Methods to determine BMD}

Dual-energy X-ray absorptiometry (DXA) is the most frequently used method for BMD measurement and is therefore considered the standard for the diagnosis of osteoporosis, the prediction of fractures and the follow-up of patients. Other methods to assess BMD are Quantitative Computed Tomography (QCT), Single-Energy Absorptiometry (SXA) and Quantitative Ultrasound (QUS). Although QCT is probably the best technique to assess bone mineral density separately in the trabecular and cortical bone compartment, it is not widely used because of lack of data on the predictive value for future fracture risk, high cost, limited availability, and, relative to DXA, a higher radiation dose needed for measurements. ${ }^{40}$

\section{DXA}

Bone density measurements with DXA are effective for predicting fractures in clinical practice and are stated to provide a gradient of risk that is as good or even better than other commonly used risk stratification measures such as blood pressure for stroke and serum cholesterol for cardiovascular disease. ${ }^{41}$ The lumbar spine is the most optimal method to study changes in BMD by bone loss after menopause or increase in BMD by treatment, as the cell/bone ratio is highest in trabecular bone compartments. ${ }^{42}$ Several studies have, however, revealed that with increasing age measurement of the spine is increasingly unreliable to document BMD, due to degenerative changes due to osteophytes and extra-osseous calcifications. ${ }^{43}$ The hip represents both trabecular (trochanter) and cortical bone (femoral neck) and in a recent study hip measurements were found to be superior to the spine in overall osteoporotic fracture prediction. ${ }^{44}$ This study showed that the commonly used rule of thumb that fracture rates double for each unit change in T-score clearly oversimplifies a more complex situation. The T-score in the hip had a much higher predictive value for fracture rates than the spine T-score. E.g. a women with spine T-score of -4.0 would be predicted to have only 2.8 times the risk of fracture of an otherwise identical woman with spine T-score of 0.0 , whereas a femoral neck T-score of -4.0 would result in over a 10 -fold relative fracture risk. Therefore the hip may be preferred as the primary site for diagnosis and fracture risk assessment as proposed by others. ${ }^{38,45}$

On the other hand, as mentioned earlier, a proportion of fractures occurs in patients with osteopenia rather than osteoporosis or even in patients with normal BMD. ${ }^{7,8}$ This is partly due to the fact that BMD measurements by DXA reflect some of the components of bone strength, including bone mass, the degree of mineralization, and to some extent bone size. However, BMD measurements by DXA do not reflect other components of bone strength, including the three-dimensional distribution of bone mass, trabecular and 
cortical microarchitecture, and the intrinsic properties of the bone matrix. To quantify these determinants high resolution CT-techniques are necessary. The first data of this technique indicate that indeed microarchitectural changes can be detected in the absence of osteoporosis. ${ }^{46}$ The applicability and value of this technique over DXA in predicting fracture risk in daily practice is, however, not documented yet.

\section{QUS}

QUS measurements have been proposed as an alternative to BMD assessment with DXA. ${ }^{47}$ Numerous ultrasound parameters used to characterize bone have been proposed, including broadband ultrasound attenuation (BUA) and speed of sound (SOS). In theory, QUS has the ability to provide additional information about bone structure, trabecular orientation and microarchitecture that is independent of bone mass and bone mineral density. ${ }^{47,48}$ Moreover, QUS instruments have advantages compared with DXA: they are radiation-free, portable, and inexpensive. ${ }^{49}$

A number of cross-sectional studies have examined the relationship between QUS and fracture. These revealed a lower, an equal, as well as a higher prediction value than that obtained with DXA. In the Osteoporosis and Ultrasound Study (OPUS), the performance of five QUS devices was compared with DXA for discrimination of women with and without osteoporotic vertebral fractures. The calcaneus QUS appeared to be as good as axial DXA in discriminating women with vertebral fracture. ${ }^{50}$

The large prospective longitudinal EPIDOS and SOF studies investigated the efficacy of calcaneus QUS to predict fracture risk. The results of these studies are close to those obtained in cross-sectional studies. In the EPIDOS study, 5662 women (median age 80.4 years) were followed for 2 years. The risk of hip fractures increased for each SD decrease with BUA by a factor of 2 (1.6-2.4) and of 1.7 (1.4-2.1) by SOS. These results are similar to the predictive value of BMD after DXA, and remained significant after adjustment for BMD. The combination of QUS and BMD appeared not superior to the use of one of them alone. ${ }^{51}$ The SOF study showed that each SD reduction of QUS increases the risk of hip (RR 2; Cl 1.5-2.7) and vertebral (RR1.3; Cl 1.3-1.5) fractures. ${ }^{52}$

\section{Methods to determine bone turnover}

\section{Biochemical markers}

Several biochemical markers of bone turnover have been developed. These provide non-invasive and fairly inexpensive methods to assess rates of bone formation (osteocalcin, bone alkaline phosphatase, peptides of type I procollagen) and resorption (deoxypiridinoline and its free and peptide-bound 
forms such as carboxy-terminal cross-linked telopeptide of type 1 collagen) in vivo. However, the precise positioning of these biochemical markers in the clinical approach to osteoporosis management has not been established. The quality of these measurements has been improved with the introduction of automated immunoassay analysers. ${ }^{53}$ Age, gender, ethnicity, menopausal status, disease status, recent fractures, immobility, certain pharmacological treatments and circadian variability were shown to influence the levels of bone markers. ${ }^{54} 55$

Bone turnover markers are mentioned to be of value to study the pathogenesis of osteoporosis, predict the risk of future fracture (independently of bone loss), and predict and monitor the response to therapy. Prospective studies have indeed shown an association between osteoporotic fractures and indices of bone turnover independent of bone mineral density in women during the menopause and in elderly women. ${ }^{56}$ In elderly women with values of resorption markers exceeding the reference range for premenopausal women, fracture risk was shown to be increased about two-fold after adjustment for bone mineral density. These findings suggest that a combined approach using bone mineral density, clinical risk factors and markers of bone turnover may improve fracture prediction. ${ }^{57}$

\section{Methods to determine fractures}

Long bone fractures can easily be diagnosed with radiological images made after an appropriate trauma and typical clinical picture. This is unfortunately not the situation for a substantial number of vertebral fractures. The statement "there is no gold standard for the diagnosis or definition of a vertebral fracture" is repeated throughout the literature and illustrates the difficulties experienced in making a diagnosis of vertebral fracture. ${ }^{58,59}$ Because a vertebral fracture is often unsuspected clinically, the diagnosis of vertebral fracture relies upon accurate interpretation of radiological images. Unfortunately, however, vertebral fractures are often missed in daily practice. In a large population of osteoporotic women recruited in a therapeutic trial, vertebral fractures were not adequately reported in the local radiology report in about $30 \%$ of patients. ${ }^{60}$ The underdiagnosis of vertebral fractures was also evaluated in 934 hospitalized women who had a lateral chest radiograph. One hundred and thirty-two women (14\%) were found to have moderate and severe vertebral fractures (Grades 2 and 3 according to Genant (Figure 2.4)), but only $50 \%$ of those were reported in the X-ray report and $23 \%$ in the medical report and thus treated. ${ }^{19}$

Vertebral fractures can be assessed by various methodologies. Radiologists, in routine clinical practice, usually visually analyze radiographs of the thoracolumbar spine in the lateral projection to identify vertebral fractures 
(=visual, qualitative technique). While diagnosing the vertebral fracture in question, the interpreter also considers the potential differential diagnoses of this deformity. Advantages of this technique are detection of anatomic variants, detection of non-osteoporotic deformities and detection of technical features causing false positives. Disadvantages are inter- and intra-reader variability and therefore specific training and expertise is necessary.

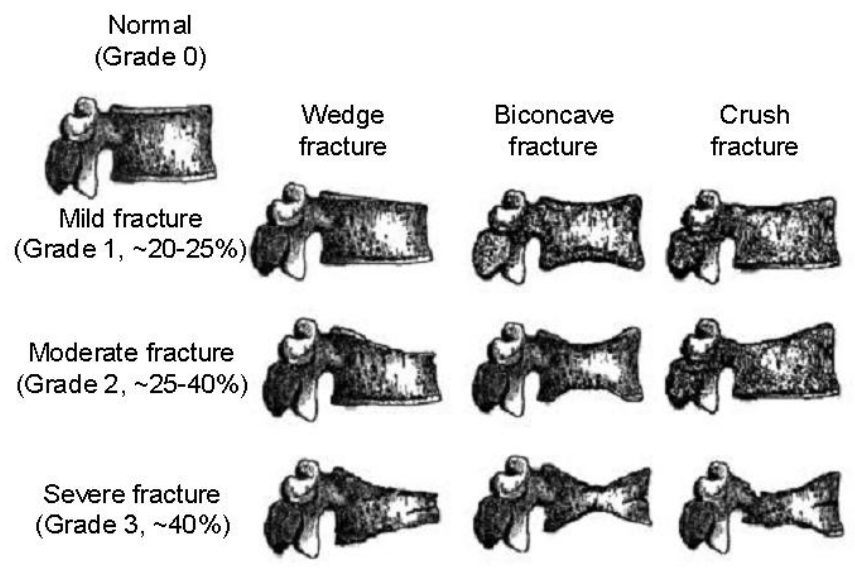

Figure 2.4 Semiquantitative technique of Genant. ${ }^{63}$

To provide in a more objective parameter, measurements of vertebral dimensions are developed and called quantitative technique or vertebral morphometry. Melton developed definitions of vertebral fractures utilizing percentage reductions in ratios of anterior, middle or posterior heights of vertebral bodies compared with normal values for that particular vertebral body. ${ }^{18}$ Eastell modified this method, defining fractures on the basis of standard deviation reductions instead of fixed percentages. ${ }^{61}$ More recently, McCloskey proposed a number of modifications to the Eastell/Melton standard criteria including the use of predicted posterior heights and the addition of more complex criteria. $^{62}$ Disadvantages of these methodologies are that the sensitivity and specificity are very much dependent on thresholds that define the prevalent and incident deformity and that there are no corrections for anatomical anomalies or other pathologies causing a deformity-like appearance.

In between these two techniques standardized visual assessment has been developed, also called semi-quantitative technique. One of these approaches is the method of Genant (Figure 2.4), in which the approximate degree of height reduction determines the assignment of grades to each vertebra; normal 
(grade 0), mildly deformed (grade 1; approximately $20-25 \%$ reduction in anterior, middle and/or posterior height and $10-20 \%$ reduction of the projected vertebral area; moderately deformed (grade 2; approximately $25-40 \%$ reduction in heights and $20-40 \%$ reduction of the projected vertebral area) and severely deformed (grade 3; approximately $40 \%$ or greater reduction in heights) ${ }^{63}$

There are, however, also limitations of this semiquantitative grading scheme that may also apply to other standardized approaches. For example, from morphometric data on normal subjects we know that vertebrae in the midthoracic spine and in the thoracolumbar junction are slightly more wedged than in other regions of the spine. The consequence is that normal variations may be misinterpreted as mild vertebral deformities. ${ }^{64}$ This may falsely increase prevalence values for vertebral fractures from visual readings in the specific regions. ${ }^{65}$ The same applies to a lesser extent to the lumbar spine, where some degree of biconcavity is frequently seen. However, mild fractures detected with this method are also associated with a lower bone density than normal, and they also predict future vertebral fractures, although to a lesser extent than moderate or severe fractures do. ${ }^{66}$

Besides the discussion mentioned above about the different methodologies to define a vertebral fracture, there is also no gold standard for interpretation of radiographic images. Traditionally vertebral deformities have been identified on conventional lateral radiographs of the thoracolumbar spine (morphometric radiography or MRX). However, an alternative method of acquiring the lateral images of the spine has been developed, which utilizes DXA machines, commonly referred to as Morphometric X-ray absorptiometry (MXA) or Instant Vertebral Assessment (IVA). This technique has several advantages when compared with conventional radiography. These include a significant lower radiation dose to the patient, acquisition of a single image of the whole spine, fracture assessment can take place at the same time as bone densitometry, straightforward supine patient positioning and plan-parallel projection minimalising projection deformities ${ }^{67}$ However, image quality is less than that of the high-resolution conventional radiograph. Previous studies revealed nevertheless that this technique enables an accurate and precise measurement of vertebral dimensions, despite its moderate image quality. ${ }^{67,68}$ This moderate image definition is, however, a significant drawback in assessing the upper thoracic region and in distinguishing fracture from other anatomical variants. There is good agreement between this technique and MRX in identifying fractures when strict criteria for fracture definition are used. ${ }^{69}$

\section{Causes of osteoporosis; primary versus secondary forms}

In the majority of patients osteoporosis is a result of bone loss due to the menopause and/or ageing. These situations are called primary osteoporosis. 
Osteoporosis may, however, also be a consequence of certain diseases or medications and is then called secondary osteoporosis. Individuals with secondary osteoporosis experience bone loss that cannot be explained by the menopause or ageing only. The differential diagnosis for conditions and medications that contribute to secondary osteoporosis is extensive ${ }^{36}$ (Table 2.3). Secondary osteoporosis is common in men and in premenopausal women with osteoporosis and in men and women with a recent clinical fracture. ${ }^{70,71}$ In addition, as many as one third of women with postmenopausal osteoporosis have identifiable secondary causes that contribute to bone loss. ${ }^{72}$ Secondary causes of osteoporosis in men account for $50-80 \%$ of cases of bone loss leading to fracture in this population. ${ }^{72}$

Table 2.3 Main conditions and medications that cause or are risk factors for secondary osteoporosis.

\begin{tabular}{ll}
\hline Disorders & Medications \\
\hline Vitamin D deficiency & Heparin \\
Primary and secondary hypogonadism & Anticonvulsants \\
Inflammatory diseases (e.g. inflammatory bowel disease, & Cyclosporine A \\
rheumatoid arthritis, sarcoidosis) & \\
Gastrectomy & Glucocorticoids \\
Anorexia Nervosa & Lithium \\
Malabsorption e.g. Celiac disease & Methotrexate \\
Hyperparathyroidism & \\
Cushing syndrome & \\
Organ transplantation & \\
Hyperthyroidism & \\
Epilepsy & \\
Etcetera & \\
\hline
\end{tabular}

\section{Glucocorticoid-induced osteoporosis}

Glucocorticoid (GC) induced osteoporosis is the most common form of osteoporosis caused by medication. GC treatment leads to rapid bone loss and impairment of bone quality. GCs adversely affect bone remodelling by both reducing bone formation and increasing resorption. GCs have been shown to decrease osteoblastogenesis and osteoblast lifespan, and induce osteocyte apoptosis. GCs effects on bone resorption most likely result from accelerated osteoclast maturation and activity induced by reductions in gonadal and adrenal hormones and a negative calcium balance due to reduced gastrointestinal absorption of calcium in combination with an increase in urinary excretion. ${ }^{73,74}$ The end result of these changes in bone metabolism induced by GCs is an increased fracture risk in patients exposed to these agents. Although the estimates of fracture risk on GCs varies, it may be substantial. Van Staa and colleagues reported in a meta-analysis an increase of vertebral fracture 
rate up to fourfold after 3-6 months of therapy with a low dose of GCs (from an equivalent of prednisone of $\geq 2.5 \mathrm{mg}$ daily). ${ }^{75}$

\section{Osteoporosis in inflammatory diseases}

It is well known that chronic inflammatory diseases affect bone physiology by the production of cytokines. ${ }^{76-78}$ Inflammation has been shown to drive osteoclast differentiation and function by activating the RANK/RANKL (see Figure 2.3) pathway. Inflammatory cytokines (including TNF- $\alpha$ ) and growth factors are shown to promote osteoclastogenesis with subsequent osteoclastmediated bone loss. This growing interest in the interaction between inflammation and bone has resulted in the emerging field of osteoimmunology. $^{79}$

\section{Osteoporosis in inflammatory bowel disease}

Decreased bone mineral density (BMD) and increased bone turnover are frequent findings in inflammatory bowel disease (IBD). On the basis of Z-scores, osteopenia can be found in 32 to $38 \%$ of patients with Crohn's disease (CD) and in 23 to $25 \%$ of patients with ulcerative colitis (UC). An even higher prevalence of decreased bone mass can be found when a T-score is used to express changes in BMD. ${ }^{80}$

Factors contributing to decreased BMD in IBD patients involve inflammatory cytokines, malabsorption due to disease activity or extensive intestinal resection, GC use, inability to achieve peak bone mass when the disease starts in childhood, malnutrition, immobilization, low body mass index, smoking and hypogonadism induced by the chronic inflammatory condition.

\section{Osteoporosis in sarcoidosis}

Sarcoidosis is an inflammatory T-cell driven disease and as a result a decreased bone mineral density can be expected in this patient group. Besides this, prolonged treatment with GCs and decreased physical activity may also negatively affect bone. A limited number of studies on BMD measurements in untreated sarcoidosis are published. All these studies are of small size and revealed predominantly an unchanged BMD with only mild trabecular bone loss in longstanding sarcoidosis. ${ }^{81-83}$

\section{Osteoporosis in thyrotoxicosis}

The effects of thyroid hormone on bone metabolism are complex. Overt hyperthyroidism is associated with an increased risk of osteoporosis and the pathophysiology of it is multifactorial. This includes shortening of the bone remodelling cycle and acceleration of bone turnover. ${ }^{84}$ Thyroid hormone indirectly promotes osteoclast formation and activation by inducing the 
expression of cytokines, prostaglandins and the receptor activator of NFKB ligand (RANKL). ${ }^{85}$

A new development has been the discovery of functional thyrotropin (TSH) receptors in bone because of the implication that effects that traditionally have been attributed to high thyroid hormone levels may be in effect related to low TSH levels. ${ }^{86}$ TSH inhibits RANKL and upregulates OPG thereby inhibiting bone loss. In subclinical hyperthyroidism TSH levels are characteristically low, resulting in an absence of this block and this can result in bone loss.

Bone loss is a uniform feature of overt hyperthyroidism. The extent of the reduction in bone density in most studies of hyperthyroid patients ranges from 10 to $20 \%{ }^{87,88}$ A history of overt hyperthyroidism is a risk factor for hip fracture later in life, ${ }^{8,89}$ and is one of the causes of excess late mortality in previously hyperthyroid patients. ${ }^{90}$ It is therefore reasonable to assume that in some hyperthyroid patients bone density does not return to normal after antithyroid treatment. Symptomatic bone disease is not a prominent feature of subclinical hyperthyroidism. However, mild (subclinical) hyperthyroidism in subjects with multinodular goiter was associated with decreased forearm bone density, while in postmenopausal women with hyperthyroidism who were treated with methimazole a higher bone density of the distal forearm was found compared to untreated women. ${ }^{91,92}$ In addition the risk of osteoporotic fractures may be increased. $^{93}$

\section{Prevention of fractures}

Since most fractures occur as a result of falls, attention to reducing the risk of falls seems important. Targeted or broad spectrum fall prevention strategies have been shown to reduce the risk of falls, but none has shown anti-fracture effect. The use of hip protectors reduces the impact of falls on hip fractures in high risk individuals if worn at the time of a fall, ${ }^{94}$ but low compliance remains the cause of lack of effect in the daily clinical setting. ${ }^{95}$

The drugs used to treat osteoporosis and to decrease fracture risk act on bone by manipulating bone turnover in quite different ways. Antiresorptive agents decrease bone resorption and bone formation, anabolic agents stimulate bone turnover (bone formation more than resorption) and strontium ranelate uncouples bone formation (increase) from bone resorption (slight decrease). With this classification, antiresorptive treatments include calcium, vitamin D, hormone replacement therapy, bisphosphonates, selective estrogen-receptor modulators (SERMs), and calcitonin. ${ }^{31,42}$ The first clearly anabolic therapy that stimulates bone formation is recombinant parathyroid hormone (rhPTH). ${ }^{96}$ Strontium ranelate has stimulated bone formation and inhibits bone resorption in animal models, but the exact anabolic mechanisms on bone formation in humans are under investigation. ${ }^{97}$ 


\section{Whom to treat?}

All clinical guidelines on postmenopausal osteoporosis recommend a casefinding strategy to identify patients at risk for fractures. ${ }^{98}$ Patients are identified by the presence of well-defined clinical risk factors followed by measurements of BMD by DXA. Those with prevalent vertebral fractures or a BMD T-score less than -2.5 should receive treatment, although higher intervention thresholds have been proposed in the presence of clinical risk factors, such as prevalent non-spine fractures and use of glucocorticoids.

\section{Treatment options}

Many treatments are documented to reduce the risk of fractures in postmenopausal women with osteoporosis, including bisphosphonates (alendronate, risedronate, ibandronate, zoledronate), SERMs (raloxifene), strontium ranelate and rhPTH. However, the anti-fracture profile differs between these drugs in terms of spectrum of fractures prevented, speed of action in prevention of fractures, duration of the trials, safety, frequency of drug intake and compliance.

\section{Management of secondary osteoporosis}

Dual-energy X-ray absorptiometry is indicated in the initial workup of secondary causes of osteoporosis. ${ }^{99}$ The presence of secondary causes of bone loss may further increase the risk of fracture independently of BMD and may necessitate earlier pharmacologic intervention. Management of bone loss in inflammatory diseases at this time should focus around reduction in inflammation and thus on treating the underlying disease. ${ }^{36}$ Treatment with anti-tumor necrosis factor alpha (TNF- $\alpha$ ) agents has been shown to reduce progression of juxta-articular bone loss in both rheumatoid arthritis and ankylosing spondylitis. ${ }^{100,101}$

Treatments directed at preventing the changes in bone metabolism induced by GCs are effective, and some have been shown to reduce fracture risk. The critical therapies include maintaining adequate calcium and vitamin $D$ stores, prevention of falls by strengthening muscles associated with balance and ambulation, and bisphosphonates which have been shown to reduce fracture risk by $40-90 \% .{ }^{102,103}$ For the prevention and treatment of glucocorticoid induced osteoporosis, data are more compelling for bisphosphonates than for any other agent. ${ }^{104}$ 


\section{References}

1. Cummings SR, Melton LJ. Epidemiology and outcomes of osteoporotic fractures. Lancet. 2002;359:1761-1767.

2. Assessment of fracture risk and its application to screening for postmenopausal osteoporosis. Report of a WHO Study Group. World Health Organ Tech Rep Ser. 1994;843:1-129.

3. Chavassieux P, Seeman E, Delmas PD. Insights into material and structural basis of bone fragility from diseases associated with fractures. How determinants of the biomechanical properties of bone are compromised by disease. Endocr Rev. 2007;28:151-164.

4. Consensus conference. Osteoporosis prevention, diagnosis and therapy. JAMA. 2001;285:785-795.

5. Kanis JA, Oden A, Johnell O, et al. The use of clinical risk factors enhances the performance of BMD in the prediction of hip and osteoporotic fractures in men and women. Osteoporos Int. 2007;18:1033-1046.

6. Melton LJ, III. How many women have osteoporosis now? J Bone Miner Res. 1995;10: 175-177.

7. Schuit SC, van der Klift M, Weel $A E$, et al. Fracture incidence and association with bone mineral density in elderly men and women: the Rotterdam Study. Bone. 2004;34:195-202.

8. Cummings SR, Nevitt MC, Browner WS, et al. Risk factors for hip fracture in white women. Study of Osteoporotic Fractures Research Group. N Engl J Med. 1995;332:767-773.

9. Siris ES, Brenneman SK, Miller PD, et al. Predictive value of low BMD for 1-year fracture outcomes is similar for postmenopausal women ages 50-64 and 65 and Older: results from the National Osteoporosis Risk Assessment (NORA). J Bone Miner Res. 2004;19:1215-1220.

10. Department of Health and Human services. Bone health and osteoporosis: a report of the Surgeon-General. Rockville. 2004.

11. Lindsay $\mathrm{R}$, Silverman $\mathrm{SL}$, Cooper $\mathrm{C}$, et al. Risk of new vertebral fracture in the year following a fracture. JAMA. 2001;285:320-323.

12. Kwaliteitsinstituut voor de Gezondheid CBO. Osteoporose: tweede herziene richtlijn. 2002.

13. Cooper C, Campion G, Melton LJ, III. Hip fractures in the elderly: a world-wide projection. Osteoporos Int. 1992;2:285-289.

14. de Laet CE, van Hout BA, Hofman A, et al. Costs due to osteoporosis-induced fractures in The Netherlands; possibilities for cost control. Ned Tijdschr Geneeskd. 1996;140:1684-1688.

15. Cooper C, Atkinson EJ, O'Fallon WM, et al. Incidence of clinically diagnosed vertebral fractures: a population-based study in Rochester, Minnesota, 1985-1989. J Bone Miner Res. 1992;7:221-227.

16. Lips P, Cooper C, Agnusdei D, et al. Quality of life in patients with vertebral fractures: validation of the Quality of Life Questionnaire of the European Foundation for Osteoporosis (QUALEFFO). Working Party for Quality of Life of the European Foundation for Osteoporosis. Osteoporos Int. 1999;10:150-160.

17. Oleksik A, Lips P, Dawson A, et al. Health-related quality of life in postmenopausal women with low BMD with or without prevalent vertebral fractures. J Bone Miner Res. 2000;15: 1384-1392.

18. Melton LJ, III, Lane AW, Cooper C, et al. Prevalence and incidence of vertebral deformities. Osteoporos Int. 1993;3:113-119.

19. Gehlbach SH, Bigelow $\mathrm{C}$, Heimisdottir $\mathrm{M}$, et al. Recognition of vertebral fracture in a clinical setting. Osteoporos Int. 2000;11:577-582.

20. Smith-Bindman R, Steiger $P$, Cummings $S R$, et al. The index of radiographic area (IRA): a new approach to estimating the severity of vertebral deformity. Bone Miner. 1991;15:137-149.

21. Melton LJ. Epidemiology of vertebral fractures. In: Christensen C, Johansen J, Riis BJ, eds. Osteoporosis. Copenhagen: 1987.

22. O'Neill TW, Felsenberg D, Varlow J, et al. The prevalence of vertebral deformity in European men and women: the European Vertebral Osteoporosis Study. J Bone Miner Res. 1996;11: 1010-1018. 
23. Silman AJ, O'Neill TW, Cooper C, et al. Influence of physical activity on vertebral deformity in men and women: results from the European Vertebral Osteoporosis Study. J Bone Miner Res. 1997;12:813-819.

24. Ismail AA, Cooper C, Felsenberg D, et al. Number and type of vertebral deformities: epidemiological characteristics and relation to back pain and height loss. European Vertebral Osteoporosis Study Group. Osteoporos Int. 1999;9:206-213.

25. Felsenberg $D$, Silman $A J$, Lunt M. Incidence of vertebral fracture in Europe: results from the European Prospective Osteoporosis Study (EPOS). J Bone Miner Res. 2002;17:716-724.

26. van der Klift M, de Laet CE, McCloskey EV, et al. The incidence of vertebral fractures in men and women: the Rotterdam Study. J Bone Miner Res. 2002;17:1051-1056.

27. Siris ES, Brenneman SK, Barrett-Connor E, et al. The effect of age and bone mineral density on the absolute, excess, and relative risk of fracture in postmenopausal women aged 50-99: results from the National Osteoporosis Risk Assessment (NORA). Osteoporos Int. 2006;17:565-574.

28. Bouxsein ML. Determinants of skeletal fragility. Best Pract Res Clin Rheumatol. 2005;19: 897-911.

29. Bouxsein ML. Bone quality: where do we go from here? Osteoporos Int. 2003;14 Suppl 5:118-127.

30. Seeman E, Delmas PD. Bone quality - the material and structural basis of bone strength and fragility. N Engl J Med. 2006;354:2250-2261.

31. Sambrook P, Cooper C. Osteoporosis. Lancet. 2006;367:2010-2018.

32. Boyle WJ, Simonet WS, Lacey DL. Osteoclast differentiation and activation. Nature. 2003; 423:337-342.

33. Yasuda H, Shima N, Nakagawa N, et al. Osteoclast differentiation factor is a ligand for osteoprotegerin/osteoclastogenesis-inhibitory factor and is identical to TRANCE/RANKL. Proc Natl Acad Sci U S A. 1998;95:3597-3602.

34. Boivin G, Lips P, Ott SM, et al. Contribution of raloxifene and calcium and vitamin D3 supplementation to the increase of the degree of mineralization of bone in postmenopausal women. J Clin Endocrinol Metab. 2003;88:4199-4205.

35. Viguet-Carrin S, Garnero P, Delmas PD. The role of collagen in bone strength. Osteoporos Int. 2006;17:319-336.

36. Kelman A, Lane NE. The management of secondary osteoporosis. Best Pract Res Clin Rheumatol. 2005;19:1021-1037.

37. van Bezooijen RL, Svensson JP, Eefting D, et al. Wnt but not BMP signaling is involved in the inhibitory action of sclerostin on BMP-stimulated bone formation. J Bone Miner Res. 2007; 22:19-28.

38. Kanis JA, Borgstrom F, De Laet C, et al. Assessment of fracture risk. Osteoporos Int. 2005; 16:581-589.

39. de Laet $\mathrm{CE}$, van Hout $\mathrm{BA}$, Burger $\mathrm{H}$, et al. Bone density and risk of hip fracture in men and women: cross sectional analysis. BMJ. 1997;315:221-225.

40. Yu W, Qin M, Xu L, et al. Normal changes in spinal bone mineral density in a Chinese population: assessment by quantitative computed tomography and dual-energy X-ray absorptiometry. Osteoporos Int. 1999;9:179-187.

41. Marshall $\mathrm{D}$, Johnell $\mathrm{O}$, Wedel $\mathrm{H}$. Meta-analysis of how well measures of bone density predict occurrence of osteoporotic fractures. BMJ. 1996;312:1254-1259.

42. Eastell R. Treatment of postmenopausal osteoporosis. N Engl J Med. 1998;338:736-746.

43. Liu G, Peacock M, Eilam O, et al. Effect of osteoarthritis in the lumbar spine and hip on bone mineral density and diagnosis of osteoporosis in elderly men and women. Osteoporos Int. 1997;7:564-569.

44. Leslie WD, Tsang JF, Caetano PA, et al. Effectiveness of bone density measurement for predicting osteoporotic fractures in clinical practice. J Clin Endocrinol Metab. 2007;92:77-81.

45. Kanis JA, Gluer CC. An update on the diagnosis and assessment of osteoporosis with densitometry. Committee of Scientific Advisors, International Osteoporosis Foundation. Osteoporos Int. 2000;11:192-202. 
46. Sornay-Rendu E, Boutroy S, Munoz F, et al. Alterations of Cortical and Trabecular Architecture Are Associated With Fractures in Postmenopausal Women, Partially Independent of Decreased BMD Measured by DXA: The OFELY Study. J Bone Miner Res. 2007;22:425-433.

47. Gluer CC, Cummings SR, Bauer DC, et al. Osteoporosis: association of recent fractures with quantitative US findings. Radiology. 1996;199:725-732.

48. Hans D, Arlot ME, Schott AM, et al. Do ultrasound measurements on the os calcis reflect more the bone microarchitecture than the bone mass?: a two-dimensional histomorphometric study. Bone. 1995;16:295-300.

49. Baran DT. Quantitative ultrasound: a technique to target women with low bone mass for preventive therapy. Am J Med. 1995;98:48S-51S.

50. Gluer CC, Eastell R, Reid DM, et al. Association of five quantitative ultrasound devices and bone densitometry with osteoporotic vertebral fractures in a population-based sample: the OPUS Study. J Bone Miner Res. 2004;19:782-793.

51. Hans D, Dargent-Molina P, Schott AM, et al. Ultrasonographic heel measurements to predict hip fracture in elderly women: the EPIDOS prospective study. Lancet. 1996;348:511-514.

52. Bauer DC, Gluer CC, Cauley JA, et al. Broadband ultrasound attenuation predicts fractures strongly and independently of densitometry in older women. A prospective study. Study of Osteoporotic Fractures Research Group. Arch Intern Med. 1997;157:629-634.

53. Garnero P, Borel O, Delmas PD. Evaluation of a fully automated serum assay for C-terminal cross-linking telopeptide of type I collagen in osteoporosis. Clin Chem. 2001;47:694-702.

54. Qvist P, Christgau S, Pedersen BJ, et al. Circadian variation in the serum concentration of Cterminal telopeptide of type I collagen (serum CTx): effects of gender, age, menopausal status, posture, daylight, serum cortisol, and fasting. Bone. 2002;31:57-61.

55. Blumsohn A, Herrington K, Hannon RA, et al. The effect of calcium supplementation on the circadian rhythm of bone resorption. J Clin Endocrinol Metab. 1994;79:730-735.

56. Garnero P, Sornay-Rendu E, Claustrat B, et al. Biochemical markers of bone turnover, endogenous hormones and the risk of fractures in postmenopausal women: the OFELY study. J Bone Miner Res. 2000;15:1526-1536.

57. Johnell $\mathrm{O}$, Oden $\mathrm{A}$, De Laet $\mathrm{C}$, et al. Biochemical indices of bone turnover and the assessment of fracture probability. Osteoporos Int. 2002;13:523-526.

58. Kiel D. Assessing vertebral fractures. National Osteoporosis Foundation Working Group on Vertebral Fractures. J Bone Miner Res. 1995;10:518-523.

59. Schwartz EN, Steinberg D. Detection of vertebral fractures. Curr Osteoporos Rep. 2005;3:126-135.

60. Delmas PD, van de LL, Watts NB, et al. Underdiagnosis of vertebral fractures is a worldwide problem: the IMPACT study. J Bone Miner Res. 2005;20:557-563.

61. Eastell R, Cedel SL, Wahner HW, et al. Classification of vertebral fractures. J Bone Miner Res. 1991;6:207-215.

62. McCloskey EV, Spector TD, Eyres KS, et al. The assessment of vertebral deformity: a method for use in population studies and clinical trials. Osteoporos Int. 1993;3:138-147.

63. Genant $\mathrm{HK}, \mathrm{Wu} \mathrm{CY}$, van $\mathrm{KC}$, et al. Vertebral fracture assessment using a semiquantitative technique. J Bone Miner Res. 1993;8:1137-1148.

64. Kleerekoper M, Nelson DA. Vertebral fracture or vertebral deformity. Calcif Tissue Int. 1992;50:5-6.

65. Zebaze RM, Maalouf G, Wehbe J, et al. The varying distribution of intra- and inter-vertebral height ratios determines the prevalence of vertebral fractures. Bone. 2004;35:348-356.

66. Black DM, Palermo L, Nevitt MC, et al. Comparison of methods for defining prevalent vertebral deformities: the Study of Osteoporotic Fractures. J Bone Miner Res. 1995;10: 890-902.

67. Blake GM, Rea JA, Fogelman I. Vertebral morphometry studies using dual-energy x-ray absorptiometry. Semin Nucl Med. 1997;27:276-290.

68. Rea JA, Li J, Blake GM, et al. Visual assessment of vertebral deformity by X-ray absorptiometry: a highly predictive method to exclude vertebral deformity. Osteoporos Int. 2000;11:660-668. 
69. Pavlov L, Gamble GD, Reid IR. Comparison of dual-energy X-ray absorptiometry and conventional radiography for the detection of vertebral fractures. J Clin Densitom. 2005;8:379-385.

70. Becker C, Crow S, Toman J, et al. Characteristics of elderly patients admitted to an urban tertiary care hospital with osteoporotic fractures: correlations with risk factors, fracture type, gender and ethnicity. Osteoporos Int. 2006;17:410-416.

71. Tannenbaum C, Clark J, Schwartzman K, et al. Yield of laboratory testing to identify secondary contributors to osteoporosis in otherwise healthy women. J Clin Endocrinol Metab. 2002;87:4431-4437.

72. Stein E, Shane E. Secondary osteoporosis. Endocrinol Metab Clin North Am. 2003;32:11534 , vii.

73. Lane NE. An update on glucocorticoid-induced osteoporosis. Rheum Dis Clin North Am. 2001;27:235-253.

74. Weinstein RS, Jilka RL, Parfitt AM, et al. Inhibition of osteoblastogenesis and promotion of apoptosis of osteoblasts and osteocytes by glucocorticoids. Potential mechanisms of their deleterious effects on bone. J Clin Invest. 1998;102:274-282.

75. van Staa TP, Leufkens HG, Cooper C. The epidemiology of corticosteroid-induced osteoporosis: a meta-analysis. Osteoporos Int. 2002;13:777-787.

76. Gravallese EM, Goldring SR. Cellular mechanisms and the role of cytokines in bone erosions in rheumatoid arthritis. Arthritis Rheum. 2000;43:2143-2151.

77. Hofbauer LC, Schoppet M. Clinical implications of the osteoprotegerin/RANKL/RANK system for bone and vascular diseases. JAMA. 2004;292:490-495.

78. Hofbauer LC, Heufelder AE. The role of osteoprotegerin and receptor activator of nuclear factor kappaB ligand in the pathogenesis and treatment of rheumatoid arthritis. Arthritis Rheum. 2001;44:253-259.

79. Walsh NC, Crotti TN, Goldring SR, et al. Rheumatic diseases: the effects of inflammation on bone. Immunol Rev. 2005;208:228-251.

80. Schoon EJ, van Nunen AB, Wouters RS, et al. Osteopenia and osteoporosis in Crohn's disease: prevalence in a Dutch population-based cohort. Scand J Gastroenterol Suppl. 2000;43-47.

81. Tervonen S, Karjalainen P, Valta R. Bone mineral in sarcoidosis. Acta Med Scand. 1974;196:497-503.

82. Montemurro L, Fraioli P, Rizzato G. Bone loss in untreated longstanding sarcoidosis. Sarcoidosis. 1991;8:29-34.

83. Sipahi S, Tuzun S, Ozaras R, et al. Bone mineral density in women with sarcoidosis. J Bone Miner Metab. 2004;22:48-52.

84. Greenspan SL, Greenspan FS. The effect of thyroid hormone on skeletal integrity. Ann Intern Med. 1999;130:750-758.

85. Hofbauer LC, Kluger S, Kuhne CA, et al. Detection and characterization of RANK ligand and osteoprotegerin in the thyroid gland. J Cell Biochem. 2002;86:642-650.

86. Abu EO, Bord S, Horner A, et al. The expression of thyroid hormone receptors in human bone. Bone. 1997;21:137-142.

87. Diamond $\mathrm{T}$, Vine $\mathrm{J}, \mathrm{Smart} \mathrm{R}$, et al. Thyrotoxic bone disease in women: a potentially reversible disorder. Ann Intern Med. 1994;120:8-11.

88. Toh SH, Claunch BC, Brown PH. Effect of hyperthyroidism and its treatment on bone mineral content. Arch Intern Med. 1985;145:883-886.

89. Wejda B, Hintze G, Katschinski B, et al. Hip fractures and the thyroid: a case-control study. J Intern Med. 1995;237:241-247.

90. Franklyn JA, Maisonneuve $P$, Sheppard $M C$, et al. Mortality after the treatment of hyperthyroidism with radioactive iodine. N Engl J Med. 1998;338:712-718.

91. Mudde AH, Reijnders FJ, Kruseman AC. Peripheral bone density in women with untreated multinodular goitre. Clin Endocrinol (Oxf). 1992;37:35-39.

92. Mudde AH, Houben AJ, Nieuwenhuijzen Kruseman AC. Bone metabolism during anti-thyroid drug treatment of endogenous subclinical hyperthyroidism. Clin Endocrinol (Oxf). 1994;41:421-424. 
93. Bauer DC, Ettinger B, Nevitt MC, et al. Risk for fracture in women with low serum levels of thyroid-stimulating hormone. Ann Intern Med. 2001;134:561-568.

94. Kannus $P$, Sievanen $H$, Palvanen $M$, et al. Prevention of falls and consequent injuries in elderly people. Lancet. 2005;366:1885-1893.

95. Parker MJ, Gillespie WJ, Gillespie LD. Hip protectors for preventing hip fractures in older people. Cochrane Database Syst Rev. 2005;CD001255.

96. Hodsman AB, Bauer DC, Dempster DW, et al. Parathyroid hormone and teriparatide for the treatment of osteoporosis: a review of the evidence and suggested guidelines for its use. Endocr Rev. 2005;26:688-703.

97. Geusens P, Reid D. Newer drug treatments: their effects on fracture prevention. Best Pract Res Clin Rheumatol. 2005;19:983-989.

98. Geusens PP. Review of guidelines for testing and treatment of osteoporosis. Curr Osteoporos Rep. 2003;1:59-65.

99. Khan AA, Hanley DA, Bilezikian JP, et al. Standards for performing DXA in individuals with secondary causes of osteoporosis. J Clin Densitom. 2006;9:47-57.

100. Jiang Y, Genant HK, Watt I, et al. A multicenter, double-blind, dose-ranging, randomized, placebo-controlled study of recombinant human interleukin-1 receptor antagonist in patients with rheumatoid arthritis: radiologic progression and correlation of Genant and Larsen scores. Arthritis Rheum. 2000;43:1001-1009.

101. Strand V, Sharp JT. Radiographic data from recent randomized controlled trials in rheumatoid arthritis: what have we learned? Arthritis Rheum. 2003;48:21-34.

102. Saag KG, Emkey R, Schnitzer TJ, et al. Alendronate for the prevention and treatment of glucocorticoid-induced osteoporosis. Glucocorticoid-Induced Osteoporosis Intervention Study Group. N Engl J Med. 1998;339:292-299.

103. Reid DM, Hughes RA, Laan RF, et al. Efficacy and safety of daily risedronate in the treatment of corticosteroid-induced osteoporosis in men and women: a randomized trial. European Corticosteroid-Induced Osteoporosis Treatment Study. J Bone Miner Res. 2000;15:10061013.

104. Adachi JD, Papaioannou A. In whom and how to prevent glucocorticoid-induced osteoporosis. Best Pract Res Clin Rheumatol. 2005;19:1039-1064. 


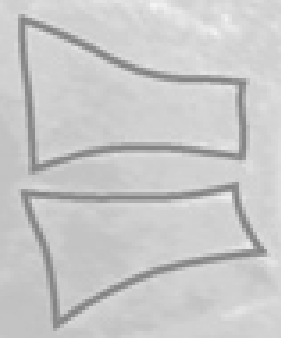

\section{Chapter 3}

Hip bone mineral density, bone turnover and risk of fracture in patients on long-term suppressive L-thyroxine therapy for differentiated thyroid carcinoma

AC Heijckmann, MSP Huijberts, P Geusens, J De Vries, PPCA Menheere, BHR Wolffenbuttel

European Journal of Endocrinology 2005;153:23-29 


\section{Abstract}

\section{Background}

Untreated hyperthyroidism and treatment with high doses of thyroid hormone are associated with osteoporosis. However, their effect on bone turnover, their contribution to bone mineral density (BMD) in the context of other clinical risk factors for osteoporosis and the prevalence of vertebral fractures is not well documented.

\section{Methods}

We studied 59 patients receiving L-thyroxine suppressive therapy for differentiated thyroid carcinoma (DTC). BMD of the hip was measured by dual X-ray absorptiometry (DXA) and lateral DXA pictures of the lumbar and thoracic vertebrae were performed. Bone resorption was measured by carboxy-terminal cross-linked telopeptide or type 1 collagen (ICTP) and bone formation by procollagen type I amino-terminal propeptide (PINP). Clinical risk factors for osteoporosis were evaluated using a questionnaire.

\section{Results}

Z-scores of BMD were similar as the NHANES (National Health and Nutrition Examination Survey) III reference group in women and men, also after long-term ( $\geq 10$ years) suppression therapy. Patients in the lowest and highest quartile of BMD showed significant differences in the presence of clinical risk factors. ICTP levels were significantly higher than in age-matched controls, PINP levels were not different. We found four patients with a prevalent vertebral deformity.

\section{Conclusions}

We conclude that patients with well-differentiated thyroid carcinoma are not at increased risk of developing low bone mass nor have a higher prevalence of vertebral deformities at least when treated with relatively low doses of L-thyroxine. 


\section{Introduction}

Patients with differentiated thyroid carcinoma (DTC) usually have a good prognosis and a near normal life expectancy. After initial ablative treatment with radioactive iodine these patients are treated with L-thyroxine (L-T4) in relatively high doses in order to suppress endogenous thyrotropin (TSH) levels and to minimize potential TSH-mediated stimulation of tumor growth. ${ }^{1,2}$ Adequate monitoring of TSH suppression has become possible since the development of second and third generation TSH assays. ${ }^{3,4}$ The degree of TSH lowering required to obtain maximal suppression of tumor growth has been subject of discussion. ${ }^{5-8}$ Most recommendations suggest maintaining TSH levels lower than $0.1 \mathrm{mU} / \mathrm{I}^{1}$, although in recent guidelines $\mathrm{TSH}$ levels between 0.1 and 0.5 $\mathrm{mU} / \mathrm{l}$ are recommended in case there is no residual disease after one year in low risk DTC patients. ${ }^{9}$ Long-term administration of supraphysiological doses of L-T4 may have adverse side-effects. In addition to physical discomfort, loss of weight, atrial fibrillation and cardiac dysfunction, ${ }^{10,11}$ the possible negative effects on bone mineral density (BMD) and bone remodelling resulting in osteopenia and loss of bone strength are an important issue. ${ }^{12}$ Several mechanisms may be involved in the development of osteopenia secondary to suppressive therapy with L-T4 such as direct or indirect stimulation of osteoclast activity by this hormone. Recently also direct effects of TSH on bone remodelling have been described. ${ }^{13}$ TSH inhibits osteoclast formation and survival and also inhibits osteoblast differentiation, and is therefore a negative regulator of skeletal remodelling.

Loss of bone mass is a uniform feature of overt hyperthyroidism; in several studies a bone loss of $10-20 \%$ has been reported. ${ }^{14-16}$ A history of overt hyperthyroidism is a risk factor for hip fracture later in life, ${ }^{17,18}$ and is one of the causes of excess late mortality in previously hyperthyroid patients. ${ }^{19}$ Symptomatic bone disease is not a prominent feature of subclinical hyperthyroidism. However, mild (subclinical) hyperthyroidism in subjects with multinodular goiter was associated with decreased forearm bone density, while in postmenopausal women with hyperthyroidism who were treated with methimazole a higher bone density of the distal forearm was found compared to untreated women. ${ }^{20,21}$ In addition the risk of osteoporotic fractures may be increased. ${ }^{22}$

Studies in patients with suppressive L-T4 therapy for DTC have generated conflicting results. Some authors ${ }^{23-26}$ found no evidence of lower bone mass in this patient group, while others reported more or less deleterious effects on bone mass. ${ }^{27-29}$ In most of these studies numbers were however small, patient selection was not well defined and characterization of patients was limited.

The aim of our study was to evaluate the impact of long-term suppressive therapy with L-T4 on BMD in a large cohort of well-characterized patients with 
DTC, and in the subgroup of patients with suppressive therapy for more than 10 years. In addition, the prevalence of vertebral deformities was assessed and markers of bone formation and resorption were measured in serum.

\section{Subjects and methods}

\section{Patients}

Between January 2002 and July 2003 all 85 patients with differentiated thyroid carcinoma from the outpatient clinic of the University Hospital Maastricht were asked to take part in this cross-sectional study. Sixty patients agreed to participate. They all had undergone total thyroidectomy and radioactive iodine ablation and were taking a suppressive dose of L-T4 (goal of therapy: TSH $<0.05 \mathrm{mU} / \mathrm{l}$ ) for a median period of five years (range 1-52 years). In the last six months prior to entering this study, TSH-levels were below $0.05 \mathrm{mU} / \mathrm{l}$ in 32 patients and below $0.6 \mathrm{mU} / \mathrm{l}$ in the remaining subjects (mean TSH in the total group $0.06 \mathrm{mU} / \mathrm{l}$, range $<0.05-0.6 \mathrm{mU} / \mathrm{l})$. One patient who had a $\mathrm{TSH}$-level of $6.1 \mathrm{mU} / \mathrm{l}$ was excluded from the study. Therefore complete data are available from 59 patients; written informed consent was obtained in all. To affirm that this patient group was under continuous suppressive therapy with L-T4 we checked serial serum TSH levels in a group of 32 patients with suppressive dose of L-T4 for more than five years resulting in a mean TSH of $0.06 \mathrm{mU} / \mathrm{l}$ (range $<0.05-0.35 \mathrm{mU} / \mathrm{l}$ ).

The general characteristics of the patients studied are summarized in Table 3.1. Of the 40 women, 26 were premenopausal and 14 postmenopausal. All patients had histologically proven differentiated papillary or follicular thyroid cancer. FT4 levels were $21.9 \pm 3.3 \mathrm{pmol} / \mathrm{l}$ (reference parameter: $8-18 \mathrm{pmol} / \mathrm{l}$ ) and the mean dose of L-T4 therapy was $2.2 \pm 0.5 \mathrm{mcg} / \mathrm{kg} / \mathrm{day}$. Ten patients used a vitamin $\mathrm{D}$ analogue and calcium supplementation because of postoperative hypoparathyroidism. None of the patients had taken estrogen replacement therapy or bisphosphonates.

Calcium intake of all patients was assessed on the basis of a detailed dietary list. Risk factors for osteoporosis as well as daily activities and exercise were assessed by a validated questionnaire, ${ }^{30}$ in which sports, daily and work activities are scored with a minimum of zero and a maximum of eighteen. None of the 25 patients who declined to participate had impaired mobility or symptoms related to vertebral fractures. Mean age of this group was 49 years and there were seven postmenopausal women in this group. 
Table 3.1 Patient characteristics.

\begin{tabular}{lccc}
\hline Variable & \multicolumn{2}{c}{ Female } & Male \\
& $\begin{array}{c}\text { premenopausal } \\
\mathrm{n}=26\end{array}$ & $\begin{array}{c}\text { postmenopausal } \\
\mathrm{n}=14\end{array}$ & $\mathrm{n}=19$ \\
\hline Age (years) & $40 \pm 7$ & $63 \pm 9$ & $52 \pm 12$ \\
Body mass index $\left(\mathrm{kg} / \mathrm{m}^{2}\right)$ & $24.4 \pm 3.2$ & $25.5 \pm 3.5$ & $28.8 \pm 3.2$ \\
Years of suppressive therapy & $4(1-14)$ & $5.5(1-52)$ & $6(1-22)$ \\
Postop. hypoparathyroidism & 6 & 1 & 3 \\
Dose L-T4 $(\mu / \mathrm{kg}$ per day) & $2.3 \pm 0.5$ & $1.9 \pm 0.4$ & $2.2 \pm 0.5$ \\
Papillary carcinoma & 13 & 8 & 12 \\
Follicular carcinoma & 10 & 4 & 6 \\
Mixed carcinoma & 3 & 2 & 1 \\
Serum $\mathrm{FT}_{4}(\mathrm{pmol} / \mathrm{l})$ & $22.0 \pm 3.2$ & $22.7 \pm 3.8$ & $21.1 \pm 3.2$ \\
\hline
\end{tabular}

Data are given as mean $\pm \mathrm{SD}$, median (range) or numbers if appropriate; Reference parameters: serum FT4 8-18 pmol/l; Abbreviations: L-T4, L-thryoxine; FT4, free thyroxine.

\section{BMD and morphometric measurements}

BMD of the hip was measured by dual energy X-ray absorption (DXA, Hologic QDR 4500, NHANES-III reference group). The hip was measured in the standard projection, and results were reported for femoral neck, trochanter and total hip. No data on bone mineral density of the lumbar spine were obtained. Standard procedures supplied by the manufacturer for scanning and analysis were performed. Calibration with the manufacturer's spine phantom and quality control analysis were performed daily. The coefficient of variation for BMD measurements was $1.0 \%$.

Furthermore after bone density measurements, a lateral single energy densitometry of the spine for vertebral fracture assessment was performed. This was done by one classified and experienced person with morphometry. Anterior, middle and posterior heights were recorded in all vertebrae from T4 to L4 (if possible). On the basis of these morphometric measurements prevalent vertebral deformity was defined as a reduction of height of $20 \%$ or more $\left(\right.$ Genant method $\left.^{31}\right)$.

\section{Laboratory assays}

All serum samples were frozen at $-20^{\circ} \mathrm{C}$ immediately after collection. All analyses were measured within one badge at the same time to reduce variability. Serum TSH was measured using the commercially available delayed enhanced Lantanide fluorescence immunometric assay (DELFIAmethod, Perkin Elmer, Wallac, Turku, Finland), measured on an automatic immunoanalyser of the same manufacturer. Serum FT4 was measured using a commercially available solid phase fluoroimmunoassay (DELFIA-method, 
Perkin Elmer, Wallac, Turku, Finland); the normal reference range in our laboratory is 8-18 pmol/l. As marker for bone formation serum procollagen type I amino-terminal propeptide (PINP) was measured and as marker for bone resorption serum level of carboxy-terminal cross-linked telopeptide of type I collagen (ICTP). PINP and ICTP were determined using commercial RIA kits (Orion Diagnostica Oy, Espoo, Finland). For PINP the interassay coefficient of variation was $3.2 \%$, the intraassay $\mathrm{CV} 2.5 \%$ and the lowest detectable concentration was found to be $0.4 \mu \mathrm{g} / \mathrm{l}$. For ICTP the interassay CV was $3.5 \%$, the intraassay CV $2.3 \%$ and the lowest detectable concentration was found to be lower than $0.1 \mu \mathrm{g} / \mathrm{l}$.

Study samples were compared to serum samples from age and sex-matched controls.

All gave informed consent. None of them were known to have thyroid diseases, and all had normal physical examination and normal results of routine lab measurements.

\section{Statistical analysis}

Results are reported as mean \pm SD or median and (range) where appropriate. T- and Z-scores of the femoral neck, trochanter and total hip (using NHANESIII) were calculated for the total group, for men, for pre- and postmenopausal women, and for a group of patients who received suppressive L-T4 therapy for ten years or more. Comparison between groups was done using Student t-test with correction for multiple comparisons among groups if the data were normally distributed and by Kruskal-Wallis test if the data were not normally distributed. Pearson's correlations were used to calculate the relationship between BMD and duration of suppressive therapy. To assess the influence of confounding factors on the bone mineral density measurements, a multiple regression analysis (stepwise method) was performed with BMD of the total hip (Z-score) as a dependent variable and known risk factors for osteoporosis (weight below $60 \mathrm{~kg}$, hip fracture mother, fractures in previous medical history, postmenopausal state and corticosteroid use), duration of suppressive therapy, BMI, calcium intake, physical activity, L-T4 /kg per day, serum FT4, and postoperative hypoparathyroidism as independent variables. Another multiple regression analysis (stepwise method) was done with BMD Z-scores as dependent variable and age, weight, L-T4 / kg per day, serum FT4, number of risk factors and physical activity index as independent variables. Patients in the highest and lowest quartile of BMD T-scores were compared on presence of risk factors with a chi-square test. All analyses were done using SPSS (version 11.5). A p-value below 0.05 was considered statistically significant. 


\section{Results}

\section{BMD and general characteristics}

Relative to the background population (NHANES reference group) bone mineral density was not decreased in the three study groups (Table 3.2). Five patients (two men, three postmenopausal women) had a T-score $\leq-2.5$ in the femoral neck or trochanter and thus met the WHO-criteria for osteoporosis. Fifteen patients had suppressive L-T4 therapy for $\geq 10$ years (median $14 \mathrm{yrs}$, range 10-52 yrs). Also in these patients no difference in BMD relative to agematched controls (Z-score total hip: median 0.40 (range -1.3-1.4) was observed, and no correlation was found between the duration of suppressive therapy and BMD of the hip $(r=0.01, p=0.91)$. Moreover we compared the group of subjects with TSH levels below 0.05 with the patients who had a slightly higher TSH and these groups were similar with regards to T-score and Z-score of total hip. BMD of the hip was also not different in patients with or without postoperative hypoparathyroidism (Z-score 0.49 versus 0.34 ), although the Z-score of the femoral neck was slightly higher in patients with postoperative hypoparathyroidism $(0.70$ versus $0.05, p=0.029)$.

Table 3.2 BMD variables.

\begin{tabular}{lccc}
\hline & \multicolumn{2}{c}{ Female } & Male \\
& $\begin{array}{c}\text { premenopausal } \\
\mathrm{n}=26\end{array}$ & $\begin{array}{c}\text { postmenopausal } \\
\mathrm{n}=14\end{array}$ & $\mathrm{n}=19$ \\
\hline Z-score & & & \\
total hip & $0.44 \pm 0.87$ & $0.23 \pm 1,07$ & $0.37 \pm 0.84$ \\
femoral neck & $0.22 \pm 0.81$ & $0.12 \pm 0.95$ & $0.09 \pm 0.93$ \\
trochanter & $0.61 \pm 1.10$ & $0.29 \pm 1.03$ & $0.49 \pm 0.91$ \\
\hline
\end{tabular}

Data are expressed as mean $\pm \mathrm{SD}$

Data regarding the presence of risk factors for osteoporosis and the daily calcium intake and physical activities have been summarized in Table 3.3. The activity index had a mean of nearly ten reflecting an average in showing activities in this patient group. The calcium intake is with a mean of $807 \mathrm{mg} / \mathrm{day}$ moderate and insufficient for the postmenopausal group. 
Table 3.3 Risk factors and questionnaires.

\begin{tabular}{lccc}
\hline & \multicolumn{2}{c}{ Female } & Male \\
& premenopausal & postmenopausal & \\
\hline Number & 26 & 14 & 19 \\
Years since menopause & & $12 \pm 10$ & 1 \\
Fracture $>50$ years & 0 & 1 & 2 \\
Vertebral fracture & 1 & 1 & 1 \\
Hip fracture mother & 0 & 4 & 0 \\
Low body weight (<60 kg) & 3 & 5 & 0 \\
Immobilisation & 0 & 0 & 0 \\
Corticosteroids in last 10 years & 0 & 0 & $822 \pm 326$ \\
Calcium intake (mg/day) & $810 \pm 357$ & $782 \pm 290$ & $9.9 \pm 3.6$ \\
Physical activity (Elders) & $10.6 \pm 4.0$ & $8.6 \pm 4.1$ & \\
\hline
\end{tabular}

Data are given as mean \pm SD or number.

Multiple regression analysis, including age, weight, L-T4 /kg per day, serum FT4, number of risk factors and physical activity, revealed that higher body weight was a significant contributor to BMD of the total hip as expressed as Z-score. There were 22 patients with in total 33 known clinical risk factors (postmenopausal state, hip fracture mother, vertebral deformity, fracture $>50$ year, body weight $<60 \mathrm{~kg}$, immobilization and corticosteroid use). Patients in the lowest and highest quartile of BMD (T-score of the total hip below -0.70 , mean -1.4 , and above 0.6 , mean 1.03) showed differences in the presence of clinical risk factors as earlier defined: in the lowest quartile, eleven of fifteen patients had one or more risk factors, in the highest quartile, two of the fifteen patients had any risk factor $(p=0.001)$ (Table 3.4).

Table 3.4 Number of patients with clinical risk factors in all 4 quartiles of BMD (T-score of total hip).

\begin{tabular}{lcc}
\hline & Number of patients in quartile & $\begin{array}{c}\text { Number of patients with one or } \\
\text { more clinical risk factor }\end{array}$ \\
\hline T-score $\leq-0.7$ & 15 & 11 \\
$-0.7<$ T-score $\leq 0$ & 15 & 7 \\
$0<$ T-score $\leq 0.5$ & 14 & 2 \\
T-score $>0.5$ & 15 & 2 \\
\hline
\end{tabular}

\section{Markers of bone formation and resorption}

Results of the measurement of markers of bone turnover are summarized in Table 3.5. Relative to an age matched control group, ICTP was increased by about $25 \%$ in all patient groups. PINP levels however, as marker of bone formation, did not significantly differ from the control group. Comparing patients with and without postoperative hypoparathyroidism, markers of bone formation $(-44 \%, \quad p<0.05)$ and resorption $(-7 \%)$ were decreased in the 
hypoparathyroidism group and this resulted in a slightly higher BMD mainly in the femoral neck.

Table 3.5 Bone markers total group (in serum in $\mu \mathrm{g} / \mathrm{l}$ ).

\begin{tabular}{lcccccc}
\hline & & \multicolumn{2}{c}{ Female } & \multicolumn{2}{c}{ Male } \\
& premenopausal & controls & postmenopausal & controls & patients & controls \\
\hline Number & 24 & 24 & 10 & 10 & 19 & 19 \\
ICTP (mg/l) & $3.8 \pm 1.3^{\mathrm{a}}$ & $3.0 \pm .7$ & $4.4 \pm 1.0^{\mathrm{a}}$ & $3.3 \pm 1.1$ & $4.1 \pm .9^{\mathrm{a}}$ & $3.5 \pm 7$ \\
PINP (mg/l) & $31.0 \pm 17.3$ & $28.4 \pm 10.1$ & $39.7 \pm 21.1$ & $42.8 \pm 20.9$ & $36.8 \pm 15.5$ & $37.2 \pm 11.3$ \\
\hline
\end{tabular}

${ }^{a} p<0.05$ vs age matched controls; Abbreviations: ICTP, serum carboxy-terminal cross-linked telopeptide of type I collagen; PINP, serum procollagen type I amino-terminal propeptide.

\section{Vertebral deformities}

Fifty-four lateral DXA pictures of the lumbar and thoracic vertebrae were of adequate quality for the identification of vertebral deformities, suggestive of fracture. Four patients were found to have pre-existing vertebral deformity, i.e. $7 \%$ of patients; two men, one pre- and one postmenopausal woman. These patients did not report earlier fractures or pain episodes. All these patients had a BMD of the hip within the age-matched reference range (Z-score $0.53 \pm 0.91$ ).

\section{Discussion}

This study demonstrates that long-term suppressive L-T4 therapy in patients with DTC does not result in reduced bone mineral density of the hip, neither in pre- and postmenopausal women nor in men. BMD, expressed as Z-score, was not correlated with duration of L-T4 therapy and even in patients with suppressive therapy for more than ten years no significant decrease in BMD was found.

The goal of suppressive L-T4 therapy is to maintain TSH levels $<0.05 \mathrm{mU} / \mathrm{l}$ with a high normal FT4. In our study the dose needed to achieve this level of suppression was $2.2 \mu \mathrm{g} / \mathrm{kg}$ of body weight per day, which resulted in FT4 levels of $20 \%$ above the upper limit of normal. In all studies on this subject in which a significant bone loss was observed patients used a 30-50\% higher dose of L-T4 compared to our patients. ${ }^{(27-29,32,33)}$ In a cross-sectional study Kung et al. found significantly lower BMD in the lumbar spine, femoral neck and trochanter $(-18 \%,-12 \%$ and $-13 \%)$ in a group of 34 postmenopausal women, and their L-T4 dose was $3.3 \mu \mathrm{g} / \mathrm{kg}$ of body weight per day. ${ }^{28}$ The same group followed a small group of 15 postmenopausal women $(3.0 \mu \mathrm{g} \mathrm{L-T} 4 / \mathrm{kg}$ of body weight per day) and found a bone loss of $6.7 \%$ in the total hip after two years, ${ }^{32}$ which could be prevented by calcium supplementation (1000 mg/day). Diamond et al 
demonstrated a negative effect on BMD in both pre- and postmenopausal women $(n=24)^{27}$ with a mean L-T4 dose of $2.8 \mu \mathrm{g} / \mathrm{kg} /$ day and found a significant correlation between the total cumulative dose of L-T4 and BMD, suggesting that overzealous L-T4 therapy may lead to bone loss. Studies in which doses lower than $2.5 \mu \mathrm{g} / \mathrm{kg}$ body weight per day were used, such as the more recent study of Rosen et al. ${ }^{24,26,34}$ did not observe any negative effect on BMD. Before the introduction of second and third generation TSH assays in the late eighties, it was more difficult to monitor suppressive L-T4 therapy, because the detection limit was within the normal range. Therefore dosing of L-T4 could not be titrated optimally and was probably unnecessary high. These high L-T4 doses could affect BMD as was shown in the studies mentioned before. The presently available TSH assays are more sensitive and thereby allow better dose titration, thereby preventing unwanted loss of BMD.

The presence of postoperative parathyroid dysfunction could also contribute to the low incidence of osteoporosis in our population. PTH is generally thought to have a net catabolic effect on bone, including a more pronounced stimulatory effect on osteoclast than on osteoblast activity. ${ }^{35}$ Abugassa et al. found a higher bone mass in the proximal femur, lumbar spine and distal radius in a group of thirteen patients treated with calcium and/or dihydrotachysterol because of postoperative hypoparathyroidism after thyroidectomy for DTC, compared to patients with normal parathyroid function after the same surgical procedure. $^{36}$ We also found in the ten subjects with postsurgical hypoparathyroidism a significantly higher BMD of the femoral neck. However the total hip measurements showed no difference between these two groups, and mean Z-scores in the group without hypoparathyroidism were not lower than the reference population.

A total of five patients met the WHO criteria for osteoporosis in the measurements of total hip, trochanter or femoral neck BMD. Our risk factor analysis indicated that this group could be identified with the known clinical risk factors such as postmenopausal state, mother with hip fracture, fracture above 50 years, immobilization, corticosteroid use and low body weight.

Although no long-term effect on BMD was found, a significant increase of bone resorption as measured by serum levels of carboxy-terminal cross-linked telopeptide of type I collagen (ICTP) was observed. The marker of bone formation PINP was not altered. Other studies in DTC patients with suppressive L-T4 therapy reported an increase in markers of both bone formation and resorption. Kung reported increases in hydroxyproline in the urine of $130 \%$ and osteocalcin levels of $150 \%{ }^{28}$ suggesting increased bone turnover. It is not clear why this change in balance between bone formation and bone resorption in our patients did not lead to bone loss in the long-term. Perhaps the increase in bone resorption is not substantial enough to affect BMD. One might also speculate that the compliance with L-T4 therapy might be 
lower in between hospital visits. ${ }^{37,38}$ Also a catch-up effect might have occurred in the periods of thyroid hormone withdrawal and subsequent hypothyroidism for diagnosis or treatment of recurrent or metastatic disease.

Vertebral fracture is a hallmark of osteoporosis. Only one of the previous studies in patients with DTC has evaluated prevalent vertebral fractures in a very small group $(n=12)$ and reported no significant difference in the incidence of spinal deformities between TSH-suppressed patients and nonsuppressed patients. ${ }^{39}$ We found four patients in this group $(7 \%)$ with one or more vertebral deformities defined as a reduction of $20 \%$ or more of the anterior, middle or posterior height. In a very large cross-sectional population based study on the prevalence of vertebral deformity in European men and women (EVOS) in a group of 15570 males and females aged 50-79 years, a prevalent vertebral deformity was observed in $12 \%$ (range $6-21 \%$ ). ${ }^{40}$ We report $7 \%$ in a group with lower mean age; these patients did not have any clinical sign of vertebral fracture nor did they have a lower BMD of the hip. Although the group is small we have no indication that the prevalence of vertebral deformity is higher than in a European reference population.

We conclude that L-T4 therapy in doses which suppress TSH just below the detection limit of a second generation TSH assay, did not result in significant bone loss in our studied population and probably also not in increased fracture risk. We suggest that specific screening for osteoporosis in this patient group is therefore not recommended, other than on the basis of the known clinical risk factors. 


\section{References}

1. Pujol P, Daures J P, Nsakala N, Baldet L, Bringer J, Jaffiol C. Degree of thyrotropin suppression as a prognostic determinant in differentiated thyroid cancer. J.Clin.Endocrinol. Metab. 1996:81:4318-4323.

2. Cooper DS, Specker B, Ho M, Sperling M, Ladenson P W, Ross D S, Ain K B, Bigos ST, Brierley JD, Haugen BR, Klein I, Robbins J, Sherman SI, Taylor T, Maxon HR. III, Thyrotropin suppression and disease progression in patients with differentiated thyroid cancer: results from the National Thyroid Cancer Treatment Cooperative Registry. Thyroid. 1998;8:737-744.

3. Demers LM, Spencer CA. Laboratory medicine practice guidelines: laboratory support for the diagnosis and monitoring of thyroid disease. Clin.Endocrinol.(Oxf). 2003;58:138-140.

4. Ross DS. Serum thyroid-stimulating hormone measurement for assessment of thyroid function and disease. Endocrinol.Metab Clin.North Am. 2001;30:245-264,vii.

5. Wartofsky L. Use of sensitive TSH assay to determine optimal thyroid hormone therapy and avoid osteoporosis. Annu.Rev.Med. 1991;42:341-345.

6. Lamberg BA, Helenius T, Liewendahl K. Assessment of thyroxine suppression in thyroid carcinoma patients with a sensitive immunoradiometric TSH assay. Clin.Endocrinol.(Oxf). 1986;25:259-263.

7. Burmeister LA, Goumaz MO, Mariash CN, Oppenheimer JH. Levothyroxine dose requirements for thyrotropin suppression in the treatment of differentiated thyroid cancer. J.Clin.Endocrinol.Metab. 1992;75:344-350.

8. Spencer CA, Lai-Rosenfeld AO, Guttler RB, LoPresti J, Marcus AO, Nimalasuriya A, Eigen A, Doss RC, Green BJ, Nicoloff JT. Thyrotropin secretion in thyrotoxic and thyroxine-treated patients: assessment by a sensitive immunoenzymometric assay. J.Clin.Endocrinol.Metab. 1986;63:349-355.

9. Schlumberger M, Berg G, Cohen O, Duntas L, Jamar F, Jarzab B, Limbert E, Lind P, Pacini F, Reiners C, Sanchez FF, Toft A, Wiersinga WM. Follow-up of low-risk patients with differentiated thyroid carcinoma: a European perspective. Eur.J.Endocrinol. 2004;150: 105-112.

10. Biondi B, Fazio S, Carella C, Amato G, Cittadini A, Lupoli G, Sacca L, Bellastella A, Lombardi G. Cardiac effects of long term thyrotropin-suppressive therapy with levothyroxine. J.Clin.Endocrinol.Metab. 1993;77:334-338.

11. Sawin CT, Geller A, Wolf P A, Belanger A J, Baker E, Bacharach P, Wilson PW, Benjamin EJ, D'Agostino RB. Low serum thyrotropin concentrations as a risk factor for atrial fibrillation in older persons. N.Engl.J.Med. 1994;331:1249-1252.

12. Greenspan SL, Greenspan FS. The effect of thyroid hormone on skeletal integrity. Ann.Intern.Med. 1999;130:750-758.

13. Abe E, Marians RC, Yu W, Wu XB, Ando T, Li Y, Iqbal J, Eldeiry L, Rajendren G, Blair HC, Davies TF, Zaidi M. TSH is a negative regulator of skeletal remodeling. Cell. 2003;115: 151-162.

14. Linde J, Friis T. Osteoporosis in hyperthyroidism estimated by photon absorptiometry. Acta Endocrinol.(Copenh). 1979;91:437-448.

15. Toh SH, Claunch BC, Brown PH. Effect of hyperthyroidism and its treatment on bone mineral content. Arch.Intern.Med. 1985;145:883-886.

16. Diamond T, Vine J, Smart R, Butler P. Thyrotoxic bone disease in women: a potentially reversible disorder. Ann.Intern.Med. 1994;120:8-11.

17. Cummings SR, Nevitt MC, Browner WS, Stone K, Fox KM, Ensrud KE, Cauley J, Black D, Vogt TM. Risk factors for hip fracture in white women. Study of Osteoporotic Fractures Research Group. N.Engl.J.Med. 1995;332:767-773.

18. Wejda B, Hintze G, Katschinski B, Olbricht T, Benker G. Hip fractures and the thyroid: a casecontrol study. J.Intern.Med. 1995;237:241-247.

19. Franklyn JA, Maisonneuve $P$, Sheppard MC, Betteridge J, Boyle P. Mortality after the treatment of hyperthyroidism with radioactive iodine. N.Engl.J.Med. 1998;338:712-718. 
20. Mudde AH, Reijnders FJ, Kruseman AC. Peripheral bone density in women with untreated multinodular goitre. Clin.Endocrinol.(Oxf). 1992;37:35-39.

21. Mudde AH, Houben AJ, Nieuwenhuijzen Kruseman AC. Bone metabolism during anti-thyroid drug treatment of endogenous subclinical hyperthyroidism. Clin.Endocrinol.(Oxf). 1994;41: 421-424.

22. Bauer DC, Ettinger B, Nevitt MC, Stone KL. Risk for fracture in women with low serum levels of thyroid-stimulating hormone. Ann.Intern.Med. 2001;134:561-568.

23. Franklyn JA, Betteridge J, Daykin J, Holder R, Oates GD, Parle JV, Lilley J, Heath DA, Sheppard MC. Long-term thyroxine treatment and bone mineral density. Lancet. 1992;340: 9-13.

24. Florkowski CM, Brownlie BE, Elliot JR, Ayling EM, Turner JG. Bone mineral density in patients receiving suppressive doses of thyroxine for thyroid carcinoma. N.Z.Med.J. 1993; 106:443-444.

25. Hawkins F, Rigopoulou D, Papapietro K, Lopez MB. Spinal bone mass after long-term treatment with L-thyroxine in postmenopausal women with thyroid cancer and chronic lymphocytic thyroiditis. Calcif.Tissue Int. 1994;54:16-19.

26. Rosen HN, Moses AC, Garber J, Ross DS, Lee SL, Ferguson L, Chen V, Lee K, Greenspan SL. Randomized trial of pamidronate in patients with thyroid cancer: bone density is not reduced by suppressive doses of thyroxine, but is increased by cyclic intravenous pamidronate. J.Clin.Endocrinol.Metab. 1998;83:2324-2330.

27. Diamond T, Nery L, Hales I. A therapeutic dilemma: suppressive doses of thyroxine significantly reduce bone mineral measurements in both premenopausal and postmenopausal women with thyroid carcinoma. J.Clin.Endocrinol.Metab. 1991;72:1184-1188.

28. Kung AW, Lorentz T, Tam SC. Thyroxine suppressive therapy decreases bone mineral density in post-menopausal women. Clin.Endocrinol.(Oxf). 1993;39:535-540.

29. Pioli G, Pedrazzoni M, Palummeri E, Sianesi M, Del FR, Vescovi PP, Prisco M, Ulietti V, Costi $D$, Passeri M. Longitudinal study of bone loss after thyroidectomy and suppressive thyroxine therapy in premenopausal women. Acta Endocrinol.(Copenh). 1992;126:238-242.

30. Elders PJ, Netelenbos JC, Lips P, Khoe E, Van Ginkel FC, Hulshof KF, Van der Stelt PF. Perimenopausal bone mass and risk factors. Bone Miner. 1989;7:289-299.

31. Genant $\mathrm{HK}, \mathrm{Wu} \mathrm{CY}$, van $\mathrm{KC}$, et al. Vertebral fracture assessment using a semiquantitative technique. J Bone Miner Res. 1993;8:1137-1148. .

32. Kung AW, Yeung SS. Prevention of bone loss induced by thyroxine suppressive therapy in postmenopausal women: the effect of calcium and calcitonin. J.Clin.Endocrinol.Metab. 1996; 81:1232-1236.

33. Muller CG, Bayley TA, Harrison JE, Tsang R. Possible limited bone loss with suppressive thyroxine therapy is unlikely to have clinical relevance. Thyroid. 1995;5:81-87.

34. Gorres G, Kaim A, Otte A, Gotze M, Muller-Brand J. Bone mineral density in patients receiving suppressive doses of thyroxine for differentiated thyroid carcinoma. Eur.J.Nucl.Med. 1996;23:690-692.

35. Rodan GA, Martin TJ. Role of osteoblasts in hormonal control of bone resorption--a hypothesis. Calcif.Tissue Int. 1981;33:349-351.

36. Abugassa S, Nordenstrom J, Eriksson S, Sjoden G. Bone mineral density in patients with chronic hypoparathyroidism. J.Clin.Endocrinol.Metab. 1993;76:1617-1621.

37. Hughes CM. Medication non-adherence in the elderly: how big is the problem? Drugs Aging. 2004;21:793-811.

38. Barat I, Andreasen F, Damsgaard EM. Drug therapy in the elderly: what doctors believe and patients actually do. Br.J.Clin.Pharmacol. 2001;51:615-622.

39. Fujiyama K, Kiriyama T, Ito M, Kimura H, Ashizawa K, Tsuruta M, Nagayama Y, Villadolid M C, Yokoyama N, Nagataki S. Suppressive doses of thyroxine do not accelerate age-related bone loss in late postmenopausal women. Thyroid. 1995;5:13-17.

40. O'Neill TW, Felsenberg D, Varlow J, Cooper C, Kanis JA, Silman AJ. The prevalence of vertebral deformity in european men and women: the European Vertebral Osteoporosis Study. J.Bone Miner.Res. 1996;11:1010-1018. 


\section{Chapter 4}

High prevalence of morphometric vertebral deformities in patients with inflammatory

bowel disease

AC Heijckmann, MSP Huijberts, EJ Schoon, P Geusens, J De Vries, PPCA Menheere, E van der Veer, RW Stockbrügger, B Dumitrescu, AC Nieuwenhuijzen Kruseman

Eur J Gastroenterol Hepatol, in press 


\section{Abstract}

\section{Background}

Previous studies have documented that the prevalence of decreased bone mineral density (BMD) is elevated in patients with inflammatory bowel disease (IBD). The objective of the current study was to investigate the prevalence of vertebral deformities in IBD patients and their relation with BMD and bone turnover.

\section{Methods}

109 Patients with Crohn's disease (CD) and 72 with ulcerative colitis (UC) (age 44.5 \pm 14.2 year) were studied. BMD of the hip (by dual-energy X-ray absorptiometry (DXA)) was measured and a lateral single energy densitometry of the spine for assessment of vertebral deformities was performed. Serum markers of bone resorption (ICTP) and formation (PINP) were measured and determinants of prevalent vertebral deformities were assessed using logistic regression analysis.

Results

Vertebral deformities were found in $25 \%$ of both CD and UC patients. Comparing patients with and without vertebral deformities, no significant difference was found between Z- and T-scores of BMD, or levels of ICTP and PINP. Using logistic regression analysis the only determinant of any morphometric vertebral deformity was gender. The presence of multiple vertebral deformities was associated with older age and glucocorticoid use.

\section{Conclusions}

The prevalence of morphometric vertebral deformities is high in CD and UC. Male gender, but neither disease activity, bone turnover markers, clinical risk factors, nor BMD predicted their presence. The determinants for having more than one vertebral deformity were age and glucocorticoid use. This implies that in addition to screening for low BMD, morphometric assessment of vertebral deformities is warranted in CD and UC. 


\section{Introduction}

Decreased bone mineral density (BMD) is a frequent finding in inflammatory bowel disease (IBD). Z-scores <-1.0 can be found in 32 to $38 \%$ of patients with Crohn's disease (CD) and in about $25 \%$ of patients with ulcerative colitis (UC). ${ }^{1}$ An even higher prevalence of decreased bone mass can be found when a T-score is used to express BMD. Following this approach, we found in a previous study osteopenia and osteoporosis in respectively 45 and $13 \%$ of patients with $C D{ }^{2}$

Specific disease-related factors contributing to decreased BMD in IBD patients involve inflammatory cytokines with associated increased bone resorption, malabsorption due to disease activity or extensive intestinal resection, glucocorticoid (GC) use, inability to achieve peak bone mass when the disease starts in childhood, malnutrition and hypogonadism induced by the chronic inflammatory condition, and eventually superposed on other clinical risk factors such as history of fracture, family history of fractures, immobilization, low BMI, smoking and alcohol abuse. ${ }^{1-7}$

As a result of the decreased BMD and disease related factors an increased overall fracture risk can be expected in patients with IBD. ${ }^{1}$ In a populationbased cohort study of patients with IBD the incidence rate ratio was $1.4(95 \%$ confidence interval $(\mathrm{Cl})$ : 1.3-1.6) for spine, hip, rib and forearm fractures compared to controls, $1.7(\mathrm{Cl}: 1.3-2.2)$ for clinical vertebral fractures and 1.6 (Cl:1.3-2.0) for hip fractures with similar increases for CD and UC. ${ }^{8}$ In a primary care-based case-control study similar increases in the risk of clinical vertebral and hip fractures were found in patients with IBD. ${ }^{9}$ In a large Danish casecontrol study a 2.5 -fold increase in the risk of symptomatic low energy fractures of spine, feet and toes was found among women with $C D$, but not in men or patients with UC. ${ }^{10}$ In a recent extensive review, Bernstein and Leslie concluded that patients with IBD have a moderate increased risk of clinical fractures but mentioned a lack of studies on the presence of morphometric vertebral fractures and the absence of data in UC. ${ }^{11}$

Indeed, the majority of studies on fractures in IBD concern clinical fractures. In particular vertebral fractures are however often not clinically recognized and can accumulate silently. ${ }^{12}$ It is well established that a vertebral fracture, clinical or morphometric only, is a strong risk factor for subsequent osteoporotic fractures, not only at the spine but also at other sites and regardless of BMD. ${ }^{13-16}$ Furthermore, vertebral fracture risk is related to the number and severity of prevalent vertebral fractures, while the risk of non-vertebral fractures is related to the severity of prevalent morphometric vertebral fractures. ${ }^{16,17}$

Data on the prevalence of morphometric vertebral fractures in subjects with IBD are scarce. A prevalence of $22 \%$ was found on X-rays using a decrease in anterior, mid or posterior height of $>20 \%$ in a study with 156 patients with CD 
and osteopenia or osteoporosis, ranging from $20 \%$ in patients $<20$ years old to $50 \%$ in patients older than 60 years. ${ }^{18}$ In another study a prevalence of morphometric vertebral fractures on X-rays (any height loss of $>20 \%$ ) of $14 \%$ was found $(11 \%$ in patients $<30$ years up to $31 \%$ in patients older than 60 years), with no correlation with bone mineral density and use of glucocorticoids. ${ }^{19}$ The prevalence of morphometric vertebral fractures in UC is not known.

For these reasons we investigated in a cohort of 181 subjects with IBD, including CD as well as UC patients, the prevalence of morphometric vertebral deformities. The findings were related to BMD, bone turnover parameters and clinical risk factors to get an impression about the risk of vertebral fractures in IBD patients and to what extent this is related to differences in BMD and bone turnover.

\section{Patients and methods}

\section{Patients}

Between January 2002 and July 2003, all patients with inflammatory bowel disease who had a disease duration of at least one year, and attended the outpatient clinic of the University Hospital Maastricht, were asked to participate in this cross-sectional study. Two hundred and two patients (78\%) agreed. All patients were Caucasians and diagnosed with CD or UC on clinical grounds using endoscopic and/or radiological evidence, and by histological investigation of mucosal biopsies and/or surgical specimens when available. For confirmation of the CD diagnosis the Lennard-Jones criteria ${ }^{20}$ and for UC the Truelove and Witts criteria ${ }^{21}$ were applied. Sixteen patients with known causes of bone mass abnormalities, such as renal failure, thyroid dysfunction, alcoholism and ankylosing spondylitis were excluded. None of the other patients had any significant co-morbidity. Five patients were excluded because of incomplete data. Thus 181 patients were included in this study. This group consisted of 81 pre-menopausal women, 26 post-menopausal women, and 74 men. Demographic, clinical and treatment data of these patients are summarized in Table 4.1. The clinical records of all patients were reviewed. Age of onset of $C D$ and $U C$, disease duration and medication use were derived from the medical records. Glucocorticoid (GC) use was scored as never, previous (stopped more than three months before including in the study) or current. If patients were currently using glucocorticoids (GCs) the daily dose was noted. Furthermore, current use of other immunosuppressive medication, vitamin $\mathrm{D}$ and calcium or budenoside use were also recorded. 
Table 4.1 Demographic, clinical, and treatment variables in the study patients $(n=181)$.

\begin{tabular}{|c|c|c|c|c|}
\hline Variable & $\begin{array}{c}\text { All } \\
n=181\end{array}$ & $\begin{array}{l}\text { Crohn's disease } \\
n=109(60 \%)\end{array}$ & $\begin{array}{l}\text { Ulcerative colitis } \\
\qquad n=72(40 \%)\end{array}$ & $\begin{array}{c}p^{*} \\
\text { between } \\
C D \text { and } C U\end{array}$ \\
\hline \multicolumn{5}{|l|}{ Demographic variables } \\
\hline Female sex & $107(59)$ & $75(69)$ & $32(44)$ & 0.001 \\
\hline Postmenopausal & $26(14)$ & $17(16)$ & $9(13)$ & ns \\
\hline Age (years) & $44.5 \pm 14.2$ & $41.9 \pm 13.9$ & $48.5 \pm 13.8$ & $<0.01$ \\
\hline Body mass index $\left(\mathrm{kg} / \mathrm{m}^{2}\right)$ & $25.0 \pm 4.2$ & $24.3 \pm 4.0$ & $26.0 \pm 4.4$ & 0.01 \\
\hline Daily dietary calcium intake $(\mathrm{mg})$ & $687 \pm 360$ & $663 \pm 369$ & $723 \pm 347$ & ns \\
\hline \multicolumn{5}{|l|}{ Clinical variables } \\
\hline Disease duration (years) & $8(1-36)$ & $8(1-36)$ & $9(1-28)$ & ns \\
\hline $1,25(\mathrm{OH})_{2} \mathrm{D}_{3}(\mathrm{nmol} / \mathrm{l})$ & $0.13 \pm 0.04$ & $0.13 \pm 0.04$ & $0.13 \pm 0.04$ & ns \\
\hline CDAI (>150=active disease) & & $118 \pm 88$ & & \\
\hline CAI (score 0-21) & & & $5.9 \pm 3.5$ & \\
\hline Physical activity index (score $0-18$ ) & $8.8 \pm 3.6$ & $8.8 \pm 3.6$ & $8.7 \pm 3.8$ & ns \\
\hline \multicolumn{5}{|l|}{ Treatment variables } \\
\hline GC use never & $40(22)$ & $19(17)$ & $21(29)$ & ns \\
\hline GC use ever & $119(66)$ & $81(74)$ & $38(53)$ & $<0.01$ \\
\hline GC use current & $22(12)$ & $9(8)$ & $13(18)$ & ns \\
\hline Current use of bisphosphonates & $22(12)$ & $14(13)$ & $8(11)$ & ns \\
\hline Current calcium supplement & $56(31)$ & $44(40)$ & $12(17)$ & 0.001 \\
\hline Current vitamin D supplement & $53(29)$ & $41(38)$ & $12(17)$ & $<0.01$ \\
\hline $\begin{array}{l}\text { Current use of immunosuppressive } \\
\text { medication }\end{array}$ & $84(46)$ & $64(59)$ & $20(28)$ & $<0.001$ \\
\hline Current use of budenoside & $54(30)$ & $46(42)$ & $8(11)$ & $<0.001$ \\
\hline Daily dose GC current group (mg) & $6,25(0-30)$ & $5(0-30)$ & $10(0-20)$ & ns \\
\hline \multicolumn{5}{|l|}{ Clinical risk factors for osteoporosis } \\
\hline Fracture $>50$ years & 0 & 0 & 0 & \\
\hline Vertebral deformity by DXA & $45(25)$ & $25(23)$ & $20(28)$ & ns \\
\hline Low body weight (<60 kg) & $30(17)$ & $22(20)$ & $8(11)$ & ns \\
\hline Low physical activity index $\leq 5$ & $37(21)$ & $20(19)$ & $17(24)$ & ns \\
\hline Mother with hip deformity & $11(6)$ & $5(5)$ & $6(8)$ & ns \\
\hline
\end{tabular}

Data are given as mean $\pm \mathrm{SD}$, median (range) or number (\%) Reference parameters: 1,25(OH)2D3 0.040-0.200 nmol//; Abbreviations: 1,25(OH)2D3, 1,25 dihydroxyvitamin D; CDAl, Crohn's disease activity index; CAI, colitis activity index; GC, glucocorticoid; DXA, dual X-ray absorptiometry

Patients were evaluated according to a standard protocol that included measurement of height and weight, measurement of bone mineral density (BMD) and collection of a blood sample and morning urine.

Calcium intake of all patients was scored on the basis of a detailed dietary list. Known clinical risk factors for osteoporosis (weight below $60 \mathrm{~kg}$, hip fracture in the mother, history of fractures after age 50 , menopausal status and severe immobilization) as well as daily activities and exercise were assessed by a validated questionnaire, ${ }^{22}$ in which sports, daily and work activities are scored with a minimum of zero and a maximum of eighteen. Current disease activity in CD was evaluated using the Crohn's Disease activity Index (CDAI ${ }^{23}$ and in UC the colitis activity index $(\mathrm{CAI})^{24}$ was applied. Patients with $\mathrm{CD}$ were considered to have active disease when CDAI was $>150$. Informed consent was obtained 
from all participants and this study was approved by the ethical committee of the hospital.

\section{Laboratory assays}

As a marker for bone formation, serum procollagen type I amino-terminal propeptide (PINP) was measured. As a marker for bone resorption, serum carboxy-terminal cross-linked telopeptide of type I collagen (ICTP) was assessed. Both PINP (interassay coefficient of variation (IE-CV) 3.2\%, intraassay CV (IA-CV) 2.5\%, lowest detectable concentration $0.4 \mu \mathrm{g} / \mathrm{l}$ ] and ICTP (IE-CV 3.5\%, IA-CV 2.3\%, lowest detectable concentration $<0.1 \mu \mathrm{g} / \mathrm{l}$ ) were measured using commercial RIA kits (Orion Diagnostica Oy, Espoo, Finland). The Z-score for these bone markers was obtained using a Dutch reference group (300 women, 150 men), checked for normal BMD of the lumbar spine and femur and normal 25-hydroxyvitamin-D levels. ${ }^{25}$ Serum 1,25-dihydroxyvitamin $\mathrm{D}$ concentration was determined by RIA using a commercially available kit (IDS Ltd, Boldon, England, IE-CV 18\%, IA-CV 15\%).

\section{Bone Mineral Density and morphometry}

In all 181 patients bone mineral density (BMD) of the hip was measured by dual X-ray absorptiometry (DXA, Hologic QDR 4500). As reference group the NHANES III database was used. Measurements were done in the standard projection, and results were reported for femoral neck and trochanter. Standard procedures supplied by the manufacturer for scanning and analyses were performed. Calibration with the manufacturer's spine phantom and quality control analysis were performed daily. The coefficient of variation for BMD measurements was $1.0 \%$. The number of patients with osteopenia and osteoporosis was determined according to the WHO classification in which osteopenia is defined as a T-score between -1 and -2.5 and osteoporosis as a T-score $\leq-2.5$. To adjust for age and gender, Z-scores were used.

Furthermore, after bone density measurement a lateral single energy densitometry of the thoracic and lumbar spine for vertebral fracture assessment (VFA) was performed (also called Morphometric X-ray absorptiometry $(\mathrm{MXA})) .{ }^{26}$ The scans obtained were analyzed twice by one trained operator (intra-observer correlation: 0.85), using the semi-quantitative method of Genant. $^{27}$ The observer was blinded to the T-score values and to the values of the first set of measurements. After visual examination six points were placed on each vertebral body. From these points three vertebral heights were measured: anterior $(\mathrm{Ha})$, mid $(\mathrm{Hm})$ and posterior $(\mathrm{Hp})$; On the basis of the average score of these morphometric measurements ratios were calculated and a prevalent vertebral deformity was defined as a reduction of height of $20 \%$ or more. ${ }^{27}$ For crush deformity ratio was calculated by dividing $\mathrm{Hp}$ of the vertebra with $\mathrm{Hp}$ of the vertebra below. Grade 1 (mild) deformity was defined 
as a reduction of 20 to $25 \%$ in any height, grade 2 (moderate) 25 to $40 \%$ and grade 3 more than $40 \%$ (severe).

\section{Statistics}

Student $t$-tests, chi-square tests, and one-way ANOVAs were used, depending on the variables and subgroups tested. The analyses were performed with Z-scores in order to correct for age and gender when comparing (sub)groups. One-sample $t$-tests were used to compare patient scores with norm scores. A logistic regression analysis was performed to examine the determinants of morphometric vertebral deformities. Sex, age, weight, disease, illness duration, CDAl, CAI, physical activity, vitamin D, GC use, current use of vitamin D, calcium, immunosuppressive medication, budenoside and hip fracture mother were examined as potential determinants. Furthermore, we analysed the risk factors for having $>1$ vertebral deformity.

\section{Results}

\section{Bone mineral density}

The results of BMD measurements and bone turnover markers are shown in Table 4.2. In the total group, osteoporosis was found in $4 \%$ of patients and osteopenia in 55\%. Excluding patients currently using glucocorticoids and/or bisphosphonates, the average Z-score of the femoral neck (FN) was decreased compared to the reference population $(-0.29, \mathrm{Cl}:-0.45,-0.14 ; \mathrm{p}<0.001)$. The average Z-scores were lower in patients with $\mathrm{CD}$ (trochanter:-0.27, $\mathrm{Cl}:-0.45$, -0.08 and $\mathrm{FN}:-0.51, \mathrm{Cl}:-0.70,-0.33)$ compared with patients with UC (trochanter $0.27, \mathrm{Cl}: 0.00,0.53$ and $\mathrm{FN}: 0.06, \mathrm{Cl}:-0.19,0.31 ; \mathrm{p}=0.001$ and $<0.001$, respectively).

Table 4.2 BMD variables and bone turnover markers in IBD patients currently not using bisphosphonates and/or glucocorticoids.

\begin{tabular}{lcccc}
\hline Variable & Total group & \multicolumn{2}{c}{ Crohn's disease Ulcerative colitis } & $\mathrm{p}$ \\
& & & & $\mathrm{n}=55$ \\
& $\mathrm{n}=143$ & $\mathrm{n}=88$ & & \\
\hline Z-score & & & & \\
Femoral neck & $-0.29 \pm 0.94^{*}$ & $-0.51 \pm 0.89^{*}$ & $0.06 \pm 0.93$ & $<0.001$ \\
$\quad$ Trochanter & $-0.06 \pm 0.94$ & $-0.27 \pm 0.86^{*}$ & $0.27 \pm 0.98$ & 0.001 \\
Bone markers in serum & & & & \\
ICTP $(\mu \mathrm{g} / \mathrm{l})$ & $3.6 \pm 1.3$ & $3.7 \pm 1.3$ & $3.5 \pm 1.2$ & $\mathrm{~ns}$ \\
Z-score ICTP & $0.49 \pm 1.6^{*}$ & $0.53 \pm 1.3^{*}$ & $0.41 \pm 1.6$ & $\mathrm{~ns}$ \\
PINP $(\mu \mathrm{g} / \mathrm{l})$ & $48.7 \pm 27.5$ & $50.9 \pm 26.0$ & $45.1 \pm 29.8$ & $\mathrm{~ns}$ \\
Z-score PINP & $0.59 \pm 1.6^{*}$ & $0.69 \pm 1.6^{*}$ & $0.42 \pm 1.7$ & $\mathrm{~ns}$ \\
\hline
\end{tabular}

Data are given as mean $\pm \mathrm{SD}$; ${ }^{*} \mathrm{p}<0.05$ versus 0 for Z-scores; Abbreviations: ICTP, carboxyterminal cross-linked telopeptide of type I collagen; PINP, procollagen type I amino-terminal propeptide. 
Patients who never used glucocorticoids $(n=40)$ had normal Z-scores of FN and trochanter compared with patients with previous or current use of this medication who had lower BMD values (respectively: $-0.07, \mathrm{Cl}:-0.35,0.22$ versus -0.52 , Cl:-0.68, $-0.37 ; \mathrm{p}<0.01$ and $0.17, \mathrm{Cl}:-0.08,0.42$ versus $-0.31, \mathrm{Cl}$ : $-0.47,-0.15 ; p<0.01)$.

\section{Bone turnover parameters}

In the total group of patients currently not on bisphosphonates and/or glucocorticoids the average Z-score for ICTP (Z-ICTP) was increased compared with the reference population $(0.49, \mathrm{Cl}: 0.22,0.76 ; p<0.001)$, as well as the marker of bone formation (Z-PINP) $(0.59, \mathrm{Cl}: 0.31,0.86$; $\mathrm{p}<0.001)$. This was especially observed in patients with CD (Z-ICTP: $0.53, \mathrm{Cl}: 0.19,0.88$; $p<0.01$, and Z-PINP: 0.69, Cl: 0.36, 1.03; $p<0.001$ respectively).

\section{Morphometric vertebral deformities}

Vertebral deformities (ratio of $<0.80$ ) were found in 77 vertebrae of 45 patients (25\% of total group). This prevalence was similar in both subgroups of patients. Fifty-nine of the deformities were wedge deformities, 16 biconcave and two crush deformities. Fifty one were mildly deformed, 22 moderate and four severe deformations were seen. With regard to the localization of the deformities (Table 4.3), prevalence peaks were found in the low thoracic region. Seventeen patients (age $51.5 \pm 17.0$ years) had more than one vertebral deformity. This group consisted of eleven men, three premenopausal and three postmenopausal women. The majority of these patients (82\%) was current or previous glucocorticoid user. Comparing the groups with and without vertebral deformities, no significant difference was found between Z- or T-scores of BMD of the trochanter or femoral neck, nor in Z-ICTP, or Z-PINP (Table 4.4, Figure 4.1). The two differences between these groups were an older age $(p<0.05)$ and more males $(p<0.01)$ in the group with deformities. Furthermore, no differences were seen between the two subgroups in current use of calcium and/or vitamin D supplements, aminosalicylates, immunosuppressive medication and budenoside. Logistic regression analysis revealed that the only determinant of prevalent morphometric vertebral deformity was sex (OR: 2.25, $\mathrm{p}<0.05, \mathrm{Cl}: 1.11,4.54)$, indicating that men have a more than twofold higher chance of morphometric vertebral deformity. In addition, the only determinants for having more than one vertebral deformity were age (OR: $1.05, p=0.02, \mathrm{Cl}$ : 1.05-1.09) and current GC use (OR: 4.98, $\mathrm{p}=0.01, \mathrm{Cl}: 1.42,17.49$ ). 
Table 4.3 Distribution of the number of vertebral deformities and rating of their severity.

\begin{tabular}{lcccc}
\hline & Number of deformities & Mild deformity & Moderate deformity & Severe deformity \\
\hline T4 & & & & \\
T5 & 5 & 3 & 2 & \\
T6 & 1 & 1 & & \\
T7 & 4 & 2 & 2 & \\
T8 & 6 & 5 & 1 & \\
T9 & 7 & 5 & 2 & 1 \\
T10 & 23 & 15 & 7 & \\
T11 & 19 & 12 & 5 & 1 \\
T12 & 5 & 4 & 1 & \\
L1 & 3 & 1 & 1 & \\
L2 & 2 & 1 & 1 & \\
L3 & 2 & 2 & & \\
L4 & 2 & & & \\
L5 & & & &
\end{tabular}

Table 4.4 Patients with morphometric vertebral deformity $(n=45)$ versus without morphometric vertebral deformity $(n=136)$.

\begin{tabular}{lccc}
\hline Variable & $\begin{array}{c}\text { Without vertebral } \\
\text { deformity }\end{array}$ & $\begin{array}{c}\text { With vertebral } \\
\text { deformity }\end{array}$ & $\mathrm{p}^{*}$ \\
\hline Z-score & $-0.40 \pm 0.96$ & $-0.49 \pm 0.93$ & $\mathrm{~ns}$ \\
$\quad$ Femoral neck & $-0.19 \pm 1.01$ & $-0.27 \pm 0.75$ & $\mathrm{~ns}$ \\
$\quad$ Trochanter & $-0.95 \pm 0.91$ & $-1.22 \pm 0.88$ & $\mathrm{~ns}$ \\
T-score & $-0.45 \pm 0.96$ & $-0.63 \pm 0.78$ & $\mathrm{~ns}$ \\
Femoral neck & & & \\
Trochanter & $0.58 \pm 1.8$ & $0.75 \pm 1.8$ & $\mathrm{~ns}$ \\
Bone markers in serum & $0.72 \pm 2.4$ & $0.34 \pm 1.6$ & $\mathrm{~ns}$ \\
Z-score ICTP & & & \\
Z-score PINP & $48(35)$ & $26(58)$ & $<0.01$ \\
Demographic and patient variables & $19(14)$ & $7(16)$ & $\mathrm{ns}$ \\
Males & $84 / 52$ & $25 / 20$ & $\mathrm{~ns}$ \\
Postmenopausal women & $30(22)$ & $10(22)$ & $\mathrm{ns}$ \\
Crohn's disease/Ulcerative colitis & $90(66)$ & $29(65)$ & $\mathrm{ns}$ \\
GC use, never & $16(12)$ & $6(13)$ & $\mathrm{ns}$ \\
GC use, previous & $8(1-36)$ & $8(1-34)$ & $\mathrm{ns}$ \\
GC use, current & $43.3 \pm 13.6$ & $48.2 \pm 15.2$ & $<0.05$ \\
Disease duration (years) & $24.9 \pm 4.4$ & $25.3 \pm 3.8$ & $\mathrm{~ns}$ \\
Age (years) & $120 \pm 89$ & $110 \pm 84$ & $\mathrm{~ns}$ \\
Body mass index (kg/m ${ }^{2}$ ) & $5.9 \pm 3.3$ & $5.9 \pm 4.0$ & $\mathrm{~ns}$ \\
CDAl (>150=active disease) & $8.6 \pm 3.6$ & $9.3 \pm 3.8$ & $\mathrm{~ns}$ \\
CAI (score 0-21) & $691 \pm 366$ & $674 \pm 345$ & $\mathrm{~ns}$ \\
Physical activity index (score 0-18) & & & \\
Calcium intake (mg) & & & \\
\hline
\end{tabular}

Data are given as mean $\pm S D$, median (range) or number $(\%)$. ${ }^{*} p$ between patients with and without vertebral deformity; Abbreviations: ICTP, carboxy-terminal cross-linked telopeptide of type I collagen; PINP, procollagen type I amino-terminal propeptide; GC, glucocorticoid; CDAI, Crohn's disease activity index; CAI, colitis activity index. 


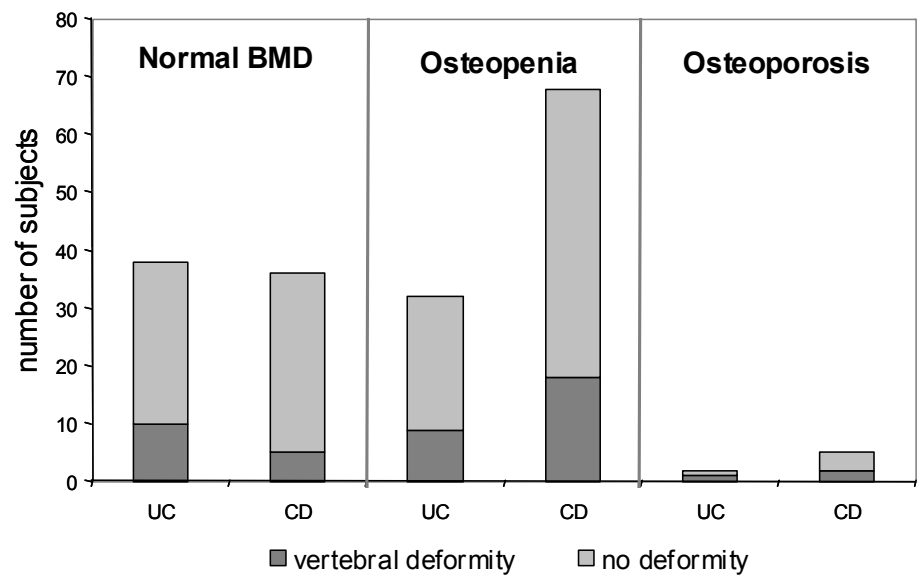

Figure 4.1 Number of patients with and without a vertebral deformity. Abbreviations: UC, ulcerative colitis; CD, Crohn's disease

\section{Discussion}

In our series of patients with IBD we found vertebral deformities with quantitative morphometric X-ray absorptiometry (MXA) in $25 \%$ of patients. This high prevalence is remarkable as the majority of our patients was relatively young and premenopausal.

Our observations of an increased prevalence of morphometric vertebral deformities are in line with the few clinical studies reported on vertebral deformities in $\mathrm{CD}$. Stockbrügger and co-workers found on X-rays a prevalence of $14 \%$ in a younger population with CD and this increased to $43 \%$ in female patients above 60 years. ${ }^{19}$ In another study in 156 patients with CD and osteopenia and osteoporosis, a prevalence of $22 \%$ of vertebral deformities was found. ${ }^{28}$ Other studies also revealed an increased risk for clinical vertebral fractures in both $C D$ and $U C$. $^{8,9,29}$ Our finding of a preferential localization of vertebral fractures at the mid and lower thoracic spine is also in line with earlier findings. ${ }^{19}$ In addition, an increase of morphometric vertebral deformities similar to $C D$ was found in UC, which has not been reported in the literature before.

To what extent the high prevalence of vertebral deformities in IBD differs from subjects without IBD is uncertain, as no data on non-clinical deformities in healthy young and premenopausal individuals are available. The best comparison with healthy subjects for the present study stems from the EVOS study, in which in a very large cross-sectional population based study European subjects aged 50 to 79 years were investigated. The prevalence of vertebral deformities on X-rays in this study was $12 \%$ (range $6-21 \%$ ) in males 
and females. ${ }^{30}$ The Rotterdam study, in which 3469 men and women aged 55 years and older were studied, revealed a prevalence of vertebral deformity suggestive of fracture in $6.9 \%$ of men and $7.5 \%$ of women. ${ }^{31}$ In a previous study on 60 subjects (mean age $49 \pm 13$ years), who were followed after initial successful treatment for differentiated thyroid carcinoma, we found vertebral deformities in $7 \% .^{32}$ All these data support the fact that IBD is a relevant risk factor for vertebral deformity suggestive for fracture.

For the determination of vertebral fractures a variety of morphometric approaches can be used. These different approaches can result in slightly different outcomes. ${ }^{27,33-35}$ Compared with subjective qualitative assessment, quantitative morphometry is a more reproducible method for assessing vertebral deformity and therefore these approaches are often used in conjunction. As, however, a gold standard for vertebral fracture is not available, it is still not clear which method is the most appropriate to establish vertebral deformities and on the basis of that to determine the occurrence of vertebral fractures. We followed the method of Genant, ${ }^{27}$ which is based on a reduction of the ratios of anterior, middle or posterior heights. This is the simplest and most practical method. ${ }^{36}$ It is also the method used in the majority of studies on IBD patients published ${ }^{18}$ and an association with future fracture risk is documented. ${ }^{37}$ The above mentioned EVOS study, however, applied the methodology described by McCloskey and Eastell and co-workers in which measurements are corrected for normal variations in vertebral shape. ${ }^{35}$ Relative to the method of Genant, the method of Eastell may result in a lower prevalence of vertebral deformities. In our series, use of the method of Eastell resulted in vertebral deformities in $20 \%$ of patients (data not shown), which is indeed lower than the prevalence found after the method of Genant, but still indicates a substantial prevalence in this young population.

We used MXA instead of standard spine radiographs for morphometric determination of vertebral deformities. Several studies have documented that MXA is comparable to standard spine radiographs for this approach. ${ }^{38-41}$ MXA, also called VFA (vertebral fracture assessment with DXA), has several advantages over vertebral morphometry on conventional spinal radiographs (MRX). The radiation dose is much lower $(<80 \mu \mathrm{Sv})$ and assessment of BMD and vertebral deformities can be combined. Although MXA is thus an established technology to detect vertebral fractures and to identify patients likely to benefit from pharmacological therapy who otherwise might not be treated, ${ }^{42}$ this technology has some limitations as well. These include limited ability to provide a differential diagnosis for the detected deformities, lower sensitivity for milder fractures and inability to evaluate the uppermost thoracic levels. However, its negative predictive value is high. ${ }^{17}$ Other disorders that may cause changes in vertebral shape involve congenital abnormalities and conditions as severe osteoarthritis ${ }^{43}$ and Scheuermann's disease. We have, 
however, no indications that these relatively rare conditions may have interfered with our observations. On the other hand, vertebrae in the midthoracic spine and thoraco-lumbar junction are slightly more wedged than in other regions of the spine $e^{34,44}$ and, as a result, normal variations may be misinterpreted as mild vertebral deformities. ${ }^{45,46}$ This may have contributed to overestimation of vertebral deformities in our series, although we feel only to a limited extent.

The occurrence of vertebral deformities in our series was equally distributed between subjects with a normal and osteopenic BMD at the hip. Only a few subjects had osteoporosis according to the WHO criteria, even when patients on bisphosphonates were included. BMD of patients with vertebral deformities was not different from the other patients studied. These findings are in line with other studies. ${ }^{19}$ In one of these studies, bone mass and fracture risk was determined and revealed a reduced BMD of the lumbar spine in patients with vertebral fractures compared with those without ( $T$-score $-2.50 \pm 0.88$ versus $-2.07 \pm 0.66 ; p<0.05)$, but also no relevant differences of BMD at the hip. ${ }^{18}$ This is in line with the many observations that indicate that low BMD is only one of the components that determines fracture risk and that most fractures, ${ }^{47}$ whether clinical or morphometric, occur in patients without osteoporosis in terms of a T-score $\leq-2.5 .^{47}$ Therefore, our results support the current trend towards identifying patients at risk for fracture even when BMD is normal ${ }^{7}$ as reflected in the current WHO initiative to develop refined models for fracture prediction in the individual patient. ${ }^{47}$ The clinical consequence of our findings is that a more systematic search for vertebral deformities is warranted in CD and UC, as suggested by others. ${ }^{11}$

It is well known that chronic inflammatory diseases affect bone physiology by the production of cytokines ${ }^{48,49}$ such as interleukin- 6 and 17 , tumour necrosis factor, the RANKL/OPG balance and the Wnt signalling pathway, probably mainly by an influence on bone turnover. ${ }^{50-52}$ We indeed found an increase in bone turnover parameters in both groups of patients, which was more pronounced in CD than in UC. In postmenopausal women, the level of bone turnover has been shown to be as strong a predictor of fractures as the level of BMD and independent of low BMD. ${ }^{53,54}$ This may be due to an effect of increased bone turnover on bone microarchitecture, in particular a loss of horizontal trabeculae not reflected in a change of BMD but nevertheless associated with an increased bone fragility and thus fracture risk. This may imply that changes in microarchitecture of bone rather than changes in BMD are involved in the occurrence of vertebral deformities in IBD and that vertebral deformities are therefore a better reflection of bone failure than low BMD. An alternative explanation may be that vertebral deformities in IBD occur during phases of active disease and increased bone turnover and bone loss, with subsequent recovery of bone during improvement of the IBD condition 
obscuring the relation of BMD with fracture. This is however unlikely, as we found no relation between vertebral deformities and current disease activity. In our study, male gender was a determinant for having a vertebral deformity. In a previous study were men with CD at greatest risk for osteoporosis, ${ }^{55}$ but no gender difference was shown in studies on fracture risk. Age was the determinant for having more than one vertebral deformity as it is a determinant in most epidemiological studies on fracture risk in healthy subjects. ${ }^{56,57}$ This was also found in a study of 218 patients with CD in which follow-up data at 20 years were compared with those of age- and gender matched controls. An overall risk ratio of 2.2 for a thoraco-lumbar fracture was calculated in this study with IBD and age as the only determinant and not use of glucocorticoids or intestinal resections. ${ }^{58}$ In another study, GC use per se appeared also not to be an important risk factor for fractures in IBD, although this study showed an increased fracture risk in CD but not in UC after long term use of GCs. ${ }^{10}$ We found that patients with current use of glucocorticoids had a higher prevalence of multiple $(>1)$ vertebral deformities. This is in line with the view that long term use of GCs is an independent risk factor for fracture. ${ }^{59}$

Limitations of our study are the cross-sectional design and the lack of an age and sex matched control population. Another limitation is the measurement of BMD in the hip only. This may have been contributed to an underestimation of osteopenia as it can not be excluded that more influence of BMD on risk of non-clinical vertebral fractures would have been found if DXA of the spine was also performed. However, as measurement of the hip allows measurement of both trabecular and cortical bone, a recent study shows that for this reason hip measurements may be superior to the spine in overall fracture prediction. ${ }^{60}$ In conclusion, we performed a large cross-sectional outpatient-based study on patients with Crohn's disease and ulcerative colitis and have demonstrated that in patients with these conditions the prevalence of non-clinical vertebral deformities suggestive of vertebral fractures is substantial, even in patients with normal BMD. Disease activity, glucocorticoid therapy and known risk factors for fracture appear to be poor predictors for the occurrence of these asymptomatic vertebral deformities, although GC use predicted the presence of multiple deformities. This implies that in addition to screening for osteoporosis by means of a bone mineral density measurement, morphometric assessment of vertebral deformities is warranted in IBD as well. As a vertebral fracture is a strong predictor of a new fracture of the spine or at other sites, one may wonder whether the high prevalence of vertebral deformities in IBD is a reason for preventive treatment as it is recommended for subjects with increased fracture risk, such as subjects who are treated with supraphysiological doses of glucocorticoids. To support this hypothesis, prospective follow-up data on the development of vertebral deformities in patients with inflammatory bowel disease are needed. 


\section{References}

1. Vestergaard P. Prevalence and pathogenesis of osteoporosis in patients with inflammatory bowel disease. Minerva Med. 2004;95:469-480.

2. Schoon EJ, van Nunen AB, Wouters RS, Stockbrugger RW, Russel MG. Osteopenia and osteoporosis in Crohn's disease: prevalence in a Dutch population-based cohort. Scand $\mathrm{J}$ Gastroenterol Suppl. 2000;43-47.

3. Habtezion A, Silverberg MS, Parkes R, Mikolainis S, Steinhart AH. Risk factors for low bone density in Crohn's disease. Inflamm Bowel Dis. 2002;8:87-92.

4. Siffledeen JS, Fedorak RN, Siminoski K, Jen H, Vaudan E, Abraham N, Seinhart H, Greenberg G. Bones and Crohn's: risk factors associated with low bone mineral density in patients with Crohn's disease. Inflamm Bowel Dis. 2004;10:220-228.

5. Hela S, Nihel M, Faten L, Monia F, Jalel B, Azza F, Slaheddine S. Osteoporosis and Crohn's disease. Joint Bone Spine. 2005;72:403-407.

6. Assessment of fracture risk and its application to screening for postmenopausal osteoporosis. Report of a WHO Study Group. World Health Organ Tech Rep Ser. 1994;843:1-129.

7. De Laet C, Oden A, Johansson H, Johnell O, Jonsson B, Kanis JA. The impact of the use of multiple risk indicators for fracture on case-finding strategies: a mathematical approach. Osteoporos Int. 2005;16:313-318.

8. Bernstein CN, Blanchard JF, Leslie W, Wajda A, Yu BN. The incidence of fracture among patients with inflammatory bowel disease. A population-based cohort study. Ann Intern Med. 2000;133:795-799.

9. van Staa TP, Cooper C, Brusse LS, Leufkens H, Javaid MK, Arden NK. Inflammatory bowel disease and the risk of fracture. Gastroenterology. 2003;125:1591-1597.

10. Vestergaard $P$, Krogh $K$, Rejnmark L, Laurberg $S$, Mosekilde L. Fracture risk is increased in Crohn's disease, but not in ulcerative colitis. Gut. 2000;46:176-181.

11. Bernstein CN, Leslie WD. Review article: Osteoporosis and inflammatory bowel disease. Aliment Pharmacol Ther. 2004;19:941-952.

12. Ettinger B, Black DM, Nevitt MC, Rundle AC, Cauley JA, Cummings SR, Genant HK. Contribution of vertebral deformities to chronic back pain and disability. The Study of Osteoporotic Fractures Research Group. J Bone Miner Res. 1992;7:449-456.

13. Black DM, Arden NK, Palermo L, Pearson J, Cummings SR. Prevalent vertebral deformities predict hip fractures and new vertebral deformities but not wrist fractures. Study of Osteoporotic Fractures Research Group. J Bone Miner Res. 1999;14:821-828.

14. Ismail AA, Cockerill W, Cooper C, Finn JD, Abendroth K, Parisi G, Banzer D, Benevolenskaya LI, Bhalla AK, Armas JB, Cannata JB, Delmas PD, Dequeker J, Dilsen G, Eastell R, Ershova O, Falch JA, Felsch B, Havelka S, Hoszowski K, Jajic I, Kragl U, Johnell O, Lopez VA, Lorenc R, Lyritis G, Marchand F, Masaryk P, Matthis C, Miazgowski T, Pols HA, Poor G, Rapado A, Raspe HH, Reid DM, Reisinger W, Janott J, Scheidt-Nave C, Stepan J, Todd C, Weber K, Woolf AD, Ambrecht G, Gowin W, Felsenberg D, Lunt M, Kanis JA, Reeve J, Silman AJ, O'Neill TW. Prevalent vertebral deformity predicts incident hip though not distal forearm fracture: results from the European Prospective Osteoporosis Study. Osteoporos Int. 2001;12:85-90.

15. Klotzbuecher CM, Ross PD, Landsman PB, Abbott TA, III, Berger M. Patients with prior fractures have an increased risk of future fractures: a summary of the literature and statistical synthesis. J Bone Miner Res. 2000;15:721-739.

16. Lindsay R, Silverman SL, Cooper C, Hanley DA, Barton I, Broy SB, Licata A, Benhamou L, Geusens P, Flowers K, Stracke H, Seeman E. Risk of new vertebral fracture in the year following a fracture. JAMA. 2001;285:320-323.

17. Delmas PD, Genant HK, Crans GG, Stock JL, Wong M, Siris E, Adachi JD. Severity of prevalent vertebral fractures and the risk of subsequent vertebral and nonvertebral fractures: results from the MORE trial. Bone. 2003;33:522-532. 
18. Klaus J, Armbrecht G, Steinkamp M, Bruckel J, Rieber A, Adler G, Reinshagen M, Felsenberg D, von TC. High prevalence of osteoporotic vertebral fractures in patients with Crohn's disease. Gut. 2002;51:654-658.

19. Stockbrugger RW, Schoon EJ, Bollani S, Mills PR, Israeli E, Landgraf L, Felsenberg D, Ljunghall S, Nygard G, Persson T, Graffner H, Bianchi PG, Ferguson A. Discordance between the degree of osteopenia and the prevalence of spontaneous vertebral fractures in Crohn's disease. Aliment Pharmacol Ther. 2002;16:1519-1527.

20. Lennard-Jones JE. Classification of inflammatory bowel disease. Scand J Gastroenterol Suppl. 1989;170:2-6.

21. Truelove SC, Witts LJ. Cortisone in ulcerative colitis; preliminary report on a therapeutic trial. Br Med J. 1954;2:375-378.

22. Elders PJ, Netelenbos JC, Lips P, Khoe E, Van Ginkel FC, Hulshof KF, Van der Stelt PF. Perimenopausal bone mass and risk factors. Bone Miner. 1989;7:289-299.

23. Best WR, Becktel JM, Singleton JW, Kern F, Jr. Development of a Crohn's disease activity index. National Cooperative Crohn's Disease Study. Gastroenterology. 1976;70:439-444.

24. Lichtiger S, Present DH, Kornbluth A, Gelernt I, Bauer J, Galler G, Michelassi F, Hanauer S. Cyclosporine in severe ulcerative colitis refractory to steroid therapy. $\mathrm{N}$ Engl J Med. 1994;330:1841-1845.

25. Van der Veer E, Koerts K, Wagenmakers L, Hoving J, Hegeman JH, Slaets JPJ, Willemsen G, Van Nieuwpoort J, Ten Duis HJ, Kreeftenberg HG. Effect of fracture on bone turnover markers in daily clinical practice. J Bone Miner Res 2005; (20 supplement 1) S 225-226.

26. Duboeuf F, Bauer DC, Chapurlat RD, Dinten JM, Delmas P. Assessment of vertebral fracture using densitometric morphometry. J Clin Densitom. 2005;8:362-368.

27. Genant HK, Wu CY, van KC, Nevitt MC. Vertebral fracture assessment using a semiquantitative technique. J Bone Miner Res. 1993;8:1137-1148.

28. Klaus J, Armbrecht G, Steinkamp M, Bruckel J, Rieber A, Adler G, Reinshagen M, Felsenberg D, von TC. High prevalence of osteoporotic vertebral fractures in patients with Crohn's disease. Gut. 2002;51:654-658.

29. Card T, West J, Hubbard R, Logan RF. Hip fractures in patients with inflammatory bowel disease and their relationship to corticosteroid use: a population based cohort study. Gut. 2004;53:251-255.

30. O'Neill TW, Felsenberg D, Varlow J, Cooper C, Kanis JA, Silman AJ. The prevalence of vertebral deformity in European men and women: the European Vertebral Osteoporosis Study. J Bone Miner Res. 1996;11:1010-1018.

31. van der Klift M, de Laet CE, McCloskey EV, Hofman A, Pols HA. The incidence of vertebral fractures in men and women: the Rotterdam Study. J Bone Miner Res. 2002;17:1051-1056.

32. Heijckmann AC, Huijberts MS, Geusens P, De VJ, Menheere PP, Wolffenbuttel BH. Hip bone mineral density, bone turnover and risk of fracture in patients on long-term suppressive Lthyroxine therapy for differentiated thyroid carcinoma. Eur J Endocrinol. 2005;153:23-29.

33. Black DM, Palermo L, Nevitt MC, Genant HK, Epstein R, San VR, Cummings SR. Comparison of methods for defining prevalent vertebral deformities: the Study of Osteoporotic Fractures. J Bone Miner Res. 1995;10:890-902.

34. McCloskey EV, Spector TD, Eyres KS, Fern ED, O'Rourke N, Vasikaran S, Kanis JA. The assessment of vertebral deformity: a method for use in population studies and clinical trials. Osteoporos Int. 1993;3:138-147.

35. Eastell R, Cedel SL, Wahner HW, Riggs BL, Melton LJ, III. Classification of vertebral fractures. J Bone Miner Res. 1991;6:207-215.

36. Black DM, Palermo L, Nevitt MC, Genant HK, Epstein R, San VR, Cummings SR. Comparison of methods for defining prevalent vertebral deformities: the Study of Osteoporotic Fractures. J Bone Miner Res. 1995;10:890-902.

37. Lindsay R, Silverman SL, Cooper C, Hanley DA, Barton I, Broy SB, Licata A, Benhamou L, Geusens P, Flowers K, Stracke H, Seeman E. Risk of new vertebral fracture in the year following a fracture. JAMA. 2001;285:320-323. 
38. Rea JA, Li J, Blake GM, Steiger P, Genant HK, Fogelman I. Visual assessment of vertebral deformity by X-ray absorptiometry: a highly predictive method to exclude vertebral deformity. Osteoporos Int. 2000;11:660-668.

39. Binkley N, Krueger D, Gangnon R, Genant HK, Drezner MK. Lateral vertebral assessment: a valuable technique to detect clinically significant vertebral fractures. Osteoporos Int. 2005; 16:1513-1518.

40. Vokes TJ, Dixon LB, Favus MJ. Clinical utility of dual-energy vertebral assessment (DVA). Osteoporos Int. 2003;14:871-878.

41. Schousboe JT, Debold CR. Reliability and accuracy of vertebral fracture assessment with densitometry compared to radiography in clinical practice. Osteoporos Int. 2006;17:281-289.

42. Lewiecki EM, Laster AJ. Clinical review: Clinical applications of vertebral fracture assessment by dual-energy x-ray absorptiometry. J Clin Endocrinol Metab. 2006;91:4215-4222.

43. Abdel-Hamid OA, Bassiouni H, Koutri R, Nijs J, Geusens P, Dequeker J. Aging of the thoracic spine: distinction between wedging in osteoarthritis and fracture in osteoporosis--a crosssectional and longitudinal study. Bone. 1994;15:437-442.

44. Black DM, Cummings SR, Stone K, Hudes E, Palermo L, Steiger P. A new approach to defining normal vertebral dimensions. J Bone Miner Res. 1991;6:883-892.

45. Spector TD, McCloskey EV, Doyle DV, Kanis JA. Prevalence of vertebral fracture in women and the relationship with bone density and symptoms: the Chingford Study. J Bone Miner Res. 1993;8:817-822.

46. Kleerekoper M, Nelson DA. Vertebral fracture or vertebral deformity. Calcif Tissue Int. 1992; 50:5-6.

47. Kanis JA. Diagnosis of osteoporosis and assessment of fracture risk. Lancet. 2002;359: 1929-1936.

48. Hofbauer LC, Schoppet M. Clinical implications of the osteoprotegerin/RANKL/RANK system for bone and vascular diseases. JAMA. 2004;292:490-495.

49. Gravallese EM, Goldring SR. Cellular mechanisms and the role of cytokines in bone erosions in rheumatoid arthritis. Arthritis Rheum. 2000;43:2143-2151.

50. Manolagas SC. The role of IL-6 type cytokines and their receptors in bone. Ann N Y Acad Sci. 1998;840:194-204.

51. Scheidt-Nave C, Bismar H, Leidig-Bruckner G, Woitge H, Seibel MJ, Ziegler R, Pfeilschifter J. Serum interleukin 6 is a major predictor of bone loss in women specific to the first decade past menopause. J Clin Endocrinol Metab. 2001;86:2032-2042.

52. Moschen AR, Kaser A, Enrich B, Ludwiczek O, Gabriel M, Obrist P, Wolf AM, Tilg H. The RANKL/OPG system is activated in inflammatory bowel disease and relates to the state of bone loss. Gut. 2005;54:479-487.

53. Garnero P, Hausherr E, Chapuy MC, Marcelli C, Grandjean H, Muller C, Cormier C, Breart G, Meunier PJ, Delmas PD. Markers of bone resorption predict hip fracture in elderly women: the EPIDOS Prospective Study. J Bone Miner Res. 1996;11:1531-1538.

54. Melton LJ, III, Khosla S, Atkinson EJ, O'Fallon WM, Riggs BL. Relationship of bone turnover to bone density and fractures. J Bone Miner Res. 1997;12:1083-1091.

55. Robinson RJ, al-Azzawi F, Iqbal SJ, Kryswcki T, Almond L, Abrams K, Mayberry JF. Osteoporosis and determinants of bone density in patients with Crohn's disease. Dig Dis Sci. 1998;43:2500-2506.

56. van der Klift M, de Laet CE, McCloskey EV, Johnell O, Kanis JA, Hofman A, Pols HA. Risk factors for incident vertebral fractures in men and women: the Rotterdam Study. J Bone Miner Res. 2004;19:1172-1180.

57. Roy DK, O'Neill TW, Finn JD, Lunt M, Silman AJ, Felsenberg D, Armbrecht G, Banzer D, Benevolenskaya LI, Bhalla A, Bruges AJ, Cannata JB, Cooper C, Dequeker J, Diaz MN, Eastell R, Yershova OB, Felsch B, Gowin W, Havelka S, Hoszowski K, Ismail AA, Jajic I, Janott I, Johnell O, Kanis JA, Kragl G, Lopez VA, Lorenc R, Lyritis G, Masaryk P, Matthis C, Miazgowski T, Gennari C, Pols HA, Poor G, Raspe HH, Reid DM, Reisinger W, Scheidt-Nave C, Stepan JJ, Todd CJ, Weber K, Woolf AD, Reeve J. Determinants of incident vertebral fracture in men and women: results from the European Prospective Osteoporosis Study (EPOS). Osteoporos Int. 2003;14:19-26. 
58. Loftus EV, Jr., Crowson CS, Sandborn WJ, Tremaine WJ, O'Fallon WM, Melton LJ, III. Longterm fracture risk in patients with Crohn's disease: a population-based study in Olmsted County, Minnesota. Gastroenterology. 2002;123:468-475.

59. Kumagai S, Kawano S, Atsumi T, Inokuma S, Okada Y, Kanai $Y$, Kaburaki J, Kameda H, Suwa $A$, Hagiyama $H$, Hirohata $S$, Makino $H$, Hashimoto $H$. Vertebral fracture and bone mineral density in women receiving high dose glucocorticoids for treatment of autoimmune diseases. J Rheumatol. 2005;32:863-869.

60. Leslie WD, Tsang JF, Caetano PA, Lix LM. Effectiveness of bone density measurement for predicting osteoporotic fractures in clinical practice. J Clin Endocrinol Metab. 2007;92:77-81. 


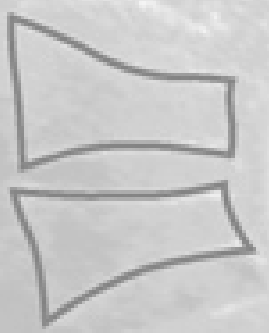

Chapter 5

Bone turnover and hip bone mineral density

in patients with sarcoidosis

AC Heijckmann, MSP Huijberts, J De Vries, PPCA Menheere, E van der Veer, AC Nieuwenhuijzen Kruseman, BHR Wolffenbuttel, P Geusens, M Drent

Sarcoidosis Vasc Diffuse Lung Dis, in press 


\section{Abstract}

\section{Background}

Sarcoidosis is a chronic inflammatory T-cell-driven disease that can also affect bone. We evaluated bone remodelling and bone mineral density (BMD) in patients with sarcoidosis and their dependency of disease-related and treatment-related factors.

\section{Methods}

In 124 patients BMD of the hip (DXA) and markers of bone resorption (ICTP) and formation (PINP) were evaluated. Furthermore a lateral DXA of the spine for morphometric assessment of vertebral deformities was performed in 87 patients. Potential predictors of bone markers, BMD and determinants of prevalent vertebral deformities were assessed using multiple and logistic regression analysis.

Results

The population studied comprised untreated patients $(n=51)$, patients that previously used glucocorticoids $(n=31)$ and patients currently using glucocorticoids $(n=42)$. In all these groups the age- and gender corrected Z-scores of the hip were normal, except in untreated patients, which revealed an increased $Z$-score at the trochanter $(p=0.004)$. In all but the patients currently on glucocorticoids the Z-scores for PINP and ICTP were increased $(p<0.05)$. In patients currently on glucocorticoids the Z-ICTP was also increased $(p<0.05)$, but the Z-PINP decreased $(p<0.01$ compared to untreated patients). In $20.6 \%$ of patients one or more morphometric vertebral deformities were found.

\section{Conclusions}

Hip BMD is normal in patients with sarcoidosis, despite an increased bone turnover. This may imply that in sarcoidosis mechanisms are involved that compensate for the well-known effects of cytokines in inflammatory diseases on osteoclastogenesis and bone resorption. Nonetheless, vertebral deformities suggestive of fracture were found in a significant number of patients which indicates that patients with sarcoidosis still have a relevant fracture risk. 


\section{Introduction}

Sarcoidosis is a multiorgan, inflammatory, granulomatous disorder of unknown origin that can affect almost any organ of the body, including bone. ${ }^{1-5}$ In addition to localized bone lesions of sarcoid granulomas, ${ }^{6}$ increased bone mineral density $(\mathrm{BMD})^{7}$ as well as generalized bone loss have been described in longstanding sarcoidosis. ${ }^{8}$

There are a number of mechanisms that may be involved in bone changes in sarcoidosis. Due to overproduction of 1,25 dihydroxyvitamin $\mathrm{D}\left(1,25(\mathrm{OH})_{2} \mathrm{D}_{3}\right)$ by sarcoid granulomas, intestinal absorption of calcium is enhanced and bone turnover can be increased. ${ }^{5,9}$ As sarcoidosis is a chronic T-cell-driven inflammatory disease, cytokines such as interleukin 6 (IL-6) and tumour necrosis factor are increased. These cytokines play a pivotal role in the pathogenesis of granulomatous diseases, ${ }^{10,11}$ and can also influence bone turnover. ${ }^{12,13}$ Finally, prolonged treatment with glucocorticoids and decreased physical activity may also negatively affect bone.

Up till now, only a limited number of studies on BMD measurements in untreated sarcoidosis are published. ${ }^{7,14,15}$ All these studies are of small size and reveal predominantly an unchanged BMD with only mild trabecular bone loss in longstanding sarcoidosis. ${ }^{14}$ This is in contrast with what can be expected in a chronic inflammatory disorder. In addition, in only one study bone turnover parameters were determined ${ }^{16}$ and no data are available of fracture risk in patients with sarcoidosis. For that reason we studied a large and wellcharacterized sarcoidosis population, consisting of a group of untreated subjects, subjects that were previously treated with glucocorticoids and subjects that were currently on glucocorticoids. In addition to measurement of bone turnover parameters and BMD, morphometry of the spine was done to identify vertebral deformities suggestive of non-clinical fractures and to substantiate the fracture risk in sarcoidosis.

\section{Patients and methods}

\section{Patients}

Between January 2002 and July 2003, all 167 sarcoidosis patients with a disease duration of at least one year attending the outpatient clinic of the Sarcoidosis Management Center of the University Hospital Maastricht, were asked to participate in this cross-sectional study. Hundred and thirty-eight patients $(82 \%)$ agreed to participate. All patients were Caucasians and diagnosed with sarcoidosis according to the WASOG guidelines, ${ }^{1}$ based on consistent clinical features and results of an analysis of bronchoalveolar lavage 
fluid. ${ }^{17}$ In $71 \%$ a biopsy confirmed the diagnosis. None of the patients had any significant co-morbidity. Known causes of bone mass abnormalities, such as renal failure, thyroid dysfunction, alcoholism and long-term anticoagulant use were exclusion criteria, but no patient was excluded on the basis of these factors. Fourteen patients were excluded because of the use of bisphosphonates or hormone replacement therapy. Finally, 124 patients were included in this study. This group consisted of 43 pre-menopausal women, 19 post-menopausal women, and 62 men. The patients were grouped according to the way of treatment, e.g. no treatment, previously treated with glucocorticoids and currently on glucocorticoids.

The clinical records of all patients were reviewed. Demographic, clinical and treatment data of these patients are summarized in Table 5.1. Patients were evaluated according to a standard protocol that included questionnaires related to risk factors for osteoporosis, calcium intake, physical activity and health status, measurement of height and weight, lung function, measurement of BMD, and collection of a blood sample and morning urine. Informed consent was obtained from all participants and this study was approved by the medical ethics committee. None of the patients who declined to participate or were excluded had impaired mobility or a history of vertebral fractures. Mean age of this group was 43 years and there were seven postmenopausal women in this group.

\section{Pulmonary evaluation}

Lung function, including forced expiratory volume in one second $\left(F E V_{1}\right)$ and forced vital capacity (FVC), was measured with a pneumotachograph. The diffusion capacity for carbon monoxide (DLCO) was measured using the singlebreath method (both Masterlab, Jaeger, Würzburg, Germany). Values were expressed as a percentage of those predicted. ${ }^{18}$

Chest radiographs were graded according to the radiographic staging of DeRemee (0 to III), adding stage IV, the end stage of lung fibrosis. ${ }^{1,19}$ All interpretations were made by a radiologist who was blinded to the patient's history.

\section{Bone Mineral Density}

In all 124 patients bone mineral density (BMD) of the hip was measured by dual X-ray absorptiometry (DXA) (Hologic QDR 4500). As reference group the NHANES III database was used. A standard protocol as described previously was used for measurement of BMD. ${ }^{20}$ Furthermore a lateral DXA of the thoracic and lumbar spine for assessment of vertebral fractures (morphometric X-ray absorptiometry $(\mathrm{MXA}))^{21}$ was performed in 87 patients. All these morphometric analyses were done twice by one trained operator using the 
quantitative technique of Genant. ${ }^{22}$ On the basis of the average score of these morphometric measurements prevalent vertebral deformity suggestive of fracture was defined as a reduction of height of $20 \%$ or more. ${ }^{22}$

Table 5.1 Demographic, clinical, and treatment variables in the study patients $(n=124)$.

\begin{tabular}{|c|c|c|c|c|c|}
\hline Variable & $\begin{array}{l}\text { Never GC use } \\
\quad(n=51)\end{array}$ & $\begin{array}{c}\text { Previous GC use } \\
\quad(n=31)\end{array}$ & $\begin{array}{l}\text { Current GC use } \\
\quad(n=42)\end{array}$ & $p^{a}$ & $p^{b}$ \\
\hline \multicolumn{6}{|l|}{ Demographic variables } \\
\hline Female sex & $36(71)$ & $13(39)$ & $14(33)$ & $<0.001$ & $<0.001$ \\
\hline Postmenopausal (\% of group) & $8(16)$ & $4(13)$ & $7(17)$ & & \\
\hline Age years & $42(20-67)$ & $45(25-66)$ & $49(28-70)$ & & \\
\hline Body mass index $\left(\mathrm{kg} / \mathrm{m}^{2}\right)$ & $26.9 \pm 5.9$ & $26.6 \pm 4.8$ & $27.4 \pm 5.8$ & & \\
\hline Smoking & $8(16)$ & $3(10)$ & $5(12)$ & & \\
\hline Daily dietary calcium intake (mg) & $736 \pm 355$ & $880 \pm 549$ & $750 \pm 347$ & & \\
\hline \multicolumn{6}{|l|}{ Clinical variables } \\
\hline Disease duration, median (range) yrs & $3(1-39)$ & $4(1-20)$ & $3,5(1-36)$ & & \\
\hline Chest X-ray stage (0-I-II-III-IV) & $15 / 10 / 16 / 10 / 0$ & $6 / 4 / 9 / 9 / 3$ & $4 / 6 / 9 / 16 / 7$ & & 0.002 \\
\hline FEV1 $(\%$ of predicted \pm SD) & $98 \pm 15$ & $83 \pm 24$ & $77 \pm 25$ & $<0.001$ & $<0.001$ \\
\hline DLCO (\% of predicted \pm SD) & $93 \pm 14$ & $79 \pm 16$ & $77 \pm 21$ & $<0.001$ & $<0.001$ \\
\hline \multicolumn{6}{|l|}{ Laboratory values (in serum) } \\
\hline Calcium $(\mathrm{mmol} / \mathrm{l})$ & $2.4 \pm 0.1$ & $2.4 \pm 0.2$ & $2.4 \pm 0.1$ & & \\
\hline 1,25(OH)2D3 (nmol/l) & $0.16 \pm 0.05$ & $0.14 \pm 0.03$ & $0.15 \pm 0.04$ & & \\
\hline $\operatorname{ACE}(\mathrm{U} / \mathrm{l})$ & $21.4 \pm 7.9$ & $21.5 \pm 11.2$ & $26.5 \pm 13.9$ & & \\
\hline slL-2R (kU/l) & $695(216-2636)$ & $638(264-4546)$ & $715(188-4315)$ & & \\
\hline Hs-CRP (mg/l) & $2.3(0.2-79)$ & $3.4(0.2-58)$ & $4.4(0.2-191)$ & & \\
\hline \multicolumn{6}{|l|}{ Treatment variables } \\
\hline Lifetime glucocorticoid dose (mg) & - & $7200(200-54000)$ & $13125(1650-189000)$ & & \\
\hline Daily dose $(\mathrm{mg})$ & - & $17.4 \pm 7.9$ & $18.1 \pm 9.0$ & & \\
\hline \multicolumn{6}{|l|}{ Clinical risk factors for osteoporosis } \\
\hline Fracture $>50$ years & 0 & 1 of $11(9)$ & 2 of $20(10)$ & & \\
\hline Vertebral fracture by DXA & 8 of $36(22)$ & 4 of $19(21)$ & 6 of $32(19)$ & & \\
\hline Low body weight (<60 kg) & $8(16)$ & $4(13)$ & $2(5)$ & & \\
\hline Severe immobilization & 0 & 0 & 0 & & \\
\hline Low physical activity index $\leq 5$ & $10(20)$ & $9(29)$ & $17(41)$ & & \\
\hline Mother with hip fracture & $2(4)$ & $1(3)$ & $3(7)$ & & \\
\hline
\end{tabular}

Data are given as mean $\pm \mathrm{SD}$, median (range) or number (\%); Reference parameters: Calcium: 2.1-2.6 mmol//; 1,25(OH)2D3 0.0400.200 nmol//; ACE: 9-25 U/l; sIL-2R: 241-846 KU/l; hs-CRP: 0-10 mg/l; Abbreviations: GC, glucocorticoid; FEV1, forced expiratory volume in one second; DLCO, diffusion capacity for carbon monoxide; 1,25(OH)2D3, 1,25 dihydroxyvitamin D; ACE, angiotensin converting enzyme; sIL-2R, soluble interleukin-2 receptor; Hs-CRP, high-sensitivity C-reactive protein. ${ }^{a} \mathrm{p}$ value never $\mathrm{GC}$ use versus previous + current; ${ }^{\mathrm{b}} \mathrm{p}$ value never versus current

\section{Laboratory assays}

As a marker for bone formation, serum procollagen type I amino-terminal propeptide (PINP) was measured. As a marker for bone resorption, serum carboxy-terminal cross-linked telopeptide of type I collagen (ICTP) was assessed. Both PINP [interassay coefficient of variation (IE-CV) $3.2 \%$, intraassay CV (IA-CV) $2.5 \%$, lowest detectable concentration $0.4 \mu \mathrm{g} / \mathrm{l}]$ and ICTP (IE-CV 3.5\%, IA-CV 2.3\%, lowest detectable concentration $<0.1 \mu \mathrm{g} / \mathrm{l}$ ) were measured using commercial RIA kits (Orion Diagnostica Oy, Espoo, Finland). 
The Z-score for these bone markers was obtained using a Dutch reference group (300 women, 150 men), checked for normal BMD of the lumbar spine and femur and normal 25-hydroxyvitamin-D levels. ${ }^{23}$ Serum 1,25-dihydroxyvitamin $\mathrm{D}$ concentration was determined by radioimmuno-assay using a commercially available kit (IDS Ltd, Boldon, England, IE-CV 18\%, IA-CV 15\%). High-sensitivity C-reactive protein (hs-CRP) was measured by particleenhanced immunonephelometry on the BN Prospec (Dade Behring). The detection limit is $0.175 \mathrm{mg} / \mathrm{l}$ and the measuring range is $0.175-1100 \mathrm{mg} / \mathrm{l}$. Soluble IL-2 receptor (sIL-2R) was determined on the IMMULITE automated analyzer, by means of a two-site chemiluminescent enzyme immunometric assay with a measuring range of 50-7500 kU/l (Diagnostic Product Corporation, Los Angeles, CA, cat no LKIP1). Serum angiotensin converting enzyme (ACE) was measured using a colorimetric method. The precision of the ACE assay was $<5.6 \%$ and the reference interval for ACE was 9-25 U/l.

\section{Questionnaires}

Known clinical risk factors for osteoporosis were evaluated (weight below 60 $\mathrm{kg}$, hip fracture in the mother, history of fractures after age 50, menopausal status, severe immobilization and use of glucocorticoids) and physical activity was scored on a scale between 0 and $18 .{ }^{24}$ Calcium intake was evaluated via an extensive dietary list and dosing and duration of glucocorticoid therapy was evaluated by means of a patient questionnaire and verified using all the records of the patient's pharmacist.

\section{Statistics}

Student t-tests, chi-square tests, and one-way ANOVAs were used, depending on the variables and subgroups tested. Z-score analyses were performed to correct for age and gender when comparing subgroups. One-sample t-tests were used to compare patient scores with norm scores. Z-scores for BMD were evaluated by univariate analysis in relation to risk factors and clinical variables using bivariate correlations for continuous and ANOVA for dichotomous variables. Bone markers were expressed as Z-scores. Factors associated $(p<0.10)$ with a low BMD and bone turnover were entered as independent variables in a multiple regression analysis (method: stepwise) with BMD and bone turnover as outcome measures. A logistic regression analysis (method: enter) was performed to examine the determinants of morphometric vertebral deformities. For the comparison of subgroups with various glucocorticoid status, a Bonferroni correction was applied, resulting in a $p<0.002$ being considered significant. For the remaining analyses, the level of significance was set at $p<0.05$. 


\section{Results}

\section{Bone Mineral Density}

The results of BMD measurements are shown in Table 5.2 and Figure 5.1. In all groups the Z-scores of the hip were normal, except the Z-scores of patients that never used glucocorticoids, which revealed an increased Z-score at the trochanter $(0.45,95 \%$ confidence interval $(\mathrm{Cl}): 0.15-0.76, \mathrm{p}=0.004$, Figure 5.1$)$. This Z-score was also higher than that of subjects using glucocorticoids when the data of patients currently on glucocorticoids were taken together with patients that previously used glucocorticoids $(0.01$ ( $\mathrm{Cl}$ : $0.06-0.84), p<0.05$, not shown in figure).

Table 5.2 BMD variables and bone markers.

\begin{tabular}{lccc}
\hline Variable & $\begin{array}{c}\text { Never GC use } \\
(\mathrm{n}=51)\end{array}$ & $\begin{array}{c}\text { Previous GC use } \\
(\mathrm{n}=31)\end{array}$ & $\begin{array}{c}\text { Current GC use } \\
(\mathrm{n}=42)\end{array}$ \\
\hline BMD $\left(\mathrm{gm} / \mathrm{cm}^{2}\right)$ & & & \\
Femoral neck & $0.84 \pm 0.13$ & $0.79 \pm 0.09$ & $0.80 \pm 0.18$ \\
$\quad$ Trochanter & $0.76 \pm 0.12$ & $0.71 \pm 0.10$ & $0.71 \pm 0.18$ \\
Z-score & & & \\
$\quad$ Femoral neck & $0.1 \pm 1.2$ & $-0.4 \pm 0.9$ & $0.0 \pm 1.0$ \\
$\quad$ Trochanter & $0.5 \pm 1.1^{\mathrm{a}}$ & $-0.1 \pm 1.0$ & $0.1 \pm 1.1$ \\
T-score & & & \\
Femoral neck & $-0.5 \pm 1.2^{\mathrm{a}}$ & $-1.1 \pm 0.9^{\mathrm{a}}$ & $-0.8 \pm 1.0^{\mathrm{a}}$ \\
$\quad$ Trochanter & $0.1 \pm 1.1$ & $-0.4 \pm 0.9^{\mathrm{a}}$ & $-0.3 \pm 1.0$ \\
Bone markers in serum & & & \\
ICTP $(\mu \mathrm{g} / \mathrm{l})$ & $4.1 \pm 1.6$ & $4.4 \pm 1.7$ & $3.7 \pm 1.5$ \\
Z-score ICTP & $1.2 \pm 2.0^{\mathrm{a}}$ & $1.3 \pm 1.9^{\mathrm{a}}$ & $0.7 \pm 2.0^{\mathrm{a}}$ \\
PINP $(\mu \mathrm{g} / \mathrm{l})$ & $43.8 \pm 19.7$ & $42.9 \pm 19.7$ & $35.6 \pm 20.4$ \\
Z-score PINP & $0.4 \pm 1.1^{\mathrm{a}}$ & $0.3 \pm 1.4$ & $-0.4 \pm 1.3$ \\
\hline
\end{tabular}

Data are given as mean $\pm \mathrm{SD} ;{ }^{a} \mathrm{p}$ value $<0.05$ one-sample t-test compared to norm scores; Abbreviations: BMD, bone mineral density, ICTP, carboxy-terminal cross-linked telopeptide of type I collagen; PINP, procollagen type I amino-terminal propeptide.

Multiple regression analysis, including factors that correlated in the univariate analysis, revealed only a positive relation between the Z-scores of the femoral neck and trochanter with body mass index (BMI). Z-scores for BMD were unrelated to $1,25(\mathrm{OH})_{2} \mathrm{D}_{3}$, radiographic stage of sarcoidosis (0/I versus $\mathrm{II} / \mathrm{III} / \mathrm{IV}$ ), lifetime glucocorticoid dose, daily glucocorticoid dose, and duration of glucocorticoid use. In the subgroups we found nevertheless a significant negative correlation in the current glucocorticoid users between Z-score at the trochanter and $1,25(\mathrm{OH})_{2} \mathrm{D}_{3}(\mathrm{r}=-0.38, \mathrm{p}=0.02)$ and between $\mathrm{Z}$-score at the femoral neck and this vitamin $D(r=-0.35, p=0.03)$. The $Z$-scores for BMD were furthermore also unrelated to life-style factors (smoking, physical activity and calcium intake) or to a family history of osteoporosis. There was also no relation between physical activity scores and BMD. 


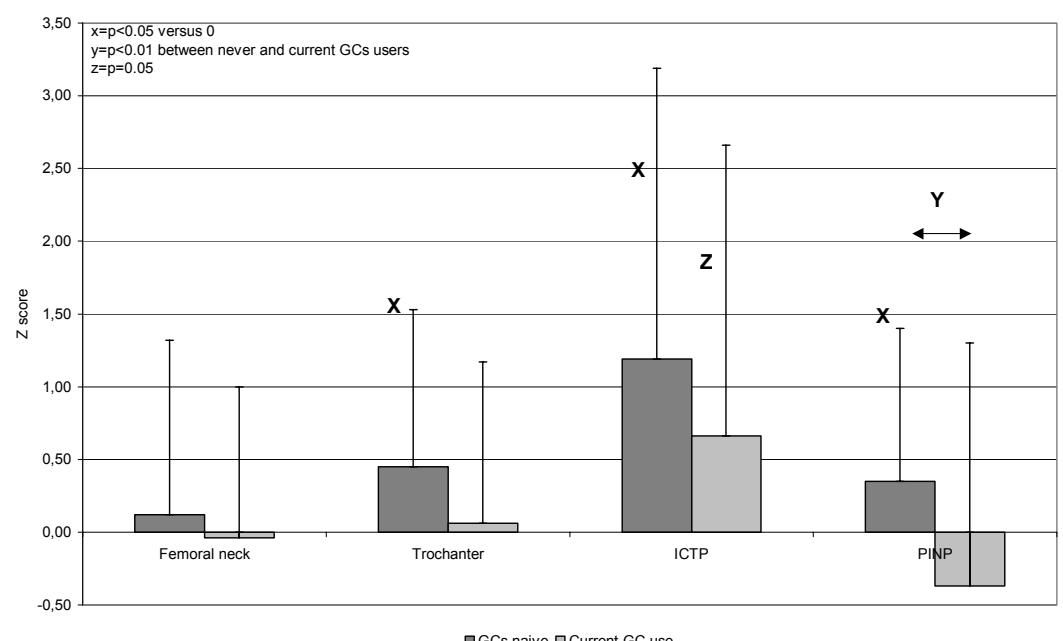

Figure 5.1 Z-scores $( \pm S D)$ in the untreated group $(n=51)$ versus current glucocorticoid users $(n=42)$; Abbreviations: ICTP, carboxy-terminal cross-linked telopeptide of type I collagen; PINP, procollagen type I amino-terminal propeptide; GC, glucocorticoid.

\section{Bone turnover parameters}

ICTP and PINP levels and their Z-scores for the different groups are shown in Table 5.2 and Figure 5.1. Z-scores for ICTP (Z-ICTP) as well as PINP (Z-PINP) were increased in the group of patients not using glucocorticoids $(1.2(\mathrm{Cl}: 0.6$, 1.8), $p<0.001$ and $0.4(\mathrm{Cl}: 0.0,0.7, p<0.05$ respectively). In the group of patients currently on glucocorticoids the Z-ICTP was also increased $(0.7(\mathrm{Cl}$ : $0.0-1.3), p=0.05)$, but the Z-PINP decreased $(-0.4$ ( $\mathrm{Cl}:-0.8,0.0), p<0.01$ compared to glucocorticoid naïve patients).

Z-ICTP was positively related to sIL-2R $(r=0.22, p<0.05), A C E(r=0.26, p<0.01)$, and negatively to DLCO $(r=-0.21, p<0.05)$ and these correlations were even stronger in patients with current glucocorticoid use $(r=0.57(p<0.001), 0.42$ $(p=0.009)$ and $-0.46(p=0.005)$ respectively). The Z-PINP revealed no relation with these parameters. Bone turnover parameters were also not related to $\mathrm{BMD}, 1.25(\mathrm{OH})_{2} \mathrm{D}_{3}$ values or fracture rate.

\section{Clinical fractures and vertebral deformities}

Three symptomatic, non-vertebral fractures were found in patients older than 50 years ( 3 out of 51 patients, $6 \%$ ), one of which appeared to be a fracture of the thumb due to a sarcoid granuloma. When the fracture occurred, these patients suffered from sarcoidosis for eight, 22 and 23 years, respectively. In 18 out of the $87(20.6 \%)$ patients of which DXA images were available for morphometric analysis one or more vertebral deformities (24 vertebrae in total) 
were found. None of these had been symptomatic. All but one of the deformities revealed a mild or moderate vertebral height loss of less than $40 \%$. When comparing the group with and without vertebral deformities (threshold value of one of the ratios of $<0.8$ ), no significant difference was found between Z-scores of BMD of the trochanter or femoral neck, nor in Z-ICTP or PINP. Using T-scores, a lower BMD at the femoral neck was found in subjects with vertebral deformities compared to those without deformities $(-1.2(\mathrm{Cl}:-1.5,-0.9)$ and $-0.3(\mathrm{Cl}:-0.6,-0.1), \mathrm{p}=0.001)$. The BMD at the trochanter was not different. Furthermore, the group with deformities appeared to be older (42 years $(\mathrm{Cl}: 40$, $45)$ versus 52 years $(\mathrm{Cl}: 48,56), p=0.001)$ and contained more males $(p=0.01)$. No differences were seen in other clinical risk factors, glucocorticoid use, daily glucocorticoid dose and disease duration.

Logistic regression analysis revealed that higher T-score for femoral neck was associated with a lower prevalence of vertebral deformities $(\mathrm{OR}=0.225(\mathrm{Cl}$ : 0.083-0.607), $p=0.003$ ). In addition, determinants of higher prevalence of these deformities were male gender $(\mathrm{OR}=6.34(\mathrm{Cl}: 1.355-32.518), p=0.020)$ and older age $(\mathrm{OR}=1.120(\mathrm{Cl}: 1.039-1.206))$.

\section{Discussion}

In our series of a large group of sarcoidosis patients the BMD measured with DXA at the hip was not different from the reference population, even if currently or previously treated with glucocorticoids. Surprisingly, in untreated patients the BMD at the trochanter appeared even increased. As sarcoidosis is a T-cell driven disease one would expect a decreased BMD, like in other inflammatory conditions. ${ }^{25}$ Our observations are, however, in line with the few clinical studies reported on BMD in sarcoidosis. ${ }^{7,14,15}$ Tervonen et al. ${ }^{7}$ reported in 14 patients with a disease duration of less than two years an increased BMD. Two other studies of small size involve BMD in untreated patients. ${ }^{14,15}$ These studies also found a normal BMD relative to age and sex-matched controls, except for five postmenopausal women in which the BMD was moderately decreased at the spine in longstanding sarcoidosis only.

In contrast to a normal BMD, untreated patients had increased values for the bone resorption marker ICTP and the bone formation marker PINP, which is suggestive of increased bone turnover.

In patients currently on glucocorticoids the bone resorption marker ICTP was also increased, although slightly less than in subjects not using glucocorticoids. PINP, however, was decreased in these patients. As this is in line with the well known effects of glucocorticoids on bone turnover, ${ }^{26,27}$ one would expect in such a situation a decreased BMD as well. This discrepancy and the finding of 
a normal BMD in untreated patients in spite of increased bone turnover is suggestive of a protective effect of sarcoidosis on bone metabolism.

It is well known that chronic inflammatory diseases affect bone physiology by the production of cytokines. ${ }^{28,29}$ Cytokines enhance RANKL expression in osteoblasts. RANKL is the receptor activator of the nuclear receptor-kB ligand that induces osteoclast differentiation by binding to the receptor activator of the nuclear factor-kB (RANK) on the surface of osteoclasts. In addition, cytokines involved in chronic inflammatory diseases can suppress osteoprotegerin (OPG) expression in osteoblasts. OPG is a decoy receptor for RANKL and prevents binding of RANKL to its osteoclast receptor and thereby inhibits osteoclast differentiation. Although there are no data on changes in the RANKL/OPG ratio in sarcoidosis, enhanced activation of nuclear receptor kappa beta (NF-kB), the downstream transcription factor of this pathway, has been reported previously in patients with sarcoidosis. ${ }^{30,31}$ The consequence of the influence of cytokines on bone mass in chronic inflammation is usually increased bone resorption rather than increased bone formation, ${ }^{25}$ which contrasts with our finding of normal BMD in sarcoidosis. Recent data, however, indicate that a cytokine as interleukin-6 may influence osteoblast proliferation and differentiation as well. ${ }^{32}$ It may well be that these dual functions of cytokines on bone physiology are responsible for the normal BMD in untreated sarcoid subjects, despite increased bone turnover.

We found a positive relation between sIL-2R and ACE and the bone resorption marker ICTP, but not between the bone formation marker PINP. No relation was found between hs-CRP and bone turnover markers. All these factors can be used as markers for disease activity in sarcoidosis. Of these, in particular sIL-2R is suitable to monitor the activity of the T-cell component in sarcoidosis. $^{33,34}$ Studies on circulating hs-CRP in several immune and inflammatory diseases have shown that increased levels of this parameter are associated with decreased BMD. ${ }^{35}$ Our finding of no such an association and a positive relation of sIL-2R and ACE with ICTP but without consequent decrease of BMD supports our suggestion that in sarcoidosis a dual mechanism different from other chronic inflammatory conditions is involved in bone metabolism.

One of the factors responsible for this possible dual mechanism in sarcoidosis may be vitamin $D$. Vitamin $D$ receptors are identified on macrophages and activated T-lymphocytes, ${ }^{36}$ which is suggestive for a potential role for vitamin $D$ in regulating the immune system. Sarcoid granulomas can induce production of the active compound of vitamin $\mathrm{D}, 1,25(\mathrm{OH})_{2} \mathrm{D} 3 .^{5,9}$ Several studies have shown that this hormone can regulate osteoblastogenesis and osteoclastogenesis, the latter partly via regulation of the OPG and RANKL expression of osteoblasts. ${ }^{37}$ As we found no differences of $1,25(\mathrm{OH})_{2} \mathrm{D} 3$ levels between the groups of patients studied besides a weak negative correlation in the current glucocorticoid users with Z-scores of BMD and no relation with bone turnover 
parameters, our findings are not indicative for such an influence of vitamin D on bone turnover on sarcoidosis, neither precludes such an effect.

As fracture risk is not only determined by loss of bone mass, but also by loss of bone micro architecture and consequent bone strength, ${ }^{38,39}$ a BMD not different from a reference population does not preclude increased fracture risk. In our series, only three clinical fractures were observed. With quantitative morphometric X-ray absorptiometry (MXA), however, vertebral deformities, which may be suggestive of vertebral fractures, were found in $21 \%$ of the 87 patients studied. It is uncertain whether or not this prevalence differs from subjects without sarcoidosis, as no data on non-clinical deformities in healthy young and premenopausal individuals are available. The best comparison with healthy subjects for the present study stems from the EVOS (European Vertebral Osteoporosis Study) study, in which in a very large cross-sectional population based study European subjects aged 50 to 79 years were investigated. The prevalence of vertebral deformities on X-rays in this study was $12 \%$ (range $6-21 \%$ ) in males and females. ${ }^{40}$ The investigators of this study used the methodology of McCloskey and Eastell and co-workers. ${ }^{41,42}$ Following this methodology measurements are corrected for normal variations in vertebral shape. Relative to the more simple and practical method of Genant we used, ${ }^{43}$ the method of Eastell may result in lower prevalences of vertebral deformities. Presumably, the prevalence of vertebral deformities we found in patients with sarcoidosis is not different or perhaps slightly more than what can be found in a reference population. To what extent these vertebral deformities are indeed related to vertebral fractures is ambiguous too in the absence of a gold standard, but may implicate that the occurrence of non-clinical vertebral fractures in patients with sarcoidosis is not rare despite a normal BMD.

One of the limitations of our study is the cross-sectional design. Longitudinal studies are necessary to determine whether or not sarcoidosis may result in substantial bone loss on long term, despite the protective mechanisms suggested before. Another limitation is the measurement of BMD at the hip only, although recently was demonstrated that hip measurements were superior to the spine in overall fracture prediction. ${ }^{44}$ This may have contributed to an underestimation of osteopenia and it can not be excluded that more differences would have been found if DXA of the spine was also performed. Despite this drawback of the study, we found an even increased BMD of the trabecular bone of the trochanter in untreated patients. Therefore, it is highly unlikely that measuring the BMD of the trabecular bone of the spine would have revealed a decreased BMD compared to the reference population. In addition, the morphometric assessment of vertebral fractures in a subset of patients may have underestimated the prevalence of fractures as well.

In conclusion, we found that in patients with sarcoidosis hip BMD is normal, even if currently or previously treated with glucocorticoid, despite an increased 
bone turnover. As the increased bone resorption was found to be related to ACE and SIL-2R, we suggest that this is - at least partly - the result of disease activity. The increased bone formation, which apparently neutralizes the increased bone resorption, may imply that in sarcoidosis mechanisms are involved that compensate for the well-known effects of cytokines in inflammatory diseases on osteoclastogenesis and bone resorption. Nonetheless, vertebral deformities suggestive of fracture were found in a significant number of patients which indicates that patients with sarcoidosis still have a relevant fracture risk. 


\section{References}

1. Hunninghake GW, Costabel U, Ando M, Baughman R, Cordier JF, du BR, Eklund A, Kitaichi M, Lynch J, Rizzato G, Rose C, Selroos O, Semenzato G, Sharma OP. ATS/ERS/WASOG statement on sarcoidosis. American Thoracic Society/European Respiratory Society/World Association of Sarcoidosis and other Granulomatous Disorders. Sarcoidosis Vasc Diffuse Lung Dis. 1999;16:149-173.

2. Baughman RP, Lower EE, du Bois RM. Sarcoidosis. Lancet. 2003;361:1111-1118.

3. Drent M, Wirnsberger RM, De Vries J, van Dieijen-Visser MP, Wouters EF, Schols AM. Association of fatigue with an acute phase response in sarcoidosis. Eur Respir $\mathrm{J}$. 1999;13:718-722.

4. Hoitsma E, Marziniak M, Faber CG, Reulen JP, Sommer C, de BM, Drent M. Small fibre neuropathy in sarcoidosis. Lancet. 2002;359:2085-2086.

5. Rizzato G. Clinical impact of bone and calcium metabolism changes in sarcoidosis. Thorax. 1998;53:425-429.

6. Fallon MD, Perry HM, III, Teitelbaum SL. Skeletal sarcoidosis with osteopenia. Metab Bone Dis Relat Res. 1981;3:171-174.

7. Tervonen S, Karjalainen P, Valta R. Bone mineral in sarcoidosis. Acta Med Scand. 1974; 196:497-503.

8. Rottoli P, Gonnelli S, Silitro S, Zacchei F, Fabbrini D, Gennari C, Vagliasindi M. Alterations in calcium metabolism and bone mineral density in relation to the activity of sarcoidosis. Sarcoidosis. 1993;10:161-162.

9. Conron M, Young C, Beynon HL. Calcium metabolism in sarcoidosis and its clinical implications. Rheumatology (Oxford). 2000;39:707-713.

10. Girgis RE, Basha MA, Maliarik M, Popovich J, Jr., lannuzzi MC. Cytokines in the bronchoalveolar lavage fluid of patients with active pulmonary sarcoidosis. Am J Respir Crit Care Med. 1995;152:71-75.

11. Sahashi K, Ina Y, Takada K, Sato T, Yamamoto M, Morishita M. Significance of interleukin 6 in patients with sarcoidosis. Chest. 1994;106:156-160.

12. Manolagas SC. The role of IL-6 type cytokines and their receptors in bone. Ann N Y Acad Sci. 1998;840:194-204.

13. Scheidt-Nave C, Bismar H, Leidig-Bruckner G, Woitge H, Seibel MJ, Ziegler R, Pfeilschifter J. Serum interleukin 6 is a major predictor of bone loss in women specific to the first decade past menopause. J Clin Endocrinol Metab. 2001;86:2032-2042.

14. Montemurro L, Fraioli P, Rizzato G. Bone loss in untreated longstanding sarcoidosis. Sarcoidosis. 1991;8:29-34.

15. Sipahi S, Tuzun S, Ozaras R, Calis HT, Ozaras N, Tuzun F, Karayel T. Bone mineral density in women with sarcoidosis. J Bone Miner Metab. 2004;22:48-52.

16. Adler RA, Funkhouser HL, Petkov VI, Berger MM. Glucocorticoid-induced osteoporosis in patients with sarcoidosis. Am J Med Sci. 2003;325:1-6.

17. Drent M, Jacobs JA, Cobben NA, Costabel U, Wouters EF, Mulder PG. Computer program supporting the diagnostic accuracy of cellular BALF analysis: a new release. Respir Med. 2001;95:781-786.

18. Quanjer PH, Tammeling GJ, Cotes JE, Pedersen OF, Peslin R, Yernault JC. Lung volumes and forced ventilatory flows. Report Working Party Standardization of Lung Function Tests, European Community for Steel and Coal. Official Statement of the European Respiratory Society. Eur Respir J Suppl. 1993;16:5-40.

19. DeRemee RA. The roentgenographic staging of sarcoidosis. Historic and contemporary perspectives. Chest. 1983;83:128-133.

20. Heijckmann AC, Huijberts MS, Geusens P, De VJ, Menheere PP, Wolffenbuttel BH. Hip bone mineral density, bone turnover and risk of fracture in patients on long-term suppressive Lthyroxine therapy for differentiated thyroid carcinoma. Eur J Endocrinol. 2005;153:23-29.

21. Duboeuf F, Bauer DC, Chapurlat RD, Dinten JM, Delmas P. Assessment of vertebral fracture using densitometric morphometry. J Clin Densitom. 2005;8:362-368. 
22. Genant HK, Wu CY, van KC, Nevitt MC. Vertebral fracture assessment using a semiquantitative technique. J Bone Miner Res. 1993;8:1137-1148.

23. Van der Veer E, Koerts K, Wagenmakers L, Hoving J, Hegeman JH, Slaets JPJ, Willemsen G, Van Nieuwpoort J, Ten Duis HJ, Kreeftenberg HG. Effect of fracture on bone turnover markers in daily clinical practice. J Bone Miner Res 2005; (20 supplement 1) S 225-226.

24. Elders PJ, Netelenbos JC, Lips P, Khoe E, Van Ginkel FC, Hulshof KF, Van der Stelt PF. Perimenopausal bone mass and risk factors. Bone Miner. 1989;7:289-299.

25. Gravallese EM, Goldring SR. Cellular mechanisms and the role of cytokines in bone erosions in rheumatoid arthritis. Arthritis Rheum. 2000;43:2143-2151.

26. Pennisi P, Trombetti A, Rizzoli R. Glucocorticoid-induced osteoporosis and its treatment. Clin Orthop Relat Res. 2006;443:39-47.

27. Canalis E, Bilezikian JP, Angeli A, Giustina A. Perspectives on glucocorticoid-induced osteoporosis. Bone. 2004;34:593-598.

28. Hofbauer LC, Schoppet M. Clinical implications of the osteoprotegerin/RANKL/RANK system for bone and vascular diseases. JAMA. 2004;292:490-495.

29. Hofbauer LC, Heufelder AE. The role of osteoprotegerin and receptor activator of nuclear factor kappaB ligand in the pathogenesis and treatment of rheumatoid arthritis. Arthritis Rheum. 2001;44:253-259.

30. Drent M, van den Berg R, Haenen GR, van den Berg H, Wouters EF, Bast A. NF-kappaB activation in sarcoidosis. Sarcoidosis Vasc Diffuse Lung Dis. 2001;18:50-56.

31. Culver DA, Barna BP, Raychaudhuri B, Bonfield TL, Abraham S, Malur A, Farver CF, Kavuru MS, Thomassen MJ. Peroxisome proliferator-activated receptor gamma activity is deficient in alveolar macrophages in pulmonary sarcoidosis. Am J Respir Cell Mol Biol. 2004;30:1-5.

32. Franchimont $\mathrm{N}$, Wertz $\mathrm{S}$, Malaise $\mathrm{M}$. Interleukin-6: An osteotropic factor influencing bone formation? Bone. 2005;37:601-606.

33. Muller-Quernheim J. Sarcoidosis: immunopathogenetic concepts and their clinical application. Eur Respir J. 1998;12:716-738.

34. Rothkrantz-Kos S, van Dieijen-Visser MP, Mulder PG, Drent M. Potential usefulness of inflammatory markers to monitor respiratory functional impairment in sarcoidosis. Clin Chem. 2003;49:1510-1517.

35. Ganesan K, Teklehaimanot S, Tran TH, Asuncion M, Norris K. Relationship of C-reactive protein and bone mineral density in community-dwelling elderly females. J Natl Med Assoc. 2005;97:329-333.

36. Provvedini DM, Tsoukas CD, Deftos LJ, Manolagas SC. 1,25-dihydroxyvitamin D3 receptors in human leukocytes. Science. 1983;221:1181-1183.

37. Clowes JA, Riggs BL, Khosla S. The role of the immune system in the pathophysiology of osteoporosis. Immunol Rev. 2005;208:207-227.

38. Seeman E, Delmas PD. Bone quality--the material and structural basis of bone strength and fragility. N Engl J Med. 2006;354:2250-2261.

39. Chavassieux P, Seeman E, Delmas PD. Insights into material and structural basis of bone fragility from diseases associated with fractures: how determinants of the biomechanical properties of bone are compromised by disease. Endocr Rev. 2007;28:151-164.

40. O'Neill TW, Felsenberg D, Varlow J, Cooper C, Kanis JA, Silman AJ. The prevalence of vertebral deformity in European men and women: the European Vertebral Osteoporosis Study. J Bone Miner Res. 1996;11:1010-1018.

41. McCloskey EV, Spector TD, Eyres KS, Fern ED, O'Rourke N, Vasikaran S, Kanis JA. The assessment of vertebral deformity: a method for use in population studies and clinical trials. Osteoporos Int. 1993;3:138-147.

42. Eastell R, Cedel SL, Wahner HW, Riggs BL, Melton LJ, III. Classification of vertebral fractures. J Bone Miner Res. 1991;6:207-215.

43. Black DM, Palermo L, Nevitt MC, Genant HK, Epstein R, San VR, Cummings SR. Comparison of methods for defining prevalent vertebral deformities: the Study of Osteoporotic Fractures. J Bone Miner Res. 1995; 10:890-902.

44. Leslie WD, Tsang JF, Caetano PA, Lix LM. Effectiveness of bone density measurement for predicting osteoporotic fractures in clinical practice. J Clin Endocrinol Metab. 2007;92:77-81. 


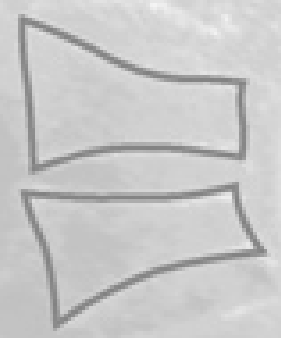

\section{Chapter}

Progressive vertebral deformities despite unchanged bone mineral density in patients

with sarcoidosis: a 4 year follow-up study

AC Heijckmann, M Drent, B Dumitrescu, J De Vries, AC Nieuwenhuijzen Kruseman, BHR Wolffenbuttel, P Geusens, MSP Huijberts

Osteoporos Int, in press 


\section{Abstract}

\section{Background}

Previous studies from our group have shown that morphometric vertebral deformities suggestive of fractures can be found in $20 \%$ of patients with sarcoidosis, despite a normal bone mineral density (BMD). The aim of this study was to determine the incidence of new and/or progressive vertebral deformities and the evolution of BMD during the course of this disease.

\section{Methods}

BMD of the hip (DXA) and vertebral fracture assessment (VFA) with lateral single energy densitometry was performed at baseline and after 45 months (range 35-49) in 66 patients with sarcoidosis. In addition, clinical risk factors and glucocorticoid use were assessed. Potential predictors of new and/or progressive vertebral deformities were assessed using logistic regression analysis.

\section{Results}

The BMD of the total group was unchanged after follow-up, even in the groups with current or previous glucocorticoid use. The prevalence of vertebral deformities increased from 20 to $32 \%$ p $<0.05$ ) of all subjects, and in 17 subjects $(26 \%)$ one or more new or progressive vertebral deformities were diagnosed. Logistic regression analysis revealed that a lower T-score of the femoral neck at baseline $(\mathrm{OR}=2.5(\mathrm{Cl}: 1.0-5.9), \mathrm{p}<0.05)$ and a mother with a hip fracture $(\mathrm{OR}=14.1$ $(\mathrm{Cl}: 1.4-142.6), \mathrm{p}<0.05)$ were determinants of new and/or progressive vertebral deformities.

\section{Conclusions}

Our study shows that in subjects with sarcoidosis the number of vertebral deformities increases in the course of this disease, despite unchanged BMD. The combination of a low normal BMD and a family history of fragility fractures confers an increased risk of the incidence of these deformities. 


\section{Introduction}

Sarcoidosis is a T-cell driven chronic inflammatory disease. Although chronic inflammation has been associated with decreased bone mineral density as a result of the effects of cytokines on bone metabolism, ${ }^{1-4}$ we and others could not demonstrate changes in BMD in subjects with this condition, even if treated with glucocorticoids (GCs). In a cross-sectional study of 124 subjects with sarcoidosis, BMD values similar to an age- and sex-matched reference population were found. ${ }^{5}$ Comparable observations were made in three small studies in untreated patients. ${ }^{6-8}$ These studies also found a normal BMD relative to age and sex-matched controls, except for a small group of postmenopausal women in which BMD was moderately decreased at the spine in longstanding sarcoidosis only. ${ }^{7}$

Although in our cross-sectional study normal BMD values were observed, increased levels of the bone resorption marker serum carboxy-terminal crosslinked telopeptide of type I collagen (ICTP) and the bone formation marker serum procollagen type I amino-terminal propeptide (PINP) suggestive of increased bone turnover were found. ${ }^{5}$ ICTP levels correlated with markers of disease activity such as soluble IL-2 receptor (sIL-2R) and angiotensin converting enzyme (ACE). In addition, vertebral deformities suggestive of fractures were demonstrated in $20 \%$ of the subjects studied in this series. This may imply that the fracture risk in sarcoidosis is increased due to an increased bone turnover with consequent changes in microarchitecture and decrease of bone strength which is not reflected by changes in BMD. ${ }^{9,10}$

If so, this may result in progressive vertebral deformities during the course of the disease. For this reason we re-examined individuals with sarcoidosis four years after the initial measurements to determine the incidence of new and/or progressive vertebral deformities and their relation with changes in BMD.

\section{Subjects and methods}

\section{Subjects}

Sixty-six of the 124 subjects with sarcoidosis that were studied in $2002^{5}$ agreed to participate in the follow-up study performed in 2006. None of the 58 subjects who declined or were unable to participate had impaired mobility or a history of vertebral fractures. The mean age of this group was 45 years and did not differ with respect to gender or glucocorticoid (GC) use from the group of subjects that were re-examined in 2006.

Demographic, clinical and treatment data of the subjects studied in 2002 and 2006 are summarized in Table 6.1. 
$86 \mid$ Chapter 6

Table 6.1 Baseline and follow-up demographic, clinical, and treatment variables $(n=66)$.

\begin{tabular}{|c|c|c|c|}
\hline Variable & $\begin{array}{c}\text { Baseline } \\
(n=66)\end{array}$ & $\begin{array}{l}\text { Follow-up } \\
(n=66)\end{array}$ & $p^{*}$ \\
\hline \multicolumn{4}{|l|}{ Demographic variables } \\
\hline Female sex & $33(50 \%)$ & & \\
\hline Postmenopausal & $11(17 \%)$ & $14(21 \%)$ & ns \\
\hline Age (years) & $43(20-66)$ & & \\
\hline Body mass index $\left(\mathrm{kg} / \mathrm{m}^{2}\right)$ & $26.9 \pm 5.7$ & $27.2 \pm 5.3$ & ns \\
\hline Smoking & $7(11 \%)$ & & \\
\hline Daily dietary calcium intake (mg) & $740(110-2360)$ & $758(150-1340)$ & ns \\
\hline \multicolumn{4}{|l|}{ Clinical variables } \\
\hline Disease duration (years) & $3(1-22)$ & $7(5-26)$ & \\
\hline Chest X-ray stage (0-I-II-III-IV) & $24 / 11 / 12 / 16 / 3$ & $27 / 5 / 12 / 15 / 7$ & ns \\
\hline FEV1 ( $\%$ of predicted) & $87 \pm 28$ & $91 \pm 26$ & ns \\
\hline DLCO (\% of predicted) & $87 \pm 16$ & $92 \pm 18$ & ns \\
\hline Physical activity & $8.6 \pm 3.7$ & $8.1 \pm 3.7$ & ns \\
\hline \multicolumn{4}{|l|}{ Laboratory values (in serum) } \\
\hline Calcium (mmol/l) & $2.4 \pm 0.1$ & $2.4 \pm 0.08$ & ns \\
\hline 1,25(OH)2D3 (nmol/l) & $0.14 \pm 0.03$ & & \\
\hline $\mathrm{ACE}(\mathrm{U} / \mathrm{l})$ & $22.5 \pm 9.8$ & $15.3 \pm 7.9$ & 0.001 \\
\hline sIL-2R (kU/l) & $654(188-4315)$ & & \\
\hline Hs-CRP (mg/l) & $3.2(0.2-191)$ & $2.0(1-16)$ & $<0.05$ \\
\hline Z-score ICTP & $0.7 \pm 1.4$ & & \\
\hline Z-score PINP & $-0.1 \pm 0.9$ & & \\
\hline \multicolumn{4}{|l|}{ Treatment variables } \\
\hline GC use never & $31(47)$ & $26(39)$ & ns \\
\hline GC use previous & $14(21)$ & $25(38)$ & $<0.01$ \\
\hline GC use current & $21(32)$ & $15(23)$ & ns \\
\hline Lifetime GC dose (mg) & $9240(200-48750)$ & $11187(200-56700)$ & $<0.001$ \\
\hline Daily dose (mg) & $12.4 \pm 6.2$ & $10.5 \pm 3.3$ & $<0.05$ \\
\hline $\begin{array}{l}\text { Started on bisphosphonates after } \\
\text { baseline measurement }\end{array}$ & & $6(9)$ & \\
\hline \multicolumn{4}{|l|}{ Clinical risk factors for osteoporosis } \\
\hline Fracture $>50$ years & $2(2 / 24=8 \%)$ & $5(5 / 28=18 \%)$ & ns \\
\hline Low body weight $(<60 \mathrm{~kg})$ & $8(12)$ & $7(11)$ & ns \\
\hline Severe immobilization & 0 & 0 & ns \\
\hline Low physical activity index $\leq 5$ & $18(27)$ & $18(27)$ & ns \\
\hline Mother with hip fracture & $6(9)$ & $7(11)$ & ns \\
\hline
\end{tabular}

Data are given as mean $\pm S D$, median (range) or number $(\%) ; "=p$ value between baseline and follow-up measurement. Reference parameters: Calcium: 2.1-2.6 mmol/l; 1,25(OH)2D3 0.040$0.200 \mathrm{nmol} / \mathrm{l}$; ACE: 9-25 U/l; sIL-2R: 241-846 KU/l; hs-CRP: <10 mg/l. Abbreviations: GC, glucocorticoid; FEV1, forced expiratory volume in one second; DLCO, diffusion capacity for carbon monoxide; 1,25(OH)2D3, 1,25 dihydroxyvitamin D; ACE, angiotensin converting enzyme; slL-2R, soluble interleukin-2 receptor; Hs-CRP, high-sensitivity C-reactive protein; ICTP, carboxy-terminal cross-linked telopeptide of type I collagen; PINP, procollagen type I amino-terminal propeptide.

The group consisted of 22 pre-menopausal women, 11 post-menopausal women, and 33 men; median age of the total group (all Caucasian) was 43 years (20-66 y). The clinical records of all patients were reviewed. In 2002 patients were evaluated according to a standard protocol that included questionnaires, measurement of height and weight, lung function, 
measurement of BMD, a single energy densitometry of the spine, and laboratory evaluation. ${ }^{5}$ In 2006 the same protocol was repeated with exception of the lung function tests. Informed consent was obtained from all participants and the study was approved by the medical ethics committee of our institution.

\section{Pulmonary evaluation}

Lung function measurements, including forced expiratory volume in one second (FEV1) and forced vital capacity (FVC), were measured with a pneumotachograph. The diffusion capacity for carbon monoxide (DLCO) was measured using the single-breath method (both Masterlab, Jaeger, Würzburg, Germany). Values were expressed as a percentage of those predicted. ${ }^{11}$

Chest radiographs were graded according to the radiographic staging of DeRemee (0 to III), adding stage IV, the end stage of lung fibrosis. ${ }^{12,13}$ All interpretations were made by a radiologist who was blinded to the patient's history.

\section{Laboratory assays}

Serum 1,25-dihydroxyvitamin $D$ concentration was determined by radioimmuno-assay using a commercially available kit (IDS Ltd, Boldon, England, interassay coefficient of variation (IE-CV) 18\%, intra-assay CV (IACV) $15 \%$ ). High-sensitivity C-reactive protein (hs-CRP) was measured by particle-enhanced immunonephelometry on the BN Prospec (Dade Behring). The detection limit is $0.175 \mathrm{mg} / \mathrm{l}$ and the measuring range is $0.175-1100 \mathrm{mg} / \mathrm{l}$. Soluble IL-2 receptor (sIL-2R) was determined on the IMMULITE automated analyzer, by means of a two-site chemiluminescent enzyme immunometric assay with a measuring range of 50-7500 kU/l (Diagnostic Product Corporation, Los Angeles, CA, cat no LKIP1). Serum angiotensin converting enzyme (ACE) was measured using a colorimetric method. The precision of the ACE assay was $<5.6 \%$ and the reference interval for ACE was $9-25 \mathrm{U} / \mathrm{l}$.

As a marker for bone formation, serum procollagen type I amino-terminal propeptide (PINP) was measured. As a marker for bone resorption, serum carboxy-terminal cross-linked telopeptide of type I collagen (ICTP) was assessed. Both PINP (IE-CV 3.2\%, IA-CV 2.5\%, lowest detectable concentration $0.4 \mu \mathrm{g} / \mathrm{I}$ ) and ICTP (IE-CV 3.5\%, IA-CV 2.3\%, lowest detectable concentration $<0.1 \mu \mathrm{g} / \mathrm{l}$ ) were measured using commercial RIA kits (Orion Diagnostica Oy, Espoo, Finland). To adjust for age and gender Z-scores for these bone markers were obtained using a Dutch reference group (300 women, 150 men), checked for normal BMD of the lumbar spine and femur and normal 25 -hydroxyvitamin-D levels. ${ }^{14}$ 


\section{Bone Mineral Density and Vertebral Morphometry}

Bone mineral density (BMD) was measured by dual X-ray absorptiometry (DXA, Hologic QDR 4500). In 2002 only the BMD of the hip was measured. In 2006 the BMD of both the hip and of the lumbar spine were determined. As reference group the NHANES III database (sex- and age-matched) was used. A standard protocol as described previously was used for measurement of BMD. To adjust for age and gender, Z-scores were used. To examine changes in Z-scores between baseline and follow-up measurements a $\Delta Z$-score was calculated reflecting the difference between the Z-score at follow-up and the Zscore at baseline.

Furthermore, after bone density measurement a lateral single energy densitometry of the thoracic and lumbar spine for vertebral fracture assessment (VFA) was performed (also called Morphometric X-ray absorptiometry $(\mathrm{MXA})){ }^{15}$ The scans obtained were analyzed twice by one trained operator (intra-observer correlation: 0.85), using the quantitative method of Genant. ${ }^{16}$ The observer was blinded to the T-score values and to the values of the first set of measurements. After visual examination six points were placed on each vertebral body from T4 to L4. From these points three vertebral heights were measured anterior $(\mathrm{Ha})$, mid $(\mathrm{Hm})$ and posterior $(\mathrm{Hp})$; On the basis of the average score of these morphometric measurements ratios were calculated and a prevalent vertebral deformity was defined as a reduction of height of $20 \%$ or more $(\mathrm{Ha} / \mathrm{Hp} ; \mathrm{Hm} / \mathrm{Hp}$ and $\mathrm{Hp} / \mathrm{Hp}$ below). Severity of deformities was assessed using the scoring system of Genant. ${ }^{16}$ A score of ' 0 ' was assigned to normal, non-fractured vertebra; ' 1 ' for a mild deformity (20-25\% reduction in anterior, middle or posterior vertebral height); ' 2 ' for a moderate deformity (25-40\% reduction) and ' 3 ' for a severe deformity ( $>40 \%$ reduction). A new vertebral deformity was scored if a normal vertebra (grade 0 ) became deformed (grade $\geq 1$ ) and a progressive deformity if the grade increased. ${ }^{16}$

\section{Questionnaires}

Calcium intake of all patients was scored in 2002 as well as 2006 on the basis of a detailed dietary list. Known clinical risk factors for osteoporosis (weight below $60 \mathrm{~kg}$, mother with hip fracture, history of fractures after age 50, menopausal status and severe immobilization) as well as daily activities and exercise were assessed by a validated questionnaire, ${ }^{17}$ in which sports, daily and work activities are scored with a minimum of zero and a maximum of eighteen. GC therapy was evaluated by means of a patient questionnaire and verified using all the records of the patient's pharmacist. It was scored as never, previous or current use and if subjects were currently using GCs, the daily dose was noted. 


\section{Statistics}

Student t-tests, chi-square tests, and one-way ANOVAs were used, depending on the variables and subgroups tested. Depending on the analysis, change scores or actual scores were used. Patients with new and/or progressive vertebral deformity were clustered for the multivariate and the receiveroperating characteristics (ROC) analysis. Multivariate logistic regression analyses was performed to assess the strength of association between the incidence of new and/or progressive vertebral deformities and gender, age, weight, clinical risk factors, GC use, lifetime GC dose, daily GC dose, disease activity, bone markers, calcium intake, physical activity and BMD measurements. The variables that were entered in the multivariable analysis were those variables that appeared related $(p<0.10)$ to this outcome measure in univariate analyses. Odds ratio (OR) and its $95 \%$ confidence intervals (Cl) were calculated by using SPSS version 12.0. ROC analysis was used to assess the ability of various levels of the T-score femoral neck to predict the incidence of a new and/or progressive vertebral deformity. The ROC curve indicates the probability of a true-positive result as a function of the probability of a false-positive result for all possible threshold values. ${ }^{18} \mathrm{~A} p$ value $<0.05$ was considered statistically significant.

\section{Results}

\section{Bone mineral density and bone turnover parameters}

The results of BMD measurements are shown in Table 6.2. The BMD of the total group remained unchanged after a median follow-up of 45 months (range 35-49 months). When stratifying patients according to GC use, also no decrease in each of the subgroups was found. Patients that never used GCs showed a $\Delta Z$ Z-score of the femoral neck (FN) of $0.03 \pm 0.36$ and a $\Delta Z$-score of the trochanter of $-0.08 \pm 0.37$. In patients with previous use of GCs these $\Delta$ $Z$-scores were $0.10 \pm 0.36$ and $0.22 \pm 0.43$ respectively. Even the group currently on GCs revealed no decrease of Z-score ( $\Delta$ Z-score FN: $0.06 \pm 0.30$ and $\Delta$ $Z$-score trochanter: $0.00 \pm 0.18)$ and also the subgroup of postmenopausal women $(n=11)$ did not show significant bone loss ( $\triangle Z$-score FN: $0.06 \pm 0.45$ and $\Delta Z$-score trochanter: $-0.05 \pm 0.52$ ). In the total group, bone turnover parameters at baseline showed an increased Z-score of ICTP compared to norm scores (0.7, 95\% confidence interval $(\mathrm{Cl}): 0.4-1.1 ; p<0.001)$; on the other hand, the marker of bone formation (Z-score PINP) did not differ from the reference population. 
Table 6.2 BMD variables at baseline and follow-up for the total group ( $n=66$, median follow-up duration 45 months (range 35-49 months).

\begin{tabular}{|c|c|c|c|}
\hline \multirow{2}{*}{$\begin{array}{l}\text { Variable } \\
\text { BMD }\left(\mathrm{gm} / \mathrm{cm}^{2}\right)\end{array}$} & \multicolumn{2}{|c|}{ Baseline measurement Follow-up measurement } & \multirow[t]{2}{*}{$p^{*}$} \\
\hline & & & \\
\hline Femoral neck & $0.84 \pm 0.12$ & $0.83 \pm 0.12$ & ns \\
\hline Trochanter & $0.74 \pm 0.13$ & $0.74 \pm 0.12$ & ns \\
\hline Total hip & $0.97 \pm 0.13$ & $0.98 \pm 0.14$ & ns \\
\hline Lumbar spine & & $1.04 \pm 0.14$ & \\
\hline \multicolumn{4}{|l|}{ Z-score } \\
\hline Femoral neck & $0.17 \pm 1.0$ & $0.23 \pm 1.1$ & ns \\
\hline Trochanter & $0.27 \pm 1.1$ & $0.32 \pm 1.1$ & ns \\
\hline Total hip & $0.18 \pm 1.0$ & $0.32 \pm 1.0$ & 0.001 \\
\hline Lumbar spine & & $0.03 \pm 1.4$ & \\
\hline \multicolumn{4}{|l|}{ T-score } \\
\hline Femoral neck & $-0.42 \pm 1.0$ & $-0.46 \pm 1.0$ & ns \\
\hline Trochanter & $-0.02 \pm 1.1$ & $-0.03 \pm 1.0$ & ns \\
\hline Total hip & $-0.14 \pm 1.0$ & $-0.10 \pm 1.0$ & ns \\
\hline Lumbar spine & & $-0.50 \pm 1.3$ & \\
\hline
\end{tabular}

Data are given as mean $\pm S D$; Abbreviations: $B M D=$ bone mineral density; * $p$ value between baseline and follow-up measurement.

\section{Clinical fractures and vertebral deformities}

Three new non-vertebral fractures occurred during the follow-up period. These included a hip fracture (twice in the same patient), an ankle fracture and a fracture of the thumb. All these fractures were related to trauma and occurred in subjects older than 50 years.

Morphometric data are summarized in Table 6.3. In 2002 vertebral deformities (ratio of $<0.80$ ) were found in 19 vertebrae of 13 subjects. Seventeen of these were wedge and 2 biconcave deformities. No crush deformities were seen. The majority of these deformities was found in the low thoracic region. At follow-up a new vertebral deformity was scored if a normal vertebra (grade 0) became deformed (grade $\geq 1$ ) and a progressive deformity if the grade increased. ${ }^{16}$ With this method, 36 vertebral deformities were found in 21 subjects. In one subject a vertebral deformity (ratio 0.78 of T11) found in 2002 was not found at followup (ratio 0.81 ). So, in total 9 new subjects revealed one or more vertebral deformities, which means an increase of vertebral deformities from 20 to $32 \%$ of the subjects studied $(p<0.05)$. From the 21 subjects with a vertebral deformity in 2006, 17 subjects ( $26 \%$ of total group) were diagnosed with one or more new or progressive vertebral deformities and in four subjects the deformity was unchanged compared to baseline. Data on number and severity of the deformities can be found in Table 6.3. Six patients were started on a bisphosphonate after baseline measurement and from these 6 patients, two had a new or progressive vertebral deformity at follow-up.

Comparing the groups with and without new or progressive vertebral deformities at follow-up, no differences in $\Delta Z$-scores of BMD of the trochanter 
or femoral neck (FN) were found ( $\Delta$ Z-score trochanter $-0.02 \pm 0.41$ and $0.08 \pm 0.38$ respectively and $\Delta Z$-score $F N 0.01 \pm 0.32$ and $0.08 \pm 0.35$ ). In addition no differences in baseline Z-scores of ICTP and PINP were seen between these groups. Multivariable logistic regression analysis, including factors that correlated in the univariate analysis, revealed that a T-score of the femoral neck at baseline (OR per 1 SD T-score reduction $=2.5(\mathrm{Cl}: 1.0-5.9), p=0.04)$, and a mother with a hip fracture $(O R=14.1 \quad(\mathrm{Cl}: 1.4-142,6), p=0.02)$ were determinants of a new and/or progressive morphometric vertebral deformity at follow-up measurement. Factors such as age, gender, calcium in take, GC use, daily GC dose, lifetime GC dose, disease activity, bone markers, radiographic stage and disease duration at baseline did not predict new and/or progressive vertebral deformities.

The threshold level of the T-score FN that maximized the combined specificity and sensitivity on the ROC curve (Figure 6.1) was <-0.45 for predicting a new and/or progressive deformity (sensitivity $88 \%$, specificity $51 \%$ ).

Table 6.3 Number and grade of deformities.

\begin{tabular}{lcc}
\hline & Baseline & Follow-up \\
\hline No. of subjects with deformity & $13(20 \%)$ & $21(32 \%)^{*}$ \\
No. of deformities & & 28 \\
mild & 17 & 8 \\
moderate & 2 & 0 \\
severe & 0 & 36 \\
Total & 19 & 2 \\
\hline
\end{tabular}

${ }^{*} \mathrm{P}<0.05$ between number of subjects with deformity at baseline and follow-up.

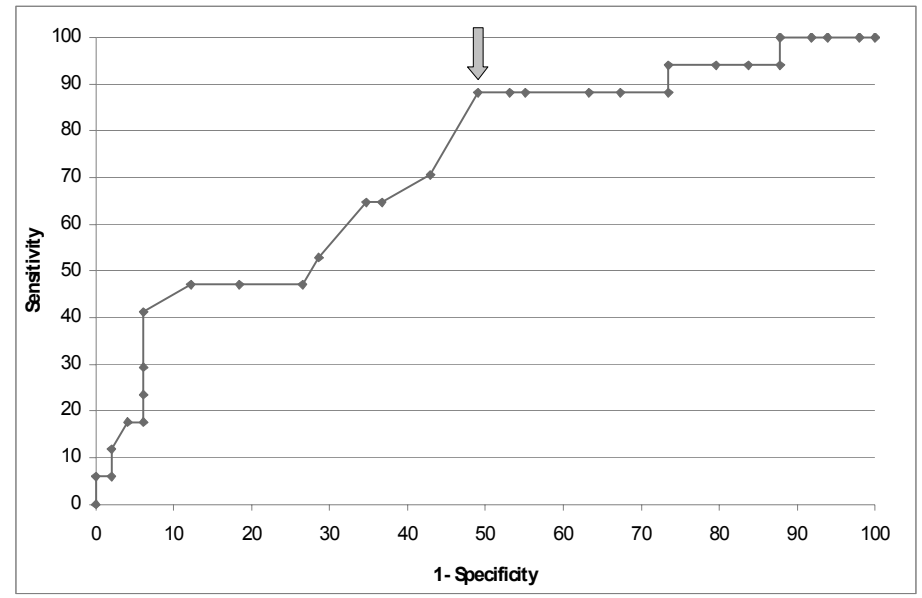

Figure 6.1 ROC curve using Femoral Neck T-score to identify patients with new and/or progressive vertebral deformity. Area under the curve (AUC): 0.72. Arrow: The threshold level of T-score FN that maximized combined specificity and sensitivity was $<-0.45$ (sensitivity $88 \%$, specificity $51 \%$ ) 


\section{Discussion}

In this cohort of subjects with sarcoidosis a high prevalence of morphometric vertebral deformities suggestive of fracture was found, as well as a substantial increase in vertebral deformities during a follow-up period of four years. In 2002 $20 \%$ of subjects were diagnosed with vertebral deformities according to the criteria of Genant, ${ }^{16}$ which increased to $32 \%$ of all subjects in 2006. In parallel, the total number of deformities in these subjects almost doubled. However, BMD of the trochanter and femoral neck did not change over time and BMD of the lumbar spine at follow-up measurement did not differ from the reference population. These data are suggestive of an increased risk of progressive vertebral deformities in individuals with sarcoidosis despite preservation of BMD.

Although data on prevalent or incident fractures in younger healthy populations are lacking, data from other studies suggest that the incidence and prevalence of vertebral deformities in this population are indeed high. Prevalence rates of $30 \%$ asymptomatic vertebral fractures are demonstrated in elderly postmenopausal women on chronic GC therapy using the same techniques. ${ }^{19}$ In a previous study in 60 subjects (mean age $49 \pm 13$ years) with differentiated thyroid carcinoma we found vertebral deformities in $7 \%$ of patients. ${ }^{20}$ Data from the European Vertebral Osteoporosis Study (EVOS), a very large crosssectional population based study on European subjects aged 50 to 79 years, showed a prevalence of vertebral deformities of $12 \%$ (range $6-21 \%$ ) in males and females. ${ }^{21}$ In the Rotterdam study, in which 3469 men and women aged 55 years and older were studied, the prevalence of vertebral deformities suggestive of fracture was $6.9 \%$ in men and $7.5 \%$ in women. ${ }^{22}$ The epidemiology of vertebral fractures in women aged $50-54$ years turned out to vary in different countries from $4.7 \%-11.5 \% .{ }^{23}$ All these studies indicate that the fracture risk in subjects with sarcoidosis is substantial, regardless the differences in populations studied and differences in methodology.

A new vertebral deformity was found in 15 subjects (23\%). To identify incident deformities several approaches can be followed. Measurement of changes in vertebral heights of the same vertebral body from a baseline to a later radiograph in which a decrease in height of 15 or $20 \%$ or $4 \mathrm{~mm}$ is suggestive of fracture, ${ }^{24,25}$ changes in indices of vertebral area ${ }^{26}$ or changes in the number or presence of prevalent deformities. ${ }^{16,27}$ Black and co-workers evaluated these different approaches and concluded that none of these were consistently better than any other method. ${ }^{28}$ As we aimed to assess the change of numbers of subjects with one or more vertebral deformities over time we used the last method, ${ }^{16}$ in which changes in number of prevalent deformities are scored. A comparable approach was followed in the European Prospective Osteoporosis Study (EPOS) ${ }^{29}$ which revealed an incidence of new deformities of $3.4 \%$ after a 
similar follow-up period. As the mean age of subjects included in this study was substantial higher than that of our cohort, these data cannot be used as a reference, although it is likely that in younger age groups even lower incident deformities would be observed. The high prevalence of vertebral deformities at baseline, the significant increase of more than $50 \%$ of subjects after follow-up with one or more deformity and the increase of severity of prevalent deformities all imply that sarcoidosis is a relevant risk factor for vertebral deformity.

What is the underlying mechanism of this predisposition to vertebral deformities in view of the lack of effects on BMD in sarcoidosis? The load bearing capacity of bone, also referred as 'whole bone strength', depends on the amount of bone, the spatial distribution of the bone mass, and the intrinsic properties of the materials that comprise the bone. Thus, properties at the cellular, matrix, micro- and macroarchitectural levels may all impact the mechanical properties of bone. ${ }^{30,31}$ Apparently, in sarcoidosis mechanisms are involved that influence bone strength without having a significant impact on bone mass. As we found in the total group an increased marker of bone resorption (Z-score ICTP) at baseline, one of the possible mechanisms could be increased bone remodelling with a negative effect on bone microarchitecture that is not reflected by a change in BMD. It is well known that chronic inflammatory diseases influence bone physiology by the production of cytokines stimulating bone turnover. ${ }^{1,2,32}$ Increased bone remodelling is associated with an increased bone fragility and thus fracture risk ${ }^{33,34}$ and in postmenopausal women the level of bone turnover turned out to be an as strong and independent predictor of fractures as BMD. ${ }^{35,36}$ These data may support the hypothesis that the chronic inflammatory state in sarcoidosis results in increased bone remodelling with a negative effect on bone strength and thus an increased fracture risk.

No changes in BMD in the group currently treated with GCs were found. This is unexpected as GCs are known to effect BMD via several mechanisms with consequent decrease of BMD. It may well be that this is due to intermittent GC use, as most of our patients were on intermittent glucocorticoids. Other studies have demonstrated that intermittent GC use has no major effects on BMD. ${ }^{37} \mathrm{~A}$ recent large retrospective cohort study on clinical fracture risk among patients from the UK General Practice Research Database showed that intermittent use of high dose of oral GCs was associated with only a small increase in the risk of osteoporotic fractures. ${ }^{38}$

Despite the on average normal BMD, we found T-score of the femoral neck and a family history of hip fractures to be predictors of a new and/or progressive vertebral deformity. This suggests that the combination of a lower BMD in combination with the increased bone turnover in sarcoidosis predisposes to progressive vertebral deformity. If so, this would mean that in these high risk individuals preventive treatment should be considered to reduce 
fracture risk. Controlled trials are needed, however, to substantiate this suggestion.

Limitations of our study are the lack of an age- and sex-matched control population, and the lack of a "gold standard" for VFA. We followed the method of Genant, ${ }^{16}$ which is based on a reduction of the ratios of anterior, middle or posterior heights and all measurements were performed twice to improve accuracy. This is the simplest and most practical method ${ }^{39}$ and an association with future fracture risk is documented. ${ }^{40}$ The above mentioned EVOS study, however, applied the methodology described by McCloskey and Eastell and co-workers in which measurements are corrected for normal variations in vertebral shape. ${ }^{24}$ Relative to the method of Genant, the method of Eastell ${ }^{24}$ or McCloskey ${ }^{27}$ may have resulted in lower prevalences of vertebral deformities. This does however not explain the differences in prevalence of vertebral deformities reported elsewhere and in this paper. The restrictions of the methodology are also the limited ability to provide a differential diagnosis for the detected deformities, a lower sensitivity for milder fractures and the inability to evaluate the uppermost thoracic levels. Other disorders that may cause changes in vertebral shape involve congenital abnormalities and conditions as severe osteoarthritis ${ }^{41}$ and Scheuermann's disease. We have, however, no indications that these relatively rare conditions may have interfered with our observations.

In conclusion, we have shown that in subjects with sarcoidosis the number of vertebral deformities increases during the course of this disease, despite preservation of BMD. It appears that subjects with sarcoidosis have an increased fracture risk, even if BMD is normal. High risk individuals can be identified by a low-normal BMD and by a family history of hip fractures. Probably these individuals will benefit from therapies that increase bone strength. A T-score FN below -0.45 may be used to identify these individuals with a high sensitivity and an acceptable specificity. Studies evaluating the effects of such therapies in individuals with sarcoidosis are however clearly needed. 


\section{References}

1. Hofbauer LC, Schoppet M. Clinical implications of the osteoprotegerin/RANKL/RANK system for bone and vascular diseases. JAMA. 2004;292:490-495.

2. Gravallese EM, Goldring SR. Cellular mechanisms and the role of cytokines in bone erosions in rheumatoid arthritis. Arthritis Rheum. 2000;43:2143-2151.

3. Manolagas SC. The role of IL-6 type cytokines and their receptors in bone. Ann N Y Acad Sci. 1998;840:194-204.

4. Scheidt-Nave C, Bismar H, Leidig-Bruckner G, Woitge H, Seibel MJ, Ziegler R, Pfeilschifter J. Serum interleukin 6 is a major predictor of bone loss in women specific to the first decade past menopause. J Clin Endocrinol Metab. 2001;86:2032-2042.

5. Heijckmann AC, Huijberts MS, De Vries J, et al. Bone turnover and bone mineral density in patients with sarcoidosis. Sarcoidosis Vasc Diffuse Lung Dis. 2007, in press.

6. Tervonen S, Karjalainen P, Valta R. Bone mineral in sarcoidosis. Acta Med Scand. 1974;196:497-503.

7. Montemurro L, Fraioli P, Rizzato G. Bone loss in untreated longstanding sarcoidosis. Sarcoidosis. 1991;8:29-34.

8. Sipahi S, Tuzun S, Ozaras R, Calis HT, Ozaras N, Tuzun F, Karayel T. Bone mineral density in women with sarcoidosis. J Bone Miner Metab. 2004;22:48-52.

9. Seeman E, Delmas PD. Bone quality--the material and structural basis of bone strength and fragility. N Engl J Med. 2006;354:2250-2261.

10. Chavassieux P, Seeman E, Delmas PD. Insights into material and structural basis of bone fragility from diseases associated with fractures: how determinants of the biomechanical properties of bone are compromised by disease. Endocr Rev. 2007;28:151-164.

11. Quanjer PH, Tammeling GJ, Cotes JE, Pedersen OF, Peslin R, Yernault JC. Lung volumes and forced ventilatory flows. Report Working Party Standardization of Lung Function Tests, European Community for Steel and Coal. Official Statement of the European Respiratory Society. Eur Respir J Suppl. 1993;16:5-40.

12. DeRemee RA. The roentgenographic staging of sarcoidosis. Historic and contemporary perspectives. Chest. 1983;83:128-133.

13. Hunninghake GW, Costabel U, Ando M, Baughman R, Cordier JF, du BR, Eklund A, Kitaichi M, Lynch J, Rizzato G, Rose C, Selroos O, Semenzato G, Sharma OP. ATS/ERS/WASOG statement on sarcoidosis. American Thoracic Society/European Respiratory Society/World Association of Sarcoidosis and other Granulomatous Disorders. Sarcoidosis Vasc Diffuse Lung Dis. 1999;16:149-173.

14. Van der Veer E, Koerts K, Wagenmakers L, Hoving J, Hegeman JH, Slaets JPJ, Willemsen G, Van Nieuwpoort J, Ten Duis HJ, Kreeftenberg HG. Effect of fracture on bone turnover markers in daily clinical practice. J Bone Miner Res 2005; (20 supplement 1) S 225-226.

15. Duboeuf F, Bauer DC, Chapurlat RD, Dinten JM, Delmas P. Assessment of vertebral fracture using densitometric morphometry. J Clin Densitom. 2005;8:362-368.

16. Genant HK, Wu CY, van KC, Nevitt MC. Vertebral fracture assessment using a semiquantitative technique. J Bone Miner Res. 1993;8:1137-1148.

17. Elders PJ, Netelenbos JC, Lips P, Khoe E, Van Ginkel FC, Hulshof KF, Van der Stelt PF. Perimenopausal bone mass and risk factors. Bone Miner. 1989;7:289-299.

18. Hanley JA, McNeil BJ. A method of comparing the areas under receiver operating characteristic curves derived from the same cases. Radiology. 1983;148:839-843.

19. Angeli A, Guglielmi G, Dovio A, Capelli G, de FD, Giannini S, Giorgino R, Moro L, Giustina A. High prevalence of asymptomatic vertebral fractures in post-menopausal women receiving chronic glucocorticoid therapy: a cross-sectional outpatient study. Bone. 2006;39:253-259.

20. Heijckmann AC, Huijberts MS, Geusens P, De VJ, Menheere PP, Wolffenbuttel BH. Hip bone mineral density, bone turnover and risk of fracture in patients on long-term suppressive Lthyroxine therapy for differentiated thyroid carcinoma. Eur J Endocrinol. 2005;153:23-29. 
21. O'Neill TW, Felsenberg D, Varlow J, Cooper C, Kanis JA, Silman AJ. The prevalence of vertebral deformity in European men and women: the European Vertebral Osteoporosis Study. J Bone Miner Res. 1996;11:1010-1018.

22. van der Klift M, de Laet CE, McCloskey EV, Hofman A, Pols HA. The incidence of vertebral fractures in men and women: the Rotterdam Study. J Bone Miner Res. 2002;17:1051-1056.

23. Cummings SR, Melton LJ. Epidemiology and outcomes of osteoporotic fractures. Lancet. 2002;359:1761-1767.

24. Eastell R, Cedel SL, Wahner HW, Riggs BL, Melton LJ, III. Classification of vertebral fractures. J Bone Miner Res. 1991;6:207-215.

25. Black DM, Cummings SR, Karpf DB, Cauley JA, Thompson DE, Nevitt MC, Bauer DC, Genant HK, Haskell WL, Marcus R, Ott SM, Torner JC, Quandt SA, Reiss TF, Ensrud KE. Randomised trial of effect of alendronate on risk of fracture in women with existing vertebral fractures. Fracture Intervention Trial Research Group. Lancet. 1996;348:1535-1541.

26. Smith-Bindman R, Steiger $P$, Cummings SR, Genant HK. The index of radiographic area (IRA): a new approach to estimating the severity of vertebral deformity. Bone Miner. 1991;15:137-149.

27. McCloskey EV, Spector TD, Eyres KS, Fern ED, O'Rourke N, Vasikaran S, Kanis JA. The assessment of vertebral deformity: a method for use in population studies and clinical trials. Osteoporos Int. 1993;3:138-147.

28. Black DM, Palermo L, Nevitt MC, Genant HK, Christensen L, Cummings SR. Defining incident vertebral deformity: a prospective comparison of several approaches. The Study of Osteoporotic Fractures Research Group. J Bone Miner Res. 1999;14:90-101.

29. Roy DK, O'Neill TW, Finn JD, Lunt M, Silman AJ, Felsenberg D, Armbrecht G, Banzer D, Benevolenskaya LI, Bhalla A, Bruges AJ, Cannata JB, Cooper C, Dequeker J, Diaz MN, Eastell R, Yershova OB, Felsch B, Gowin W, Havelka S, Hoszowski K, Ismail AA, Jajic I, Janott I, Johnell O, Kanis JA, Kragl G, Lopez VA, Lorenc R, Lyritis G, Masaryk P, Matthis C, Miazgowski T, Gennari C, Pols HA, Poor G, Raspe HH, Reid DM, Reisinger W, Scheidt-Nave C, Stepan JJ, Todd CJ, Weber K, Woolf AD, Reeve J. Determinants of incident vertebral fracture in men and women: results from the European Prospective Osteoporosis Study (EPOS). Osteoporos Int. 2003;14:19-26.

30. Bouxsein ML. Determinants of skeletal fragility. Best Pract Res Clin Rheumatol. 2005;19: 897-911.

31. Sambrook P, Cooper C. Osteoporosis. Lancet. 2006;367:2010-2018.

32. Hofbauer LC, Heufelder AE. The role of osteoprotegerin and receptor activator of nuclear factor kappaB ligand in the pathogenesis and treatment of rheumatoid arthritis. Arthritis Rheum. 2001;44:253-259.

33. Boivin G, Lips P, Ott SM, Harper KD, Sarkar S, Pinette KV, Meunier PJ. Contribution of raloxifene and calcium and vitamin D3 supplementation to the increase of the degree of mineralization of bone in postmenopausal women. J Clin Endocrinol Metab. 2003;88: 4199-4205.

34. Viguet-Carrin S, Garnero P, Delmas PD. The role of collagen in bone strength. Osteoporos Int. 2006;17:319-336.

35. Garnero P, Hausherr E, Chapuy MC, Marcelli C, Grandjean H, Muller C, Cormier C, Breart G, Meunier PJ, Delmas PD. Markers of bone resorption predict hip fracture in elderly women: the EPIDOS Prospective Study. J Bone Miner Res. 1996;11:1531-1538.

36. Melton LJ, III, Khosla S, Atkinson EJ, O'Fallon WM, Riggs BL. Relationship of bone turnover to bone density and fractures. J Bone Miner Res. 1997;12:1083-1091.

37. Frediani B, Falsetti P, Bisogno S, Baldi F, Acciai C, Filippou G, Bacarelli MR, Filipponi P, Galeazzi M, Marcolongo R. Effects of high dose methylprednisolone pulse therapy on bone mass and biochemical markers of bone metabolism in patients with active rheumatoid arthritis: a 12-month randomized prospective controlled study. J Rheumatol. 2004;31: 1083-1087.

38. de Vries F, Bracke M, Leufkens HG, Lammers JW, Cooper C, van Staa TP. Fracture risk with intermittent high-dose oral glucocorticoid therapy. Arthritis Rheum. 2007;56:208-214. 
39. Black DM, Palermo L, Nevitt MC, Genant HK, Epstein R, San VR, Cummings SR. Comparison of methods for defining prevalent vertebral deformities: the Study of Osteoporotic Fractures. J Bone Miner Res. 1995;10:890-902.

40. Lindsay R, Silverman SL, Cooper C, Hanley DA, Barton I, Broy SB, Licata A, Benhamou L, Geusens $P$, Flowers K, Stracke H, Seeman E. Risk of new vertebral fracture in the year following a fracture. JAMA. 2001;285:320-323.

41. Abdel-Hamid OA, Bassiouni H, Koutri R, Nijs J, Geusens P, Dequeker J. Aging of the thoracic spine: distinction between wedging in osteoarthritis and fracture in osteoporosis--a crosssectional and longitudinal study. Bone. 1994;15:437-442. 


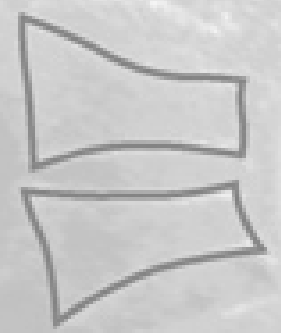

\section{Chapter 7}

Quantitative ultrasound does not identify patients with an inflammatory disease at risk for vertebral deformities

AC Heijckmann, B Dumitrescu, AC Nieuwenhuijzen Kruseman, P. Geusens BHR Wolffenbuttel, J De Vries, M Drent, MSP Huijberts 


\section{Abstract}

\section{Background}

Previous studies from our group have shown that a high prevalence of vertebral deformities suggestive of fracture can be found in patients with an inflammatory disease, despite a near normal bone mineral density (BMD). As quantitative ultrasound (QUS) of the heel can be used for refined assessment of bone strength, we evaluated whether QUS can be used to trace subjects with an inflammatory disease at risk for fracture.

\section{Methods}

246 patients (mean age: $44 \pm 12.4$ years) with an inflammatory disease were studied. QUS of the heel and BMD of the hip (by dual X-ray absorptiometry (DXA)) were measured. Furthermore lateral single energy densitometry of the spine for assessment of vertebral deformities was done. Logistic regression analysis was performed to assess the strength of association between the prevalence of a vertebral deformity and BMD and QUS parameters, adjusted for gender and age.

\section{Results}

Vertebral deformities (ratio of $<0.80$ ) were found in 72 vertebrae of 54 subjects $(22 \%)$. In contrast to the QUS parameters BUA (broadband ultrasound attenuation) and SOS (speed of sound), T-score of QUS and T-scores of the femoral neck and trochanter (DXA) were lower in the group of patients with vertebral deformities. Logistic regression analysis showed that the vertebral deformity risk increases by about 60 to $90 \%$ per 1 SD reduction of BMD determined with DXA but not with QUS.

\section{Conclusions}

We have shown that QUS measurements of the calcaneus in patients with an inflammatory condition are not of value to identify patients at risk for fracture. 


\section{Introduction}

Osteoporosis is a skeletal disease characterized by low bone mass and microarchitectural deterioration resulting in increased bone fragility and hence susceptibility to fracture. ${ }^{1,2}$ The benchmark for the diagnosis of osteoporosis is the assessment of bone mineral density (BMD) with dual energy X-ray absorptiometry (DXA), ${ }^{2}$ as it is well established that the risk of future fracture rises with the decline of BMD. However, low BMD alone is not the only determinant of fracture risk ${ }^{3}$ and it is evident that assessment of fracture risk should encompass all aspects of risk and not be guided exclusively by results of bone mineral density measurements. ${ }^{4}$ In addition, in several conditions BMD evaluation provides a modest prediction of fracture risk. For example, the use of glucocorticoids (GCs) is a substantial risk factor for future fractures, which is largely independent of BMD. ${ }^{5,6}$

We reported recently that a high prevalence of vertebral deformities suggestive of fracture can be found in patients who are considered at risk for secondary osteoporosis due to an inflammatory disease, such as sarcoidosis and inflammatory bowel disease (IBD), despite a near normal BMD. ${ }^{7}$ This may imply that bone strength is decreased in patients with inflammatory diseases, and that changes in bone microarchitecture rather than low BMD result in an increased fracture risk. ${ }^{8,9}$

The last years there has been increasing interest in Quantitative Ultrasound (QUS) methods for refined assessment of bone strength. ${ }^{10}$ This noninvasive technique may assess microarchitecture and elasticity in addition to bone mineral density. ${ }^{11}$ Several studies have demonstrated that QUS of the heel can predict fracture comparable to and independent of spine and femur BMD, and that it can be used to identify patients with higher risk. ${ }^{12-14}$ Compared with DXA, QUS is less expensive, portable, does not require specially trained personnel and does not employ ionizing radiation.

To evaluate whether QUS can indeed be used to identify subjects at risk for fracture irrespective of changes in BMD, we performed QUS on our series of subjects with sarcoidosis and $\mathrm{IBD}^{7}$ and compared the results with results of vertebral fracture assessment and BMD measurements with DXA.

\section{Subjects and methods}

\section{Patients}

This is a cross-sectional study on 246 patients (mean age: $44 \pm 12.4$ years) of which 87 were diagnosed with sarcoidosis and 159 with inflammatory bowel disease. All patients were Caucasians and diagnosed with sarcoidosis 
according to the WASOG guidelines, ${ }^{15}$ based on consistent clinical features and results of an analysis of bronchoalveolar lavage fluid ${ }^{16}$ or with $C D(n=95)$ or UC $(n=64)$ on clinical grounds using endoscopic and/or radiological evidence, and by histological investigation of mucosal biopsies and/or surgical specimens when available. For confirmation of the CD diagnosis the LennardJones criteria ${ }^{17}$ and for UC the Truelove and Witts criteria ${ }^{18}$ were applied.

The clinical records of all patients were reviewed. Demographic, clinical and treatment data of these patients are summarized in Table 7.1. None of the patients was on bisphosphonates.

Table 7.1 Demographic, treatment variables and clinical risk factors in the study patients.

\begin{tabular}{lc}
\hline Variable & $\begin{array}{c}\text { Total group } \\
(\mathrm{n}=246)\end{array}$ \\
\hline Age (years) & $44 \pm 12.4$ \\
Males/premenopausal women/postmenopausal women & $109 / 103 / 34(44 / 42 / 14)$ \\
Body mass index $\left(\mathrm{kg} / \mathrm{m}^{2}\right)$ & $25.5 \pm 4.7$ \\
Sarcoidosis/CD/UC & $87 / 95 / 64(35 / 39 / 26)$ \\
Disease duration (years) & $6(1-36)$ \\
GC use never/ever/current & $74 / 124 / 48(30 / 50 / 20)$ \\
Daily dose GC current group & $12.9(2.5-39)$ \\
Fracture $>50$ years & $2 / 83(2)$ \\
Vertebral deformity by DXA & $54(22)$ \\
Low body weight (<60 kg) & $44(18)$ \\
Low physical activity index $\leq 5$ & $53(22)$ \\
Mother with hip deformity & $16(7)$ \\
\hline
\end{tabular}

Data are given as mean \pm SD, median (range) or number (\%). Abbreviations: $C D$, Crohn's disease; UC, ulcerative colitis; GC, glucocorticoid; DXA, dual-energy X-ray absorptiometry.

Patients were evaluated according to a standard protocol that included questionnaires related to known clinical risk factors for osteoporosis (weight below $60 \mathrm{~kg}$, hip fracture in the mother, history of fractures after age 50, menopausal status and severe immobilization), ${ }^{19}$ calcium intake, physical activity, ${ }^{20}$ measurement of height and weight and measurement of BMD. Glucocorticoid therapy was evaluated by means of a patient questionnaire and verified using all the records of the patient's pharmacist. Informed consent was obtained from all participants and this study was approved by the ethical committee of the hospital.

\section{Bone mineral density and morphometry}

QUS and DXA measurements were performed. QUS was performed in the left calcaneus using a Sahara device (Hologic, Waltham, MA, USA). This equipment measures the broadband ultrasound attenuation (BUA) $(\mathrm{dB} / \mathrm{MHz})$ and the speed of sound $(\mathrm{SOS})(\mathrm{m} / \mathrm{sec})$ in a fixed region of interest in the central 
calcaneal zone. The device combines the values of BUA and SOS to yield a parameter known as the "quantitative ultrasound index" (QUI) or stiffness, based on the following equation: QUI=0.41 * (BUA+SOS) -571 . The $\mathrm{QUI}$ is also expressed as a T-score (reference data were those provided by the manufacturer). The heel of each patient was measured three times with complete repositioning between measurements. The definitive result was the mean of these three measurements. The coefficient of variation (CV) of the QUI was $1.4 \%$. The instrument was subjected to daily quality control using a phantom provided by the manufacturer.

BMD of the hip was measured by dual energy X-ray absorptiometry (DXA, Hologic QDR 4500, NHANES-III reference group). The hip was measured in the standard projection, and results were reported for femoral neck, trochanter and total hip. Standard procedures supplied by the manufacturer for scanning and analysis were performed. Calibration with the manufacturer's spine phantom and quality control analysis was performed daily. The CV for BMD measurements was $1.0 \%$. Furthermore, after bone density measurement a lateral single energy densitometry of the thoracic and lumbar spine for vertebral fracture assessment (VFA) was performed (also called Morphometric X-ray absorptiometry $(\mathrm{MXA})) .{ }^{21}$ The scans obtained were analyzed twice by one trained operator (BD) (intra-observer coefficient of variation: 0.85 ), using the quantitative method of Genant. ${ }^{22}$ The observer was blinded to the T-score values and to the values of the first set of measurements. After visual examination six points were placed on each vertebral body from T4 to L4. From these points three vertebral heights were measured anterior $(\mathrm{Ha}), \mathrm{mid}(\mathrm{Hm})$ and posterior $(\mathrm{Hp})$; On the basis of the average score of these morphometric measurements ratios were calculated and a prevalent vertebral deformity was defined as a reduction of height of $20 \%$ or more $(\mathrm{Ha} / \mathrm{Hp} ; \mathrm{Hm} / \mathrm{Hp}$ and $\mathrm{Hp} / \mathrm{Hp}$ below). ${ }^{22}$ Severity of deformities was assessed according to the method of Genant. ${ }^{22}$ A score of ' 0 ' was assigned to normal, non-fractured vertebra; ' 1 ' for a mild deformity $(20-25 \%$ reduction in anterior, middle or posterior vertebral height); ' 2 ' for a moderate deformity (25-40\% reduction) and ' 3 ' for a severe deformity ( $>40 \%$ reduction).

\section{Statistical analysis}

Student t-tests, chi-square tests, and one-way ANOVAs were used, depending on the variables and subgroups tested. Multivariate logistic regression analyses was performed to assess the strength of association between the prevalence of a vertebral deformity and BMD and QUS parameters, adjusted for gender and age. A $p$ value $<0.05$ was considered statistically significant. Analyses were performed with SPSS version 12.0. 


\section{Results}

As summarized in Table 7.1, our series consisted of 103 pre-menopausal women, 34 post-menopausal women, and 109 men. The mean age ( \pm SD) of this group of patients was $44 \pm 12.4$ years and this was similar in both sarcoidosis and IBD. With QUS, the broadband ultrasound attenuation (BUA) value was higher in men than in women $(78 \pm 16$ versus $73 \pm 15 \mathrm{~dB} / \mathrm{MHz}$, $p<0.005)$. No differences between the sexes of the other QUS parameters were found. The T- or Z-scores of FN or trochanter determined with DXA were not different between the sexes as well.

T-scores of femoral neck and/or trochanter determined with DXA were in the osteopenic (T-score $<-1$ and $>-2.5$ ) or osteoporotic $(\leq-2.5)$ range in respectively $50 \%$ and $2 \%$ of the patients studied, in total in $52 \%$. In contrast, QUS of the calcaneus revealed a T-score below -1 in $32 \%$ of the patients. Correlations between DXA and QUS T-scores were $r=0.35$ for the T-score of the quantitative ultrasound index (QUI) with the T-score of the femoral neck $(p<0.001)$ (Figure 7.1) and $r=0.36$ for the T-score QUI with the T-score of the trochanter $(p<0.001)$.

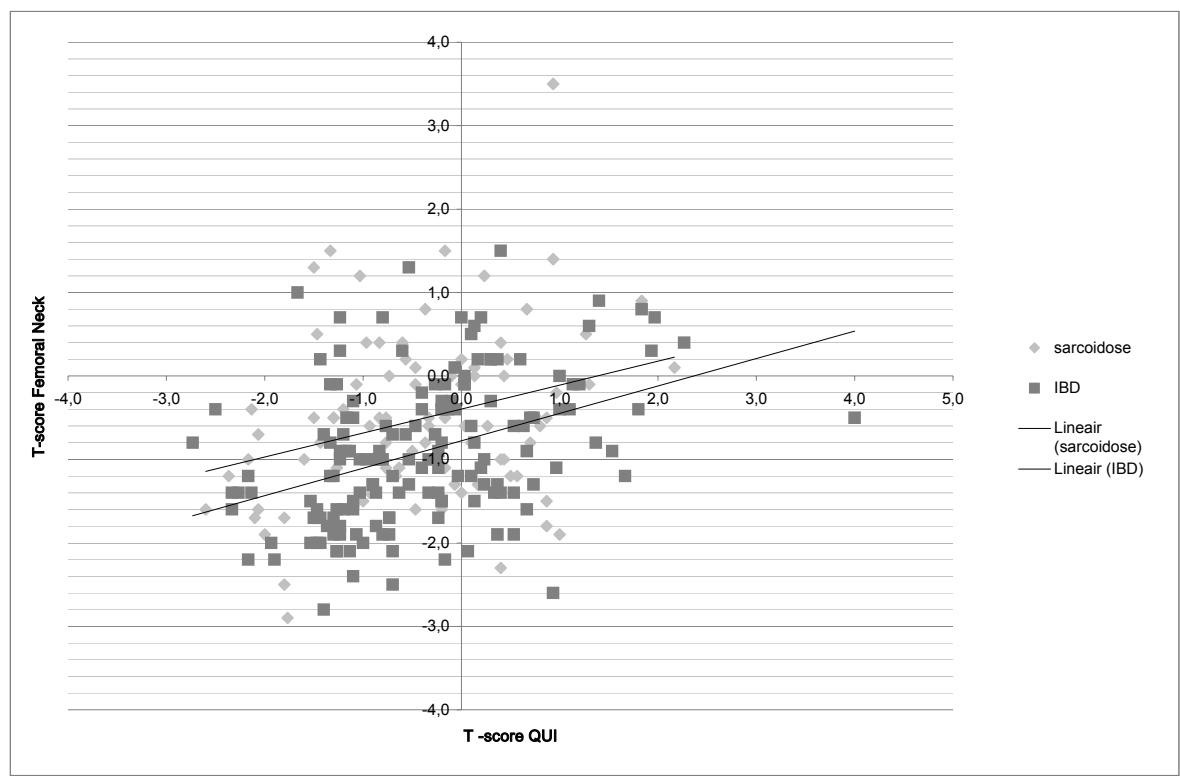

Figure 7.1 T-score Femoral neck (DXA) versus T-score QUI (QUS).

Abbreviations: DXA, dual energy X-ray absorption; QUI, quantitative ultrasound index; QUS, quantitative ultrasound; IBD, inflammatory bowel disease. 
Clinical non-vertebral fractures had occurred in two postmenopausal women. Vertebral deformities with VFA (ratio of $<0.80$ ) were found in 72 vertebrae of 54 subjects $(22 \%)$ with a higher prevalence in men $(32 \%)$ than in women $(14 \%)$. Sixty-one of these were wedge and 9 biconcave deformities. Two crush deformities were seen. Multiple vertebral deformities were observed in $6 \%$ of the entire cohort and $7 \%$ had one or more moderate or severe deformities.

In Table 7.2 data of BMD measurements with DXA and QUS in the group of patients with or without vertebral deformities are summarized. Relative to the patients without vertebral deformities, those with vertebral deformities were on average older, and this group comprised more men. T-scores but not Z-scores of the femoral neck and trochanter (DXA) were lower in the group of patients with vertebral deformities. The T-score of the calcaneus (QUS) was also lower in this group of patients. No differences for the other ultrasound parameters were found between the groups with or without vertebral deformities. Furthermore, no differences were found in clinical risk factors, for the different diseases, GC use, disease duration, BMI, physical activity, calcium intake, current use of calcium and/or vitamin D supplements, aminosalicylates, immunosuppressive medication, and budenoside.

Table 7.2 Bone variables in patients with and without any vertebral deformity, measured morphometrically.

\begin{tabular}{lcccc}
\hline & $\begin{array}{c}\text { Without deformity } \\
(\mathrm{n}=192)\end{array}$ & $\begin{array}{c}\text { With any deformity } \\
(\mathrm{n}=54)\end{array}$ & All & $\mathrm{p}^{*}$ \\
\hline DXA variables & & & & \\
Femoral neck $\left(\mathrm{g} / \mathrm{cm}^{2}\right)$ & $0.80 \pm 0.12$ & $0.76 \pm 0.10$ & $0.79 \pm 0.11$ & $<0.01$ \\
T-score & $-0.66 \pm 0.9$ & $-1.16 \pm 0.8$ & $-0.77 \pm 0.9$ & $<0.001$ \\
Z-score & $-0.13 \pm 1.0$ & $-0.43 \pm 0.9$ & $-0.20 \pm 1.0$ & $\mathrm{~ns}$ \\
Trochanter (g/cm2) & $0.72 \pm 0.13$ & $0.69 \pm 0.10$ & $0.71 \pm 0.13$ & $\mathrm{~ns}$ \\
T-score & $-0.21 \pm 1.0$ & $-0.51 \pm 0.8$ & $-0.27 \pm 1.0$ & $<0.05$ \\
Z-score & $0.05 \pm 1.1$ & $-0.16 \pm 0.8$ & $0.00 \pm 1.0$ & $\mathrm{~ns}$ \\
QUS variables & & & & \\
BUA (dB/MHz) & $76 \pm 16$ & $73 \pm 14$ & $75 \pm 16$ & $\mathrm{~ns}$ \\
SOS (m/s) & $1545 \pm 89$ & $1531 \pm 99$ & $1542 \pm 92$ & $\mathrm{~ns}$ \\
QUI & $103 \pm 45$ & $94 \pm 16$ & $101 \pm 41$ & $\mathrm{~ns}$ \\
T-score & $-0.34 \pm 1.1$ & $-0.65 \pm 0.9$ & $-0.41 \pm 1.0$ & $<0.05$ \\
\hline
\end{tabular}

Data are given as mean \pm SD or number $(\%)$; ${ }^{*} p$ between patients with and without vertebral deformity; Abbreviations: DXA, dual-energy X-ray absorption; QUS, quantitative ultrasound; BUA, broadband ultrasound attenuation; SOS, speed of sound; QUI, quantitative ultrasound index.

Table 7.3 gives odds ratios (OR) per 1 SD T-score reduction for any vertebral deformity for the three separate regression analyses. The vertebral deformity risk increases by about 60 to $90 \%$ per 1 SD reduction determined with DXA but not with QUS. 
Table 7.3 Odds ratios for any vertebral deformity per 1 SD T-score reduction of various bone measurements adjusted for gender and age in patients with an inflammatory disease.

\begin{tabular}{lccc}
\hline & OR & $95 \% \mathrm{Cl}$ & $\mathrm{p}$ \\
\hline BMD femoral neck & 1.88 & $1.26-2.81$ & 0.002 \\
BMD trochanter & 1.63 & $1.12-2.37$ & 0.01 \\
QUI & 1.31 & $0.95-1.81$ & $\mathrm{~ns}$ \\
\hline
\end{tabular}

Abbreviations: OR, odds ratio; $\mathrm{BMD}$, bone mineral density; $\mathrm{Cl}$, confidence interval; $\mathrm{QUI}$, quantitative ultrasound index.

\section{Discussion}

Our study shows that in a group of patients with an inflammatory disease as sarcoidosis and inflammatory bowel disease (IBD) none of the QUS variables had added value to recognize patients with a prevalent vertebral deformity suggestive of fracture.

In several other studies QUS has been compared with DXA in patients with IBD. Robinson and co-workers ${ }^{23}$ studied 100 patients with Crohn's disease (CD) and 52 age-matched controls and found lower values of both BUA and SOS in CD. The correlation between BUA and BMD-values determined at the hip and spine with DXA was, however, insufficient to recommend QUS as a screening tool. In another study, 53 patients with CD and 57 with ulcerative colitis (UC) were included and QUS variables (BUA and SOS) were compared with DXA-measurements of the hip and lumbar spine. ${ }^{24}$ Although this study also revealed a correlation between the QUS variables and DXA ( $r=0.50$ to 0.67 ), the agreement between measurements in individual patients was poor. Similar observations were made in two other studies on patients either with $C D$ or UC. ${ }^{25,26}$ No studies with QUS have been performed in patients with sarcoidosis.

A shortcoming of all the reported studies on the value of QUS in IBD is of course that they used BMD determined by DXA as gold standard, assuming that fracture risk increases with a decrease in BMD as in subjects without inflammatory conditions. No assessment of clinical and prevalent vertebral fractures was done. In our series, vertebral deformities suggestive of nonclinical fractures were found in $22 \%$ of patients. The T-scores of these patients determined by both DXA and QUS were on average lower than those in patients without vertebral deformities. Although there was a correlation between T-scores determined with QUS and DXA, this correlation was moderate, as found by others. ${ }^{27}$ In addition, the calculated Odds ratios for any vertebral deformity per $1 \mathrm{SD}$ T-score reduction was increased for BMD of the hip (DXA) but not for the QUI of the calcaneus. This supports the view that the predictive value of QUS in patients with inflammatory conditions is poor. 
Our findings are in contrast with several large prospective studies that have shown that QUS of the calcaneus can predict fracture risk nearly as good as DXA. ${ }^{12-14}$ These studies are, however, all studies in elderly women and involve prediction of clinical (mainly non-vertebral) fractures. Kanis explored the relationship between QUS-determinations at the phalanges with age and the probability of symptomatic vertebral fractures and concluded that the 10-year probability of clinical vertebral fractures above the age of 45 increased for each SD decrease in measurement of SOS and fast wave amplitude (RR 1.7, respectively 2.4/SD). ${ }^{28}$ Studies on morphometric vertebral deformities and QUS parameters are, however, scarce. In 764 postmenopausal women (mean age $73 \pm 6.4$ years) the prevalence of nontraumatic vertebral fractures assessed with DXA was compared with an age matched control group with normal morphometry and this study showed that heel QUS enabled discrimination of women with fracture from those without. ${ }^{29}$ The same findings were reported in another study in postmenopausal women with rheumatoid arthritis. ${ }^{30}$ On the other hand, other studies revealed no differences in patients with and without a prevalent vertebral deformity. In one cross-sectional study in 551 postmenopausal women (mean age 65.2 13.1 ) receiving chronic glucocorticoid therapy a high prevalence of asymptomatic morphometric vertebral fractures was found $(37 \%)$, without any difference in QUS measurements between patients with and without deformities. ${ }^{31}$ This indicates that if QUS may be of any value to predict fracture risk, this will be in postmenopausal women and not in the type of patients included in our study.

Although the T-scores of patients with vertebral deformities of our series were lower than in those without, the Z-cores, although available for DXA measurements only, were not different. This means that the differences in Tscore are likely due to differences in age rather than differences in disease activity. In addition, despite the fact that the T-scores were lower, they were certainly not diagnostic for osteoporosis, indicating that in inflammatory conditions, besides a decrease in BMD, changes in bone strength contribute to an increased risk for fracture. ${ }^{7}$

In conclusion, in our hands QUS measurements of the calcaneus in patients with an inflammatory condition, such as sarcoidosis and IBD, were not associated with prevalent vertebral deformities and were not of value to recognise patients at risk for fracture. Hence, we feel that both BMD measurement with DXA and vertebral fracture assessment are better methods to identify such patients. Follow-up studies are, however, needed to substantiate this view. 


\section{References}

1. Cummings SR, Melton LJ. Epidemiology and outcomes of osteoporotic fractures. Lancet 2002;359:1761-1767.

2. Assessment of fracture risk and its application to screening for postmenopausal osteoporosis. Report of a WHO Study Group. World Health Organ Tech Rep Ser 1984;843:1-129.

3. Schuit SC, van der KM, Weel AE, de Laet CE, Burger H, Seeman E, Hofman A, Uitterlinden $A G$, van Leeuwen JP, Pols HA. Fracture incidence and association with bone mineral density in elderly men and women: the Rotterdam Study. Bone 2004;34:195-202.

4. Kanis JA, Borgstrom F, De Laet C, Johansson H, Johnell O, Jonsson B, Oden A, Zethraeus N, Pfleger B, Khaltaev N. Assessment of fracture risk. Osteoporos Int 2005;16:581-589.

5. Kanis JA, Johansson H, Oden A, Johnell O, de LC, Melton III LJ, Tenenhouse A, Reeve J, Silman AJ, Pols HA, Eisman JA, McCloskey EV, Mellstrom D. A meta-analysis of prior corticosteroid use and fracture risk. J Bone Miner Res 19:2004;893-899.

6. van Staa TP, Geusens P, Bijlsma JW, Leufkens HG, Cooper C. Clinical assessment of the long-term risk of fracture in patients with rheumatoid arthritis. Arthritis Rheum 2006;54:3104-3112.

7. Heijckmann AC, Huijberts MS, De Vries J, Menheere PP, van der Veer E, Nieuwenhuijzen Kruseman AC, Wolffenbuttel BH, Geusens P, Drent M. Bone turnover and bone mineral density in patients with sarcoidosis. Sarcoidosis Vasc Diffuse Lung Dis 2007 in press.

8. Seeman E , Delmas PD. Bone quality--the material and structural basis of bone strength and fragility. N Engl J Med 2006;354:2250-2261

9. Chavassieux P, Seeman E, Delmas PD. Insights into material and structural basis of bone fragility from diseases associated with fractures: how determinants of the biomechanical properties of bone are compromised by disease. Endocr Rev 2007;28:151-164.

10. Gluer CC. Quantitative Ultrasound--it is time to focus research efforts. Bone 2007;40:9-13.

11. Njeh CF, Fuerst T, Diessel E, Genant HK. Is quantitative ultrasound dependent on bone structure? A reflection. Osteoporos Int 2001;12:1-15.

12. Bauer DC, Gluer CC, Cauley JA, Vogt TM, Ensrud KE, Genant HK, Black DM. Broadband ultrasound attenuation predicts fractures strongly and independently of densitometry in older women. A prospective study. Study of Osteoporotic Fractures Research Group. Arch Intern Med 1997;157:629-634.

13. Hans D, Dargent-Molina P, Schott AM, Sebert JL, Cormier C, Kotzki PO, Delmas PD, Pouilles $\mathrm{JM}$, Breart G, Meunier PJ. Ultrasonographic heel measurements to predict hip fracture in elderly women: the EPIDOS prospective study. Lancet 1996;348:511-514.

14. Pluijm SM, Graafmans WC, Bouter LM, Lips P. Ultrasound measurements for the prediction of osteoporotic fractures in elderly people. Osteoporos Int 1999;9:550-556.

15. Hunninghake GW, Costabel U, Ando M, Baughman R, Cordier JF, du BR, Eklund A, Kitaichi M, Lynch J, Rizzato G, Rose C, Selroos O, Semenzato G, Sharma OP. ATS/ERS/WASOG statement on sarcoidosis. American Thoracic Society/European Respiratory Society/World Association of Sarcoidosis and other Granulomatous Disorders. Sarcoidosis Vasc Diffuse Lung Dis 1999;16:149-173.

16. Drent M, Jacobs JA, Cobben NA, Costabel U, Wouters EF, Mulder PG. Computer program supporting the diagnostic accuracy of cellular BALF analysis: a new release. Respir Med 2001;95:781-786.

17. Lennard-Jones JE. Classification of inflammatory bowel disease. Scand J Gastroenterol Suppl 1989;170:2-6.

18. Truelove SC, Witts LJ. Cortisone in ulcerative colitis; preliminary report on a therapeutic trial. Br Med J 1954;2:375-378.

19. Kwaliteitsinstituut voor de Gezondheid CBO. Osteoporose: tweede herziene richtlijn. 2002.

20. Elders PJ, Netelenbos JC, Lips P, Khoe E, Van Ginkel FC, Hulshof KF, Van der Stelt PF. Perimenopausal bone mass and risk factors. Bone Miner 1989;7:289-299.

21. Duboeuf F, Bauer DC, Chapurlat RD, Dinten JM, Delmas P. Assessment of vertebral fracture using densitometric morphometry. J Clin Densitom 2005;8:362-368. 
22. Genant HK, Wu CY, van KC, Nevitt MC. Vertebral fracture assessment using a semiquantitative technique. J Bone Miner Res 1993;8:1137-1148.

23. Robinson RJ, Carr I, lqbal SJ, al-Azzawi F, Abrams K, Mayberry JF. Screening for osteoporosis in Crohn's disease. A detailed evaluation of calcaneal ultrasound. Eur J Gastroenterol Hepatol 1998;10:137-140.

24. Jahnsen J, Falch JA, Mowinckel P, Aadland E. Ultrasound measurements of calcaneus for estimation of skeletal status in patients with inflammatory bowel disease. Scand $\mathrm{J}$ Gastroenterol 1999;34:790-797.

25. Fries W, Dinca M, Luisetto G, Peccolo F, Bottega F, Martin A. Calcaneal ultrasound bone densitometry in inflammatory bowel disease--a comparison with double x-ray densitometry of the lumbar spine. Am J Gastroenterol 1998;93:2339-2344.

26. Schwartz DA, Connolley CD, Koyama T, Wise PE, Herline AJ. Calcaneal ultrasound bone densitometry is not a useful tool to screen patients with inflammatory bowel disease at high risk for metabolic bone disease. Inflamm Bowel Dis 2005;11:749-754.

27. Nayak S, Olkin I, Liu H, Grabe M, Gould MK, Allen IE, Owens DK, Bravata DM. Metaanalysis: accuracy of quantitative ultrasound for identifying patients with osteoporosis. Ann Intern Med 2006;144:832-841.

28. Kanis JA, Johnell O, Oden A, De Laet C, de TF. Ten-year probabilities of clinical vertebral fractures according to phalangeal quantitative ultrasonography. Osteoporos Int 2005;16: 1065-1070.

29. Frediani B, Acciai C, Falsetti P, Baldi F, Filippou G, Siagkri C, Spreafico A, Galeazzi M, Marcolongo R. Calcaneus ultrasonometry and dual-energy X-ray absorptiometry for the evaluation of vertebral fracture risk. Calcif Tissue Int 2006;79:223-229.

30. Orstavik RE, Haugeberg G, Uhlig T, Mowinckel P, Kvien TK, Falch JA, Halse JI. Quantitative ultrasound and bone mineral density: discriminatory ability in patients with rheumatoid arthritis and controls with and without vertebral deformities. Ann Rheum Dis 2004;63:945-951.

31. Angeli A, Guglielmi G, Dovio A, Capelli G, de FD, Giannini S, Giorgino R, Moro L, Giustina A. High prevalence of asymptomatic vertebral fractures in post-menopausal women receiving chronic glucocorticoid therapy: a cross-sectional outpatient study. Bone 2006;39:253-259 


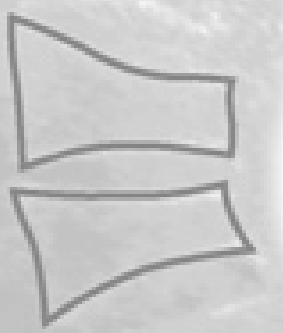

Chapter 8

General discussion 
112 Chapter 8 


\section{General discussion}

The studies described in this thesis touch on the diagnosis of osteoporosis in subjects at risk and the clinical implications. The most important findings of the studies performed are:

1. A substantial number of patients with an inflammatory condition as sarcoidosis and inflammatory bowel disease had vertebral deformities suggestive of fracture;

2. Measurement of bone mineral density (BMD) appeared not of value to discriminate between patients with and without vertebral deformities;

3. Bone turnover appeared increased in patients with an inflammatory disease.

These findings indicate that patients with an inflammatory condition have an increased fracture risk due to increased bone remodelling and consequently a decreased bone strength independently of bone mass and BMD.

In contrast, we found no increase of vertebral deformities in patients with differentiated thyroid carcinoma during treatment with a suppressive dose of levothyroxin. In these patients, BMD was also not different from sex- and agematched controls. These findings are in line with the publication of Reverter and co-workers who also found that the proportion of women with DTC with normal BMD, osteopenia, and osteoporosis is similar to that in healthy control women matched for body mass index and menopausal status. ${ }^{1}$ These observations imply that the effects of levothyroxine on bone metabolism and bone strength are minimal and not comparable to the effects of inflammation on bone.

The questions that arise from these studies are how to define osteoporosis and how to involve vertebral fracture assessment (VFA) and bone turnover markers in this definition. In addition, to what extent other imaging techniques may contribute to a redefinition of osteoporosis and better recognition of patients at risk for fracture.

In 1994, an expert panel convened by the World Health Organization (WHO) formulated an operational definition for osteoporosis for postmenopausal women on the basis of BMD with dual energy X-ray absorptiometry (DXA). ${ }^{2}$ However, as the majority of fractures occur in persons without osteoporosis, ${ }^{3,4}$ it is clear that bone density is not the only determinant for fracture. It is nowadays well recognized that relying on BMD alone as a predictor of fracture risk is of limited value, and that, in addition to fall and bone related risk factors, there is need to include other aspects of bone strength in the definition of osteoporosis as well. In support of this view, a later consensus conference has defined osteoporosis as 'a skeletal disorder characterized by compromised bone strength leading to an increased risk of fracture'. ${ }^{5}$ Although BMD determined with DXA is strongly related to bone strength, it is only reflecting 
part of its components. ${ }^{6}$ There is therefore a need for other imaging tools or markers to determine bone quality and hence to identify patients who are at risk for fragility fractures in a better way than can be done on the basis of DXA alone.

One of the additional tools to recognize decreased bone strength appears to be VFA, as is illustrated by the studies summarized in this thesis. We found a high prevalence of vertebral deformities suggestive of fracture in the patients with inflammatory conditions irrespective of BMD. This indicates that these diseases have an effect on bone strength rather than bone mass and hence is illustrative for the relevance of VFA in addition to DXA to identify patients with reduced bone strength.

As no data on non-clinical deformities in healthy young and premenopausal individuals are available yet, it is questionable whether the prevalence of vertebral deformities in inflammatory conditions we found is indeed high. The best comparison with healthy subjects is offered by the EVOS study, in which in a very large cross-sectional population based study, European subjects aged 50 to 79 years were investigated. The prevalence of vertebral deformities on Xrays in this study was $12 \%$ (range $6-21 \%$ ) in males and females. ${ }^{7}$ In addition, the Rotterdam study, in which 3469 men and women aged 55 years and older were studied, revealed a prevalence of vertebral deformity suggestive of fracture in $6.9 \%$ of men and $7.5 \%$ of women. ${ }^{8}$ As the subjects described in our studies are younger and have hence a lower risk to fracture, the prevalence of vertebral deformities we found $(21-25 \%)$ is probably indeed high. Furthermore, our unique prospective data in patients with sarcoidosis showed that the prevalence of vertebral deformities appeared increased from 20 to $32 \%$ after four years of follow-up, and in $26 \%$ of subjects one or more new or progressive vertebral deformities were diagnosed. This again supports the relevance of VFA to identify patients with an increased fracture risk and also the view that patients with a vertebral fracture have an increased risk for another vertebral fracture within a couple of years, irrespective of changes in BMD. ${ }^{9}$

Unfortunately, one of the limitations of VFA is lack of a gold standard for vertebral fracture. This is the reason that we prefer the description 'vertebral deformity suggestive of fracture' rather than vertebral fracture as a natural interpretation of a vertebral deformity. Because of the absence of a gold standard, it is still not clear which method is the most appropriate to establish vertebral deformities and on the basis of that to determine the occurrence of vertebral fractures. For the determination of vertebral deformities a variety of morphometric approaches can be used. These different approaches can result in slightly different outcomes. ${ }^{10-13}$ Compared with subjective qualitative assessment, quantitative morphometry is a more reproducible method for assessing vertebral deformities and therefore these approaches are often used in conjunction. We followed the method of Genant, ${ }^{11}$ which is based on a 
reduction of the ratios of anterior, middle or posterior heights and all measurements were performed twice to improve accuracy. This is the simplest and most practical method ${ }^{14}$ and an association with future fracture risk is documented. $^{9,10,15}$ The above mentioned EVOS study, however, applied the methodologies described by McCloskey and Eastell and co-workers in which measurements are corrected for normal variations in vertebral shape. ${ }^{13}$ Vertebrae in the mid-thoracic spine and thoraco-lumbar junction are slightly more wedged than in other regions of the spine ${ }^{12,16}$ and, as a result, with the method of Genant normal variations may be misinterpreted as mild vertebral deformities. $^{17,18}$ This may have contributed to overestimation of vertebral deformities in our series, although we feel only to a limited extent. In one of our series (IBD patients), we also used the method of Eastell and this resulted in vertebral deformities in $20 \%$ of patients (data not shown), compared to $25 \%$ found with the method of Genant. This is indeed lower, but still indicates a substantial prevalence in this young population.

We used X-ray absorptiometry (MXA) instead of standard radiographs (MRX) for morphometric determination of vertebral deformities. Several studies have documented that morphometric MXA is comparable to MRX (morphometric radiography) for this approach. ${ }^{19-22}$ Vertebral morphometry after MXA has several advantages over conventional radiographs. The radiation dose is much lower $(<80 \mu \mathrm{Sv})$ and assessment of BMD and vertebral deformities can be combined. Although MXA is thus an established technology to detect vertebral deformities and to identify patients likely to benefit from pharmacological therapy who otherwise might not be treated, ${ }^{23}$ this technology has some limitations as well. These include limited ability to provide a differential diagnosis for the detected deformities, lower sensitivity for milder deformities and inability to evaluate the uppermost thoracic levels. However, its negative predictive value is high. ${ }^{24}$ Other disorders that may cause changes in vertebral shape involve congenital abnormalities and conditions as severe osteoarthritis $^{25}$ and Scheuermann's disease. These conditions usually present in a characteristic way and are relatively rare. We consider this disadvantage therefore not that relevant.

One of the other alternatives to DXA to analyse bone mass and bone strength is quantitative ultrasound (QUS). QUS of the heel is shown to predict fractures comparable to DXA and independent of spine and femur BMD. As QUS is simple and easy to perform, some consider it a valuable tool to identify postmenopausal women with an increased fracture risk. ${ }^{26-28}$ The results of QUS are, however, rather variable, in particular in other populations than postmenopausal women. In our hands, QUS measurements in patients with an inflammatory disease were not associated with prevalent vertebral deformities and therefore likely not of value to recognize patients at risk for fracture. Similar observations have been made by other investigators. ${ }^{29,30}$ 
Hence, the value of QUS in the diagnostic work up of subjects at risk for osteoporotic fractures is still questionable.

One more alternative to DXA is offered by three dimensional quantification of trabecular structure with high-resolution peripheral quantitative computed tomography (hr-pQCT) or micro-magnetic resonance imaging $(\mu \mathrm{MRI})$. Although MRI is widely available, the measurement of bone microarchitecture requires special equipment and software. The method is still in development and therefore not applicable in daily practice yet.

With hr-pQCT significant age-related changes in density, trabecular structure, and cortical thickness can be detected. ${ }^{31}$ In the OFELY cohort, a study on postmenopausal women, it is found that alterations of cortical and trabecular structure are associated with fragility fractures and that this association is partially independent of BMD assessed by DXA. ${ }^{32}$ Thus, hr-pQCT measurements appear useful for gaining an insight into structural mechanisms underlying various causes of skeletal fragility. At present, however, the majority of studies with hr-QCT are done in vitro on bone biopsies, or in vivo on the distal radius. ${ }^{32}$ The majority of $\mathrm{hr}-\mathrm{CT}$ apparatus is still not adequate to study other sites in vivo, in particular the spine. As soon as these technical difficulties are overcome and apparatus become available to study the microarchitecture of vertebrae in detail, it can be expected that hr-QCT will replace DXA to study bone mass and bone strength resulting in better prediction of subjects with an increased fracture risk.

In our studies we have clearly shown that both in patients with inflammatory bowel disease and in patients with sarcoidosis, increased bone turnover is associated with an increased fracture risk, even in patients with a normal BMD, which implies an effect of bone remodelling in these conditions on bone strength rather than bone mass. ${ }^{33}$ Long-term prospective studies have shown that markers of bone resorption in particular are beneficial in fracture prediction. ${ }^{34,35}$ In a study in elderly women the BMD-corrected risk of hip fracture increased by $1.4(95 \% \mathrm{Cl}: 1.1-1.7)$ for each SD increase in urinary free deoxypiridinoline (D-Pyr) and by 1.3 (1.0-1.6) for urinary type 1 C-telopeptide (CTX). Garnero et al. ${ }^{36}$ found that a combination of high CTX and low BMD had an odds ratio of 4.8 for hip fracture in elderly women after a follow-up of on average 22 months. The same combination in women aged 65 years showed a relative risk of 4.2 for all fractures. ${ }^{37}$ These investigators demonstrated in another study, although without data of DXA, that the combination of history of fractures and urinary CTX may predict hip fracture risk in elderly women comparable to hip BMD determinations. ${ }^{38}$ Ross and co-workers found an association between spine and non-spine fractures and high serum bone alkaline phosphatase, with an odds ratio of 1.5-1.9 per 1 SD change, which persisted after adjustment for BMD. ${ }^{39}$ These studies indicate that indices of skeletal turnover give information on fracture risk independently of BMD and 
might therefore complement and improve fracture risk assessment by BMD. These studies are, however, all performed in postmenopausal women only. Prospective studies with fracture endpoints in men and in patients at risk for secondary osteoporosis, like the patient groups we have studied, are lacking. Beside this, the question arises whether measuring bone turnover may be helpful in estimating fracture risk in patients with T-scores above -2.5 , and whether medical intervention in subjects with osteopenia but elevated bone markers may lead to a reduction in fractures. A recent study demonstrated that with measurement of bone turnover markers a subset of post-menopausal women can indeed be identified in which therapy with bisphosphonates is costeffective. ${ }^{40}$ Further studies are however needed to substantiate this finding.

Are patients with inflammatory conditions in whom vertebral deformities have been demonstrated, candidates for preventive treatment with - for instance antiresorptive medications like bisphosphonates? According to current guidelines, patients with prevalent vertebral fractures or a BMD T-score less than -2.5 should receive treatment. Many guidelines are available on the prevention and treatment of patients that are expected to be, or already are, on long-term (>3 months) glucocorticoid treatment. Treatment with oral glucocorticoids has been associated with increase in the risk of fractures, particularly fractures of the hip and vertebrae and this may be partially independent of BMD. ${ }^{41}$ This effect is dose dependent and occurs rapidly after the start of treatment. ${ }^{42}$ However, intermittent use of high-dose oral glucocorticoids (daily dose $\geq 15 \mathrm{mg}$ and cumulative exposure $\leq 1 \mathrm{gm}$ ) may result in only a small increased risk of osteoporotic fractures. Conversely, patients who receive several courses of high-dose oral GCs (daily dose $\geq 15 \mathrm{mg}$ and cumulative exposure $\geq 1 \mathrm{gm}$ ) have a substantially increased risk of fractures. ${ }^{43}$ In the Dutch guidelines, bone measurement is not considered necessary in high risk patients, e.g. those who will take $>60 \mathrm{mg} /$ day of hydrocortisone or another equipotent glucocorticoid for more than three months. In such patients preventive treatment is indicated, irrespective of BMD values. The same is recommended for postmenopausal women and older men (>70 years) who will take intermediate doses (30-60 mg hydrocortisone). In all other patients on glucocorticoids a DXA measurement is recommended and if it is found to be low (a T-score of <-2.5), treatment should be started. ${ }^{44-46}$ In patients not on glucocorticoids, a BMD measurement is recommended for a) those with a clinical fracture above 50 years, b) patients older than 60 years and at least three clinical risk factors and c) patients $>70$ years with two risk factors. ${ }^{44}$ Specific guidelines for patients with IBD or sarcoidosis do not exist. As both we and others found a high prevalence of vertebral deformities in IBD patients, whereas no discrimination between patients with and without a vertebral deformity could be made with DXA, we feel that in this type of patients morphometric assessment of vertebral deformities better reflects reduced bone 
strength than DXA measurements. As we found in patients with sarcoidosis not only a relevant prevalence of vertebral deformities during the initial crosssectional study, but also a substantial increase of incident deformities after four years of follow-up, one may even wonder whether in this type of patients preventive treatment should be instituted, irrespective of the results of BMD or VFA-studies.

If preventive treatment in subjects at risk is considered, the next question is, which class of medication is to be preferred and for how long the therapy should be continued. At present, the drug of choice for prevention of osteoporotic fractures is a bisphosphonate. If this drug is not tolerated, strontium ranelate can be considered. Both types of drugs have been proven to be effective in the reduction of the risk of vertebral fractures (40-50\%) and nonvertebral fractures $(20-40 \%) .^{47-49}$ If there is progress of fractures during treatment, recombinant human parathyroid hormone (rhPTH) 1-34 fragment of the whole rhPTH 1-84 can be considered. Unlike bisphosphonates, that act mainly by reduction of bone resorption, and strontium ranelate, that at least in animal models acts by both reduction of bone resorption and stimulation of bone formation, daily injections of rhPTH primarily stimulate bone formation, more than bone resorption. ${ }^{50}$ Phase III trials with $\mathrm{rhPTH}$ (1-34) in postmenopausal women demonstrated a $65 \%$ reduction in risk of new vertebral fractures and a $53 \%$ reduction of non-vertebral fractures, ${ }^{51}$ while for rhPTH (184 ) only a reduction of vertebral fractures could be demonstrated. ${ }^{52}$ So, rhPTH appears to be at least as effective as bisphosphonates and strontium ranelate in the prevention of fractures, which may be relevant if treatment is considered in patients with a substantial fracture risk, as in patients with an inflammatory disease. However, because of still existing safety concerns, the high cost and the fact that treatment periods are at this moment limited to 18-24 months, the benefit in terms of bone mineral density seems to wane after discontinuation unless followed by an antiresorptive agent, we feel that also in patients with an inflammatory disease parathyroid hormone is a second line drug and that bisphosphonates or strontium ranelate are the first drugs of choice.

As for the period that treatment should be continued in patients with an inflammatory disease, no data are available. So far, available data of oral bisphosphonate treatment in postmenopausal women for up to 10 years, show sustained, but not progressive, suppression of bone remodelling and provide no evidence of an adverse effect of bisphosphonates on bone metabolism. In addition, the favourable effect of bisphosphonates on skeletal integrity seems to be sustained. ${ }^{53}$ At present, the usual policy is to reconsider continuation of treatment after five years. It is our policy to continue treatment if after five years treatment the T-score with DXA is still <-2.5 and/or a vertebral fracture is evident or new risks appear. In low risk patients (T-score $>-2.5$, no new fracture) we are used to give a drug holiday. This may be different in patients 
with an inflammatory disease as long as activity of the disease is still notable. Follow-up studies are, however, needed to clarify this point.

\section{Recommendations for further studies}

Although our studies point to a high prevalence of vertebral fractures in patients at risk for secondary osteoporosis and hence new fractures, these data would be strengthened by studies that evaluate the presence of vertebral deformities in healthy young populations. Prospective follow-up studies in patients with IBD will have to demonstrate whether a similarly high rate of new deformities as in patients with sarcoidosis can be found. Finally, intervention studies on patients with vertebral deformities, irrespective of BMD-measurements, are needed to determine whether or not recognition and treatment of such patients reduce the incidence and progression of vertebral deformities. 


\section{References}

1. Reverter JL, Holgado S, Alonso N, Salinas I, Granada ML, Sanmarti A. Lack of deleterious effect on bone mineral density of long-term thyroxine suppressive therapy for differentiated thyroid carcinoma. Endocr Relat Cancer. 2005;12:973-981.

2. Assessment of fracture risk and its application to screening for postmenopausal osteoporosis. Report of a WHO Study Group. World Health Organ Tech Rep Ser. 1994;843:1-129.

3. Siris ES, Chen YT, Abbott TA, Barrett-Connor E, Miller PD, Wehren LE, Berger ML. Bone mineral density thresholds for pharmacological intervention to prevent fractures. Arch Intern Med. 2004;164:1108-1112.

4. Pasco JA, Seeman E, Henry MJ, Merriman EN, Nicholson GC, Kotowicz MA. The population burden of fractures originates in women with osteopenia, not osteoporosis. Osteoporos Int. 2006;17:1404-1409.

5. Consensus conference. Osteoporosis prevention, diagnosis and therapy. JAMA. 2001;285:785-795.

6. Jiang Y, Zhao J, Geusens P, Liao EY, Adriaensens P, Gelan J, Azria M, Boonen S, Caulin F, Lynch JA, Ouyang X, Genant HK. Femoral neck trabecular microstructure in ovariectomized ewes treated with calcitonin: MRI microscopic evaluation. J Bone Miner Res. 2005;20: $125-130$.

7. O'Neill TW, Felsenberg D, Varlow J, Cooper C, Kanis JA, Silman AJ. The prevalence of vertebral deformity in European men and women: the European Vertebral Osteoporosis Study. J Bone Miner Res. 1996;11:1010-1018.

8. van der Klift M, de Laet CE, McCloskey EV, Hofman A, Pols HA. The incidence of vertebral fractures in men and women: the Rotterdam Study. J Bone Miner Res. 2002;17:1051-1056.

9. Lindsay R, Silverman SL, Cooper C, Hanley DA, Barton I, Broy SB, Licata A, Benhamou L, Geusens $P$, Flowers K, Stracke H, Seeman E. Risk of new vertebral fracture in the year following a fracture. JAMA. 2001;285:320-323.

10. Black DM, Palermo L, Nevitt MC, Genant HK, Epstein R, San VR, Cummings SR. Comparison of methods for defining prevalent vertebral deformities: the Study of Osteoporotic Fractures. J Bone Miner Res. 1995;10:890-902.

11. Genant HK, Wu CY, van KC, Nevitt MC. Vertebral fracture assessment using a semiquantitative technique. J Bone Miner Res. 1993;8:1137-1148.

12. McCloskey EV, Spector TD, Eyres KS, Fern ED, O'Rourke N, Vasikaran S, Kanis JA. The assessment of vertebral deformity: a method for use in population studies and clinical trials. Osteoporos Int. 1993;3:138-147.

13. Eastell R, Cedel SL, Wahner HW, Riggs BL, Melton LJ, III. Classification of vertebral fractures. J Bone Miner Res. 1991;6:207-215.

14. Black DM, Palermo L, Nevitt MC, Genant HK, Epstein R, San VR, Cummings SR. Comparison of methods for defining prevalent vertebral deformities: the Study of Osteoporotic Fractures. J Bone Miner Res. 1995;10:890-902.

15. Siris ES, Genant HK, Laster AJ, Chen P, Misurski DA, Krege JH. Enhanced prediction of fracture risk combining vertebral fracture status and BMD. Osteoporos Int. 2007;18:761-770.

16. Black DM, Cummings SR, Stone K, Hudes E, Palermo L, Steiger P. A new approach to defining normal vertebral dimensions. J Bone Miner Res. 1991;6:883-892.

17. Spector TD, McCloskey EV, Doyle DV, Kanis JA. Prevalence of vertebral fracture in women and the relationship with bone density and symptoms: the Chingford Study. J Bone Miner Res. 1993;8:817-822.

18. Kleerekoper M, Nelson DA. Vertebral fracture or vertebral deformity. Calcif Tissue Int. 1992;50:5-6.

19. Rea JA, Li J, Blake GM, Steiger P, Genant HK, Fogelman I. Visual assessment of vertebral deformity by X-ray absorptiometry: a highly predictive method to exclude vertebral deformity. Osteoporos Int. 2000;11:660-668. 
20. Binkley N, Krueger D, Gangnon R, Genant HK, Drezner MK. Lateral vertebral assessment: a valuable technique to detect clinically significant vertebral fractures. Osteoporos Int. 2005;16:1513-1518.

21. Vokes TJ, Dixon LB, Favus MJ. Clinical utility of dual-energy vertebral assessment (DVA). Osteoporos Int. 2003;14:871-878.

22. Schousboe JT, Debold CR. Reliability and accuracy of vertebral fracture assessment with densitometry compared to radiography in clinical practice. Osteoporos Int. 2006;17:281-289.

23. Lewiecki EM, Laster AJ. Clinical review: Clinical applications of vertebral fracture assessment by dual-energy x-ray absorptiometry. J Clin Endocrinol Metab. 2006;91:4215-4222.

24. Delmas PD, Genant HK, Crans GG, Stock JL, Wong M, Siris E, Adachi JD. Severity of prevalent vertebral fractures and the risk of subsequent vertebral and nonvertebral fractures: results from the MORE trial. Bone. 2003;33:522-532.

25. Abdel-Hamid OA, Bassiouni H, Koutri R, Nijs J, Geusens P, Dequeker J. Aging of the thoracic spine: distinction between wedging in osteoarthritis and fracture in osteoporosis--a crosssectional and longitudinal study. Bone. 1994;15:437-442.

26. Bauer DC, Gluer CC, Cauley JA, Vogt TM, Ensrud KE, Genant HK, Black DM. Broadband ultrasound attenuation predicts fractures strongly and independently of densitometry in older women. A prospective study. Study of Osteoporotic Fractures Research Group. Arch Intern Med. 1997;157:629-634.

27. Hans D, Dargent-Molina P, Schott AM, Sebert JL, Cormier C, Kotzki PO, Delmas PD, Pouilles JM, Breart G, Meunier PJ. Ultrasonographic heel measurements to predict hip fracture in elderly women: the EPIDOS prospective study. Lancet. 1996;348:511-514.

28. Pluijm SM, Graafmans WC, Bouter LM, Lips P. Ultrasound measurements for the prediction of osteoporotic fractures in elderly people. Osteoporos Int. 1999;9:550-556.

29. Angeli A, Guglielmi G, Dovio A, Capelli G, de FD, Giannini S, Giorgino R, Moro L, Giustina A. High prevalence of asymptomatic vertebral fractures in post-menopausal women receiving chronic glucocorticoid therapy: a cross-sectional outpatient study. Bone. 2006;39:253-259.

30. Schwartz DA, Connolley CD, Koyama T, Wise PE, Herline AJ. Calcaneal ultrasound bone densitometry is not a useful tool to screen patients with inflammatory bowel disease at high risk for metabolic bone disease. Inflamm Bowel Dis. 2005;11:749-754.

31. Boutroy S, Bouxsein ML, Munoz F, Delmas PD. In vivo assessment of trabecular bone microarchitecture by high-resolution peripheral quantitative computed tomography. J Clin Endocrinol Metab. 2005;90:6508-6515.

32. Sornay-Rendu E, Boutroy S, Munoz F, Delmas PD. Alterations of Cortical and Trabecular Architecture Are Associated With Fractures in Postmenopausal Women, Partially Independent of Decreased BMD Measured by DXA: The OFELY Study. J Bone Miner Res. 2007;22:425-433.

33. Seeman E, Delmas PD. Bone quality--the material and structural basis of bone strength and fragility. N Engl J Med. 2006;354:2250-2261.

34. Looker AC, Bauer DC, Chesnut CH, III, Gundberg CM, Hochberg MC, Klee G, Kleerekoper $\mathrm{M}$, Watts NB, Bell NH. Clinical use of biochemical markers of bone remodeling: current status and future directions. Osteoporos Int. 2000;11:467-480.

35. Delmas PD, Eastell R, Garnero P, Seibel MJ, Stepan J. The use of biochemical markers of bone turnover in osteoporosis. Committee of Scientific Advisors of the International Osteoporosis Foundation. Osteoporos Int. 2000;11 Suppl 6:S2-17.

36. Garnero P, Hausherr E, Chapuy MC, Marcelli C, Grandjean H, Muller C, Cormier C, Breart G, Meunier PJ, Delmas PD. Markers of bone resorption predict hip fracture in elderly women: the EPIDOS Prospective Study. J Bone Miner Res. 1996;11:1531-1538.

37. Garnero P, Sornay-Rendu E, Claustrat B, Delmas PD. Biochemical markers of bone turnover, endogenous hormones and the risk of fractures in postmenopausal women: the OFELY study. J Bone Miner Res. 2000;15:1526-1536.

38. Garnero P, Dargent-Molina P, Hans D, Schott AM, Breart G, Meunier PJ, Delmas PD. Do markers of bone resorption add to bone mineral density and ultrasonographic heel measurement for the prediction of hip fracture in elderly women? The EPIDOS prospective study. Osteoporos Int. 1998;8:563-569. 
39. Ross PD, Kress BC, Parson RE, Wasnich RD, Armour KA, Mizrahi IA. Serum bone alkaline phosphatase and calcaneus bone density predict fractures: a prospective study. Osteoporos Int. 2000;11:76-82.

40. Schousboe JT, Bauer DC, Nyman JA, Kane RL, Melton LJ, Ensrud KE. Potential for bone turnover markers to cost-effectively identify and select post-menopausal osteopenic women at high risk of fracture for bisphosphonate therapy. Osteoporos Int. 2007;18:201-210.

41. Kanis JA, Johansson H, Oden A, Johnell O, de LC, Melton III LJ, Tenenhouse A, Reeve J, Silman AJ, Pols HA, Eisman JA, McCloskey EV, Mellstrom D. A meta-analysis of prior corticosteroid use and fracture risk. J Bone Miner Res. 2004;19:893-899.

42. van Staa TP, Leufkens HG, Abenhaim L, Zhang B, Cooper C. Use of oral corticosteroids and risk of fractures. J Bone Miner Res. 2000;15:993-1000.

43. de VF, Bracke M, Leufkens HG, Lammers JW, Cooper C, van Staa TP. Fracture risk with intermittent high-dose oral glucocorticoid therapy. Arthritis Rheum. 2007;56:208-214.

44. Kwaliteitsinstituut voor de Gezondheid CBO. Osteoporose: tweede herziene richtlijn. 2002.

45. Geusens PP, de Nijs RN, Lems WF, Laan RF, Struijs A, van Staa TP, Bijlsma JW. Prevention of glucocorticoid osteoporosis: a consensus document of the Dutch Society for Rheumatology. Ann Rheum Dis. 2004;63:324-325.

46. Geusens P, Lems WF, Verhaar HJJ, et al. Review and evaluation of the Dutch Guidelines for Osteoporosis. 2006.

47. Cranney A, Guyatt G, Griffith L, Wells G, Tugwell P, Rosen C. Meta-analyses of therapies for postmenopausal osteoporosis. IX: Summary of meta-analyses of therapies for postmenopausal osteoporosis. Endocr Rev. 2002;23:570-578.

48. Meunier PJ, Roux C, Seeman E, Ortolani S, Badurski JE, Spector TD, Cannata J, Balogh A, Lemmel EM, Pors-Nielsen S, Rizzoli R, Genant HK, Reginster JY. The effects of strontium ranelate on the risk of vertebral fracture in women with postmenopausal osteoporosis. $\mathrm{N} \mathrm{Engl}$ J Med. 2004;350:459-468.

49. Reginster JY, Seeman E, de Vernejoul MC, Adami S, Compston J, Phenekos C, Devogelaer JP, Curiel MD, Sawicki A, Goemaere S, Sorensen OH, Felsenberg D, Meunier PJ. Strontium ranelate reduces the risk of nonvertebral fractures in postmenopausal women with osteoporosis: Treatment of Peripheral Osteoporosis (TROPOS) study. J Clin Endocrinol Metab. 2005;90:2816-2822.

50. Hodsman AB, Bauer DC, Dempster DW, Dian L, Hanley DA, Harris ST, Kendler DL, McClung MR, Miller PD, Olszynski WP, Orwoll E, Yuen CK. Parathyroid hormone and teriparatide for the treatment of osteoporosis: a review of the evidence and suggested guidelines for its use. Endocr Rev. 2005;26:688-703.

51. Neer RM, Arnaud CD, Zanchetta JR, Prince R, Gaich GA, Reginster JY, Hodsman AB, Eriksen EF, Ish-Shalom S, Genant HK, Wang O, Mitlak BH. Effect of parathyroid hormone (134 ) on fractures and bone mineral density in postmenopausal women with osteoporosis. $\mathrm{N}$ Engl J Med. 2001;344:1434-1441.

52. Greenspan SL, Bone HG, Ettinger MP, Hanley DA, Lindsay R, Zanchetta JR, Blosch CM, Mathisen AL, Morris SA, Marriott TB. Effect of recombinant human parathyroid hormone (184) on vertebral fracture and bone mineral density in postmenopausal women with osteoporosis: a randomized trial. Ann Intern Med. 2007;146:326-339.

53. Papapoulos SE. Who will benefit from antiresorptive treatment (bisphosphonates)? Best Pract Res Clin Rheumatol. 2005;19:965-973. 


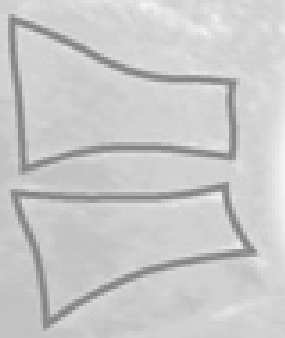

Chapter 9

Summary 


\section{Summary}

In this thesis several aspects of bone quality in patients at risk for secondary osteoporosis are studied. In chapter 2 an overview of osteoporosis and fracture risk is given. The subsequent chapters involve studies on clinical risk factors and measurements of bone mineral density, bone turnover and prevalent vertebral fractures in patients with thyroid carcinoma, sarcoidosis or inflammatory bowel disease (IBD).

In chapter 3 a study is described in which we investigated the influence of a suppressive dose of levothyroxin on bone in patients with differentiated thyroid carcinoma. Z-scores of bone mineral density (BMD) were not different from the reference population, even after long-term ( $>10$ years) suppression therapy. Patients with a BMD in the lowest and highest quartile showed significant differences in the presence of known clinical risk factors. The bone turnover parameter carboxy-terminal cross-linked telopeptide of type I collagen (ICTP, a marker of bone resorption) was higher than in age-matched controls. In addition, we found in $7 \%$ of patients a vertebral deformity, suggestive of fracture. As data on vertebral fractures in healthy young patients are lacking, the best comparison we have is the EVOS study, comprising a very large cross-sectional population based study on the prevalence of vertebral deformities in European men and women. In this study, in a group of 15570 males and females aged 50-79 years, a prevalent vertebral deformity was observed in $12 \%$ (range 6-21\%). We therefore had no indication that the prevalence of vertebral fractures in this particular patient group is higher than in a European reference population. In all studies published thus far on this subject, a significant bone loss was observed in patients using a 30-50\% higher dose of levothyroxin than in our study. We therefore concluded that patients with well-differentiated thyroid carcinoma are not at increased risk of developing low bone mass nor have a higher prevalence of vertebral fracture, at least when treated with levothyroxin with doses not higher than necessary to suppress TSH.

Chapter 4 involves a study on the prevalence of vertebral deformities in IBD patients and their relation with BMD and bone turnover. Vertebral deformities were found in $25 \%$ of patients either with Crohn's disease (CD) or ulcerative colitis (UC). Comparing patients with and without vertebral deformities, no significant difference was found between Z- and T-scores of BMD, or levels of ICTP and serum procollagen type I amino-terminal propeptide (PINP). Neither disease activity, bone turnover markers, clinical risk factors, nor BMD were predictive for the presence of vertebral deformities. The determinants for having more than one vertebral deformity were age and glucocorticoid use. 
This may imply that in addition to screening for low BMD, morphometric assessment of vertebral deformities is warranted in CD and UC to identify patients with decreased bone quality and consequently an increased fracture risk.

Sarcoidosis is a chronic inflammatory T-cell-driven disease that can also affect bone. In chapter 5, a study is summarized regarding bone remodelling, BMD and prevalent vertebral deformities in patients with sarcoidosis and their dependency of disease-related and treatment-related factors. We found that hip BMD was normal in patients with sarcoidosis, despite an increased bone turnover. As the increased bone resorption was found to be related to angiotensin converting enzyme (ACE) and soluble IL-2 receptor (sIL-2R), we concluded that this is - at least partly - the result of disease activity. In addition, vertebral deformities suggestive of fracture were found in a significant number of patients $(21 \%)$. This implies that in sarcoidosis increased bone turnover affects bone quality rather than bone density.

As we found a high incidence of morphometric vertebral deformities suggestive of fractures in this patient group, the aim of the subsequent follow-up study was to determine the incidence of new and/or progressive vertebral deformities and the evolution of BMD during the course of sarcoidosis (chapter 6). The BMD of the total group appeared unchanged after follow-up, even in the groups with current or previous glucocorticoid use. The prevalence of vertebral deformities, however, appeared increased from 20 to $32 \%$ in the total group, and in $26 \%$ of subjects one or more new or progressive vertebral deformities were diagnosed. We found that the combination of a low normal BMD and a family history of fragility fractures confers an increased risk of the incidence of these deformities.

The last years there has been increasing interest for Quantitative Ultrasound (QUS) methods for refined assessment of bone strength. We hypothesized that in these populations (IBD and sarcoidosis) with decreased bone strength as reflected by the presence of vertebral deformities but with preservation of BMD, QUS measurements might have additional value to BMD measured with DXA to predict the presence of morphometric vertebral fractures. This is the subject of chapter 7. In addition to measurement of QUS vertebral fracture assessment and BMD measurement with DXA was done to determine whether or not QUS could be used to identify subjects with an inflammatory disease at risk for fracture. It appeared that, in contrast to DXA, decrease of bone density parameters of calcaneal QUS measurements was not associated with prevalent vertebral deformities and is hence not a useful clinical tool to identify patients at risk for fracture. 
The studies described in this thesis imply that in subjects with inflammatory diseases who are at risk for secondary osteoporosis both DXA BMD measurements and assessment of vertebral deformities are warranted to identify individuals with reduced bone strength. 


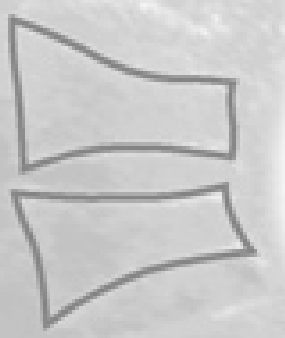

Chapter 10

Samenvatting 
130 Chapter 10 


\section{Samenvatting}

In dit proefschrift wordt een aantal studies beschreven waarin verschillende aspecten van de kwaliteit van bot bij patiënten met een hoog risico op secundaire osteoporose zijn bestudeerd. In hoofdstuk 2 wordt een overzicht van osteoporose en het risico op botbreuken gegeven. De daarop volgende hoofdstukken gaan over klinische risicofactoren, metingen van de botdichtheid, botombouwparameters en de aanwezigheid van werveldeformiteiten bij patiënten met een schildkliercarcinoom, sarcoïdose of een inflammatoire darmziekte.

In hoofdstuk 3 is een studie beschreven waarin we de invloed van een suppressiedosis van levothyroxine op bot hebben onderzocht bij patiënten met een schildkliercarcinoom. Wij vonden dat Z-scores van de met behulp van "dual-energie X-ray absorptiometry (DEXA)" gemeten botdichtheid niet verschillend waren van de referentiepopulatie, zelfs niet na langdurige $(\geq 10$ jaar) suppressietherapie. Patiënten met een botdichtheid in het laagste en hoogste kwartiel toonden een significant verschil in de aanwezigheid van klinische risicofactoren. Daarnaast bleek de marker van botresorptie (ICTP) hoger te zijn dan bij gezonde controlepatiënten van dezelfde leeftijd en vonden we bij $7 \%$ van de patiënten een werveldeformiteit, suggestief voor een wervelfractuur. Hoewel gegevens over wervelfracturen bij gezonde jonge mensen ontbreken, zijn onze resultaten het beste te vergelijken met de gegevens van een grote Europese studie naar de aanwezigheid van werveldeformiteiten bij mannen en vrouwen (EVOS) in de leeftijd van 50-79 jaar. In deze studie (15570 mannen en vrouwen) werd een werveldeformiteit gevonden bij $12 \%$ (range 6-21\%). We hebben derhalve geen aanwijzingen dat werveldeformiteiten vaker voorkomen bij onze patiëntengroep dan bij deze Europese referentiepopulatie. In alle tot op heden over dit onderwerp gepubliceerde studies werd met name een significant botverlies gezien bij patiënten die een $30-50 \%$ hogere dosis levothyroxin kregen dan in onze studie. We hebben daarom geconcludeerd dat indien patiënten met een goed gedifferentieerd schildkliercarcinoom behandeld worden met levothyroxin doses niet hoger dan nodig om het TSH te supprimeren, ze geen verhoogd risico hebben op het ontwikkelen van een verlaagde botmassa of een wervelfractuur.

In hoofdstuk 4 wordt een studie beschreven naar de aanwezigheid van werveldeformiteiten in een groep patiënten met een inflammatoire darmziekte en de relatie van deze deformiteiten met botdichtheid en botombouwparameters. Werveldeformiteiten werden gevonden bij 25\% van zowel de patiënten met de ziekte van Crohn als met colitis ulcerosa. Er werd geen 
verschil gevonden in Z- of T-scores van de botdichtheid of hoogte van de botombouwparameters tussen patiënten met en patiënten zonder een werveldeformiteit. Zowel ziekteactiviteit als botombouwparameters, klinische risicofactoren en botdichtheid bleken géén voorspellers voor de aanwezigheid van werveldeformiteiten. De determinanten voor het hebben van meer dan één werveldeformiteit waren leeftijd en gebruik van corticosteroïden. Dit kan betekenen dat in aanvulling op het screenen op een verlaagde botdichtheid, morfometrie van de wervels eveneens gerechtvaardigd is in deze groep, namelijk om die patiënten te identificeren die een verminderde kwaliteit van het bot hebben en als gevolg daarvan een toegenomen fractuurrisico.

Sarcoïdose is een chronische inflammatoire ziekte die ook het bot kan aantasten. In hoofdstuk 5 is een studie beschreven over botombouw, botdichtheid en het aanwezig zijn van werveldeformiteiten bij patiënten met sarcoïdose en hun relatie met ziekte- en behandelingsgerelateerde factoren. We vonden dat de botdichtheid van de heup normaal was bij deze patiënten, ondanks een verhoogde botombouw. Omdat de parameter van botresorptie gerelateerd bleek aan "angiotensin converting enzyme (ACE)" en de "soluble IL-2 receptor (sIL2R)" concludeerden wij dat een verhoogde botresorptie het resultaat zou kunnen zijn van een verhoogde ziekteactiviteit. Daarnaast vonden we werveldeformiteiten, suggestief voor fracturen bij een groot aantal patiënten (21\%). Dit impliceert dat bij sarcoïdose een toegenomen botombouw de botkwaliteit meer aantast dan de botdichtheid.

Omdat we in deze patiëntengroep een hoge incidentie van morfometrische werveldeformiteiten vonden was het doel van de follow-up studie om vast te stellen wat het voorkomen zou kunnen zijn van nieuwe en progressieve werveldeformiteiten en hoe de botdichtheid zou veranderen gedurende het beloop van sarcoïdose (hoofdstuk 6). De botdichtheid van de totale groep bleek na follow-up onveranderd, zelfs in de groep met gebruik van corticosteroïden. Het aanwezig zijn van werveldeformiteiten bleek echter toegenomen van 20 naar $32 \%$ van de totale groep en bij $26 \%$ van de patiënten werden één of meer nieuwe of progressieve werveldeformiteiten gediagnosticeerd. Wij vonden dat een lage botdichtheid en een familieanamnese met heupfracturen een verhoogd risico gaf op deze deformiteiten.

De laatste jaren is er een toegenomen interesse ontstaan voor ultrageluid als methode om een indruk te krijgen over de sterkte van bot. Onze hypothese was dat in de bestudeerde populaties waarbij we een afgenomen botsterkte vonden - zich uitend in aanwezigheid van werveldeformiteiten - maar toch een normale botdichtheid, een ultrageluidmeting van de hiel van additionele waarde 
zou kunnen zijn naast een botdichtheidsmeting met DEXA. Dit om de aanwezigheid van morfometrische wervelfracturen te voorspellen (hoofdstuk 7). Het bleek dat de ultrageluidparameters van de hiel niet geassocieerd waren met het aanwezig zijn van werveldeformiteiten. Geconcludeerd is dus dat meting van de botdichtheid met ultrageluid geen bruikbaar instrument is om patiënten met verhoogd risico op een fractuur te identificeren.

De studies beschreven in dit proefschrift impliceren, dat bij patiënten met een inflammatoire ziekte die een verhoogd risico hebben op secundaire osteoporose, zowel een botdichtheidsmeting met DEXA als het bepalen van werveldeformiteiten nodig zijn om individuen met een verlaagde botsterkte, met als gevolg een toegenomen fractuurrisico te identificeren. 
$134 \mid$ Chapter 10 


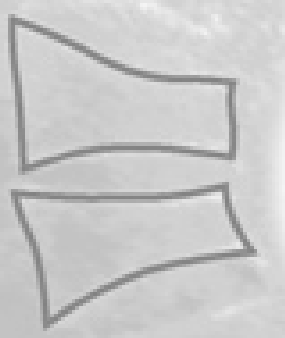

Dankwoord 


\section{Dankwoord}

In 2000 ben ik begonnen met de eerste voorbereidingen voor deze studies. Ik heb er lang aan getwijfeld of ik ooit de eindstreep zou halen. Nu, ruim 7 jaar later, worden alle inspanningen beloond met dit proefschrift. Zonder de hulp van vele mensen die mij de ruimte en de mogelijkheden gaven en mij motiveerden om door te gaan, was dit zeker niet gelukt.

Dr. M.S.P. Huijberts, mijn begeleider en co-promotor, wil ik als eerste noemen. Lieve Maya, voor een (mental) coach als jij, met jouw eindeloze inzet en enorme werklust, schieten woorden tekort om je te bedanken. Niet alleen op wetenschappelijk gebied ben je belangrijk voor me geweest maar ook als vriendin. Naast een aantal leuke congressen, hebben we ook al vele mooie vakanties met onze gezinnen samen doorgebracht. Ongetwijfeld zal ik me, nu ik meer "vrije tijd" ga krijgen, verder gaan bekwamen op culinair gebied. Ik hoop dan ook je ooit nog eens als "chalet girl" te kunnen evenaren. Ik kijk uit naar nog vele mooie en gezellige momenten samen.

Prof. dr. A.C. Nieuwenhuijzen Kruseman, beste Arie, met jouw hulp zijn er grote hindernissen genomen. Knopen werden vlot doorgehakt en geen enkel probleem leek onoverkomelijk. Het is bekend dat een promotieonderzoek zelden zonder tegenslagen verloopt, maar de hindernissen op mijn weg waren - voor mijn gevoel - soms wel buitenproportioneel. Jouw stimulerende woorden zijn op bepaalde momenten van cruciaal belang geweest. Ik wil je hartelijk danken voor de manier waarop je het hele proces hebt bewaakt en voor je bereidheid om samen met mij dit proefschrift tot een goed einde te brengen.

Prof. dr. P. Geusens, beste Piet, jouw ongekende enthousiasme zorgde ervoor dat ik telkens blij terugkwam uit Maastricht. Jij gaf me steeds het gevoel met heel belangrijke dingen bezig te zijn. Ik ben je zeer erkentelijk voor alle opbouwende commentaren, ideeën en de telkens weer snelle en kritische beoordeling van alle manuscripten.

Prof. dr. B.H.R. Wolffenbuttel, beste Bruce, ons eerste gesprek over dit onderzoek aan het keukentafeltje van ons appartement in Breda kan ik me nog als de dag van gisteren herinneren. De eerste gedachten hebben we toen op papier gezet. Tijdens deze fase en de praktische uitvoer van de studie heb je een heel belangrijke rol gespeeld. Ik ben je daar zeer dankbaar voor.

Prof. dr. M. Drent, beste Marjolein, bedankt voor de heel prettige samenwerking. Je hulp en enthousiasme tijdens de afgelopen jaren heb ik zeer op 
prijs gesteld. Jouw passie voor het vak en je gedrevenheid zijn een voorbeeld voor me.

Prof. dr. J. de Vries, beste Jolanda, dank voor je onmisbare hulp bij de statistische analyses. Ik heb veel van je geleerd. Telkens lukte het je snel tijd voor me vrij te maken om weer eens een vraag te beantwoorden.

Dr. P.P.C.A. Menheere, beste Paul, dank voor al je inspanningen om het bepalen van de botmarkers te realiseren. Dr. E. van der Veer, beste Eveline, ook jou ben ik zeer dankbaar voor je positieve woorden en voor de mogelijkheid die je hebt gegeven om Z-scores van onze botombouw parameters te berekenen.

Prof. dr. R.W. Stockbrügger, beste Reinhold, dank voor de plezierige samenwerking en het meedenken over de IBD-data. Dr. E.J. Schoon, beste Erik, jouw pionierswerk op het gebied van osteoporose bij IBD patiënten is ook weer van belang geweest voor dit onderzoek. Ik dank je voor de begeleiding en het becommentariëren van de stukken.

Dr. J.R. Juttmann, beste Job, dankzij jou ben ik in het onderzoeksgebied van osteoporose terecht gekomen. Deze interesse is mede door jou ontstaan en heeft uiteindelijk geleid tot dit onderzoek. Daarnaast was je samen met dr. C. van der Heul verantwoordelijk voor mijn opleiding in Tilburg. Ik heb er veel geleerd, waarvoor ik jullie zeer dankbaar ben. Ik denk met veel plezier terug aan de "rode-bankjes-tijd" en wil daarvoor ook mijn collegae arts-assistenten bedanken.

De leden van de beoordelingscommissie: prof. dr. G.J. Dinant, prof. dr. J.M.A. van Engelshoven, prof. dr. A.A.M. Masclee, prof. dr. G.J.J. Teule en prof dr. E.F.M. Wouters dank ik voor het kritisch doorlezen van het manuscript.

Dany Simon heeft een heel belangrijke rol gespeeld bij het coördineren van de studie, het zien van de patiënten en het invoeren van de data. Ik dank ook Pauline Versteeg, Esther ten Hoor, Gé van Kan voor hun hulp hierbij. Petal Wijnen heeft gezorgd voor de database met de sarcoidose patienten. Lia van lersel en haar collega's dank ik voor het maken van de DEXA's en hun bereidheid om alle onderzoeken tussendoor in te plannen.

Uiteraard dank ik ook Tiny Wouters, die een belangrijke rol heeft gespeeld in de laatste fase van het proefschrift. 
Dear Bianca, without your tremendous efforts it would not have been possible to do all the morphometric measurements. Even when you were in Bucharest it seemed like you were sitting next door. Debby Vosse dank ik voor het delen van de promotie-emoties, het samen werken aan onze data was iets minder succesvol. Ik hoop dat ook jouw proefschrift binnenkort afgerond kan worden.

Maatschap interne geneeskunde ziekenhuis Bernhoven. Beste collegae: de gezelligheid en een goede dosis humor zorgen ervoor dat ik elke dag weer met veel plezier naar het ziekenhuis ga. Het is een voorrecht om met kundige collega's in zo'n prettige sfeer te mogen werken en ik hoop dat er zo nog vele jaren zullen volgen.

Lieve hulptroepen in huis: Kim, Celia, Šefika en Asim. Jullie vormen mede de veilige basis thuis voor onze kinderen en zorgen dat het huishouden altijd perfect draait. Zonder jullie hulp zou dit alles zeker niet gelukt zijn.

Mijn paranimfen, lieve Corinne en Tamara. Goede en iets minder goede tijden hebben we met elkaar gedeeld. Ik dank jullie voor jullie vriendschap, gezelligheid en warmte. Ook veel dank aan Joop en Anneke, jullie hebben gezorgd voor veel momenten waaruit ik weer energie kon putten om door te gaan. En lieve An, de tocht door de Alpen is inderdaad gelopen, maar met het kabelbaantje de Mont Blanc op is toch ook nog vermoeiend. Ik probeer nu alleen wel van het uitzicht te genieten! Dank voor je bemoedigende woorden. Alle andere vrienden dank ik voor het begrip dat ik het toch te regelmatig heb laten afweten.

Mijn lieve ouders. Jullie hebben ervoor gezorgd dat ik ben geworden wie ik nu ben. Mijn "drive" en doorzettingsvermogen dank ik aan jullie en die karaktereigenschappen hebben mij enorm geholpen in dit traject. Ik ben jullie ongelofelijk dankbaar voor alles wat jullie voor mij hebben gedaan en nog steeds doen. Ik realiseer me dat ik de laatste jaren wel eens te weinig tijd en aandacht voor jullie heb gehad maar ik hoop dat het voltooien van mijn proefschrift dat een beetje goed kan maken.

Mijn broers, Frank en Martijn. De periode dat jullie last hadden van de ijverige, brave, grote zus die op school te goed haar best deed en alleen maar goede cijfers haalde ligt ver achter ons. Waarschijnlijk vinden jullie het schrijven van dit boekje hier nog wel een uiting van. Inmiddels zijn jullie succesvolle "zakenmannen" geworden en ben ik trots op jullie. Ik dank ook Magda en Henk voor de telkens weer warme ontvangst en voor de interesse, steun en hulp gedurende de afgelopen periode. En Yvonne... die halve marathon in Palma is afgesproken. Marieke en broertjes, doen jullie mee? 
Lieve Bram, Hannah, Thijs en Lotte, het boekje van mama is af! Jullie vrolijkheid en stralende lach hebben gezorgd voor de nodige relativering zodat ik zeker niet uit het oog ben verloren dat er in het leven belangrijker zaken zijn dan het schrijven van een proefschrift.

Liefste Bart, met name het afgelopen jaar was voor ons beiden ongelofelijk zwaar. Dankzij jou, mijn rots in de branding, heb ik het "overleefd". Dank voor je onvoorwaardelijke steun en voor je enorme vertrouwen in mij. Dank dat je mijn datamanager was, mijn computerdokter en nog veel meer. Bedankt, gewoon voor alles! 


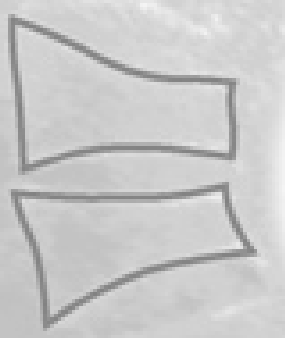

Curriculum vitae 


\section{Curriculum vitae}

Caroline Heijckmann werd op 3 mei 1967 geboren te Eindhoven. Na het behalen van het Gymnasium $\beta$ diploma in 1985 aan het R.K. Gymnasium "Beekvliet" te Sint-Michielsgestel studeerde zij Geneeskunde aan de rijksuniversiteit Utrecht. Zij behaalde haar artsexamen in 1993, waarna zij als arts-assistent ging werken in het Diaconessenhuis Eindhoven. Een jaar later werd de overstap gemaakt naar het St. Elisabeth ziekenhuis te Tilburg, alwaar zij in 1996 startte met de opleiding tot internist (opleider dr. C. van der Heul). In 2000 werd deze opleiding voortgezet in het Academisch Ziekenhuis Maastricht en werd tevens een start gemaakt met de opleiding in het aandachtsgebied endocrinologie (opleiders: prof. dr. H.F.P. Hillen (interne geneeskunde) en prof. dr. B.H.R. Wolffenbuttel (endocrinologie)). De registratie als internistendocrinoloog vond plaats in 2002. Vanaf 1 mei 2002 is zij werkzaam in ziekenhuis Bernhoven te Veghel en Oss. Gedurende de laatste jaren van haar opleiding en de vijf jaren daarna heeft zij gewerkt aan dit proefschrift. Zij is gehuwd met Bart-Jeroen Heesen en samen hebben zij vier kinderen: Bram (1999), Hannah (2001), Thijs (2006) en Lotte (2007). 